\title{
The distribution and influence of the introduced alga Colpomenia bullosa in the rocky intertidal.
}

\author{
by \\ Daniel McNaughtan
}

A thesis

submitted to the Victoria University of Wellington in part fulfilment of the requirements for the degree of Master of Science in Marine Biology.

Victoria University of Wellington 2008 


\begin{abstract}
The brown alga Colpomenia bullosa was first observed in New Zealand more than 20 years ago, yet very little is known about its current intertidal distribution or possible effects it may be having on native communities. This study addresses some of these issues. Surveys indicate little spatial variation in abundance around the Wellington region, however, the sporophytic crustose phase is restricted to pools high in the littoral zone while the gametophytic upright has a low- to sub-littoral distribution. Physiology experiments indicate that $C$. bullosa can tolerate a wide range of environmental conditions, but the crustose phase has a poor desiccation tolerance. A series of tranplant and competition experiments confirmed this and suggested that the crustose phase requires some level of facilitation by molluscan herbivores in order to become established. These experiments also revealed that crustose C. bullosa does not compete well against more upright macroalgal species. The effects of this introduced algae on native communities are likely to be minimal given its restricted intertidal distribution and its inability to compete against more upright species.
\end{abstract}




\section{Acknowledgments}

Thanks to everyone involved with this project, particularly Joe Zuccarello and Ken Ryan for their input and time spent reading all my drafts. Thanks to all my fellow grad students and others who have also endured reading a thesis on a subject they have no great interest in. I now realise that not everyone enjoys intertidal crustose algae as much as I do! Thanks to Shirley Pledger for her statistical advice and for employing me during term time enabling me to pay rent. Thanks to the technical staff at VUCEL for their support and advice. Last of all thanks to my friends and family who have put up with me while I have been playing around at the beach. 


\section{Contents}

1 Introduction 1

1.1 Introduction . . . . . . . . . . . . . . . 1

1.2 Species background . . . . . . . . . . . . . . . . 4

1.3 Proposed Research . . . . . . . . . . . . . . . . . . 11

2 Spatial and Temporal Surveys 13

2.1 Introduction ....................... 13

2.2 Methods ...................... . . 16

2.2.1 Spatial Variation Survey . . . . . . . . . . 16

2.2.2 Temporal Variation Survey . . . . . . . . . . . . 19

2.2.3 Neighbouring Species Interaction Survey . . . . . . 20

2.3 Results . . . . . . . . . . . . . . . . . 22

2.3.1 Visual vs. Point Estimate $\%$ Cover . . . . . . . . . 22

2.3.2 Spatial Variation Survey . . . . . . . . . . . . 23

2.3.3 Crustose Species Abundance . . . . . . . . . 25

2.3.4 Temporal Variation Surveys . . . . . . . . . . . . . 25

2.3.5 Neighbouring Species Interactions . . . . . . . . . 27

2.4 Discussion . . . . . . . . . . . . . . . . . 29

3 Physiological tolerance 36

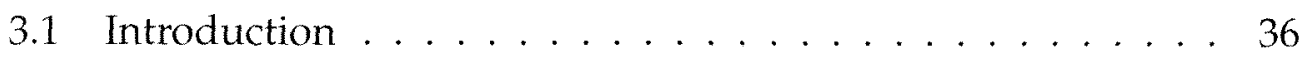

3.1.1 Pulsed Amplitude Modulated Fluorometry and Photosystems .................... 38 
3.2 Methods . . . . . . . . . . . . . . . . . . . 40

3.2.1 Initial investigations . . . . . . . . . . . 40

3.2 .2 Follow-up experiment . . . . . . . . . . . . . 43

3.2.3 Response to salinity variation . . . . . . . . . . . 43

3.2.4 Recovery from desiccation exposure . . . . . . . . 44

3.2.5 Thylakoid membrane integrity . . . . . . . . . 45

3.3 Results . . . . . . . . . . . . . . . . . 47

3.3.1 Field measurements of temperature . . . . . . . 47

3.3.2 Initial investigations . . . . . . . . . . . . 47

3.3.3 Follow-up experiment . . . . . . . . . . . . . . . 49

3.3.4 Response to salinity variation . . . . . . . . . . . . 51

3.3.5 Recovery from desiccation exposure . . . . . . . . 54

3.3.6 Thylakoid membrane integrity . . . . . . . . . 56

3.4 Discussion . . . . . . . . . . . . . . . . . . . 57

4 Habitat and herbivore manipulations 63

4.1 Introduction . . . . . . . . . . . 63

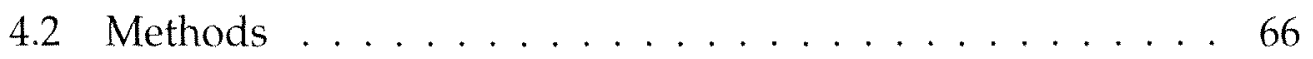

4.2.1 Habitat manipulation / Survival analysis . . . . . 66

4.2.2 Grazer exclusion manipulation . . . . . . . . . . . 69

4.2.3 Competition manipulation . . . . . . . . . 71

4.3 Results . . . . . . . . . . . . . . . 72

4.3.1 Habitat manipulation / Survival analysis . . . . . 72

4.3.2 Grazer exclusion manipulation . . . . . . . . . . 73

4.3.3 Competition manipulation . . . . . . . . . 77

4.4 Discussion . . . . . . . . . . . . . . . . . . . 80

5 Conclusion $\quad 86$

5.1 Future directions . . . . . . . . . . . . . . 88

5.2 Conclusion . . . . . . . . . . . . . . . . 88

Appendix: GPS Table $\quad 90$ 


\section{List of Figures}

1.1 Gametophytic uprights of $C$. bullosa. The upper sample of thallus still has the holdfast attached and it is on the extreme right of the sample. The lower sample was removed from a holdfast containing multiple projections. The coin on the left of the image is approximately $20 \mathrm{~mm}$ in diameter. . . . . 6

1.2 Gametophytic plant with multiple upright projections. Note the smaller projections arising from the same holdfast. . . . 6

1.3 Sporophytic crustose $C$. bullosa. Note the distinctive overlapping lobe pattern that is absent from other native crustose species. . . . . . . . . . . . . . . . . 7

1.4 Colpomenia species in the lower intertidal. The upright finger-like projections are Colpomenia bullosa gametophytes and the saccate globular thalli are $C$. sinuosa. The C. bullosa gametophytes visible are new settlers less than 1 month old and would be expected to double in size while the larger C. sinuosa thalli are established and older specimens. Hormosira banksii and Corallina officinalis can also be seen in this picture. . . . . . . . . . . . . . . . 
2.1 Distribution survey sampling locations. The numbers indicate the general location of the respective survey sites around the Wellington Region and the GPS coordinates for the exact locations are listed in the appendix. Location (1) Point Halswell, Location (2) Palmer Head, Location (3) Owhiro Bay, Location (4) Makara, and Location (5) Porirua Harbor. . 17

2.2 Location of the fixed quadrats around the Wellington region. Site (6) Palmer Head, Site (7) Island Bay, Site (8) Red Rocks. There were nine plots at each site- three in each lit-

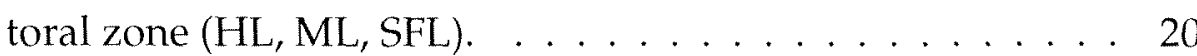

2.3 Visual estimation vs point intercept regression plot. The visual estimates of $\%$ cover were a close match to the point estimate \%'s. $R^{2}=0.92(p<0.001) \ldots \ldots . \ldots . . . . . .22$

2.4 Multi Dimensional Scaling plot. The numbers refer to the survey locations with $1=\mathrm{Kau}$ Bay, $2=$ Wahine Park, $3=$ Red Rocks, 4=Makara, and 5=Porirua Harbour. The axis label 'Distance' refers to the statistical distance between the locations and shows there is significant statistical distance between location 1 and the other locations. . . . . . . . . . . . 24

2.5 Tidal height: Habitat interaction plot. The \% cover of crustose C. bullosa is significantly different between the tidal heights and habitat. No crustose C. bullosa was found on emergent rock on any tidal height.

2.6 Percentage cover of crustose species within pools in the 3 tidal zones ( \pm 1SE). The key indicates the shading combinations for the respective tidal heights. High $=$ High mid littoral zone, Mid = Mid littoral zone, and Low $=$ Sub-littoral

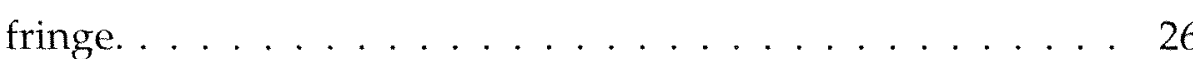


2.7 The abundance of gametophytic upright Colpomenia bullosa over 12 months at the low tidal level ( \pm 1 SE.) The total number of uprights peaked during spring or the November / December period and the number of settlers peaked in early spring. No uprights were found in any of the plots between March and August. . . . . . . . . . . . . . . . . 27

2.8 The \% cover of crustose Colpomenia bullosa over 12 months ( \pm 1SE). None of the observed monthly variation in \% cover was significant and the high zone had the highest \% cover out of the 3 tidal zones. . . . . . . . . . . . . . . . . . 28

3.1 Intertidal pool temperature $( \pm 1 S E)$ during a $24 \mathrm{~h}$ period. The solid line signifies the temperature and the dashed line signifies the tidal variation. The shaded area indicates daylight hours with sunrise occurring at 0608 and sunset occurring at 1823 on the 26th September 2006. The influence of solar heating on the pool temperature can be seen by the constant temperature rise during the tidal cycle until the tidal flush lowers the pool temperature. The pool was situated in the high littoral zone with fine and sunny weather during the 24 h measurement period. . . . . . . . . . . . . .

3.2 Yield and rETRmax measurements for seven days at 7-, 12-, 20-, and $30^{\circ} \mathrm{C} \pm \mathbf{1 S E}$. The 50, 100, and 150 refer to the light level and are measured in $\mu \mathrm{mol} \mathrm{m}^{-1} \mathrm{~s}^{-1}(\mu \mathrm{E})$. There is a significant decline in Yield after one day at $30^{\circ} \mathrm{C}$ and by the end of the seven day period, the samples at $30^{\circ} \mathrm{C}$ have very limited photosystem function. This trend is reflected in the rETRmax measurements. . . . . . . . . . . . . 50 
3.3 Yield and rETRmax measurements for seven days at 20-, 24-,27-, and $30^{\circ} \mathrm{C} \pm \mathbf{1 S E}$. The 50, 100, and 150 refer to the light level and are measured in $\mu \mathrm{mol} \mathrm{m} \mathrm{m}^{-1} \mathrm{~s}^{-1}(\mu \mathrm{E})$. There was a significant decline in Yield and rETRmax for the 27- and $30^{\circ} \mathrm{C}$ treatments after one day but only the $30^{\circ} \mathrm{C}$ treatment continued to complete photosystem shutdown. . . . . . . . 52

3.4 Yield measurements for seven days at 10-, 30-, 35-, and $50 \mathrm{psu} \pm 1 \mathrm{SE}$. After the initial reduction in the 10-, 30-, and 50 psu treatments, the Yield stablished and did not show any further significant variation. The natural seawater treatment of 35 psu did not show any significant variation during the experiment period. . . . . . . . . . . . .

3.5 Yield measurements following desiccation \pm 1 SE. The different time treatments are shown in the lower left of the plot and number indicates the desiccation time in hours. The two and four hour emmersion yield values recovered to pre-treatment yield quickly and the six hour treatment recovered after eight hours. The eight and ten hour emmersion treatments did not recover to the pre-treatment values and displayed larger variation in the measured values compared to the shorter desiccation treatments. . . . . . . . . . 56

3.6 Determination of critical temperature levels for thylakoid membrane integrity. The plot on the left shows Fo measurements for the upright and crustose thalli $( \pm 1 \mathrm{SE})$ with no fitting lines while the plot on the right shows the same data but has the fitting lines shown on the plot. The arrows indicate the Tc and Tp positions on the plot. Temperature in shown above the $x$-axis and Time is shown below. . . . . . 57 
4.1 Location of transplant experiment sites on Wellington South

Coast. The experiment sites are indicated by the bold numbers. Site (9) Gibraltar Rock at Palmer Head. Site (10) Waitaha Cove and Site (11) The Sirens Rocks formation. The shaded area of the map indicates land with Cook Strait at the bottom of the map. . . . . . . . . . . . . . 67

4.2 Location of herbivore manipulation experiment sites on the Wellington South Coast. Site (12) Palmer Head, Site (13) Moa Point, Site (14) The Drain Pipe, Site (15) The Sirens Rock formation, and Site (16) Red Rocks. The shaded area of the map indicates land with Wellington City located in the central part of the map. . . . . . . . . . . . . 69

4.3 Survival of thalli transplanted into pools. Survival was greatest in the high zone with all of the mortality occurring between months two and three. The Mid and Low zones had relatively constant mortality after the second month with one or two plants dying each month. . . . . . . . . . . . 74

4.4 Weibull survival curves fitted onto the pool transplants. The curves from the three zones had a similar shape and are shown by the dashed lines. The curves are consistent with a type I and II survival response. . . . . . . . . . . . 74

4.5 Survival of thallus transplanted onto emergent rock. The Low zone transplants had the greatest survival however no transplant from any of the zones survived longer than four months and none of the transplants from the high zone survived the first month. . . . . . . . . . . . . 75

4.6 Weibull survival curves fitted to the emergent rock transplants. The shape of the combined curve is consistent with a type III survival response. The survival curves from the Mid and Low zones also follow this shape but the curve for the High zone is distorted poor survival rate. . . . . . . . 75 
4.7 Exclusion plot after 24hrs. Most of the available substrate in the plot is covered by crustose C. bullosa with two small macroalgal species. Note that the exclusion plot has only been in place for $24 \mathrm{hrs}$ but there is already a fine layer of sediment covering the plot. . . . . . . . . . . . 77

4.8 Exclusion plot after 3 months. The plot has very high sedimentation and there is significant filamentous algal growth throughout the plot. There is also a small amount of foliose algal growth with very little exposed C. bullosa. . . . . . . . 78

4.9 Exclusion plot after 5 months. All exposed substrate within the plot has been covered in filamentous or foliose algae. A thick layer of sediment can be observed close to the substrate and around the holdfasts of the algae. No crustose $C$. bullosa can be seen in the plot. . . . . . . . . . . 78

4.10 Species cover in herbivore exclusion plots ( \pm 1SE). The coverage of C. bullosa quickly declines and is almost completely absent by December. The coverage by the more foliose species starts to significantly increase around this time also. . . . . . 79

4.11 Species growth rate in the presence and absence of molluscan grazers ( $\pm \mathbf{1 S E}$ ). A positive value indicates $C$. bullosa growth and a negative value indicates growth by the labeled species. No significant differences between growth rate and herbivore access were detected. . . . . . . . . . . . 81 


\section{List of Tables}

2.1 Nested ANOVA table. The order of the variables indicates the nesting order. . . . . . . . . . . . . . . 23

2.2 Observed and Expected values for species interactions. The event 'Under' $=$ the respective species found underneath C.bullosa and 'Over' $=$ the respective species found growing over C.bullosa. . . . . . . . . . . . . . . . . . . . . 29

3.1 Repeated Measures ANOVA table for Yield measurements taken during initial investigations. . . . . . . . . . . . . . 49

3.2 Repeated Measures ANOVA table for rETRmax measurements taken during initial investigations. . . . . . . . . . 51

3.3 Repeated Measures ANOVA table for Yield measures in second tolerance experiment. . . . . . . . . . 53

3.4 Repeated Measures ANOVA table for rETRmax measurements in second tolerance experiment. . . . . . . . . . 53

3.5 ANOVA results for recovery experiments. The results of the repeated measures and standard ANOVA tests are listed with $\mathrm{df}$ and F-values. . . . . . . . . . . . . . 55

4.1 Exclusion plot repeated measures ANOVA table. . . . . . 77 


\section{Chapter 1}

\section{Introduced species and Colpomenia species in New Zealand}

\subsection{Introduction}

The rocky intertidal shore encompasses a gradient of environmental conditions from the subtidal marine to the fully terrestrial just above the splash and spray zone (Underwood, 2000; Nybakken, 2001). Because this gradient occurs over a relatively small vertical distance, a great variety of plants and animals from a number of different functional groups can be found interacting over small spatial scales (Menge and Sutherland, 1987; Underwood and Chapman, 1996; Harley and Helmuth, 2003), leading to highly complex and dynamic communities (Harley, 2006b).

One of the defining features of the intertidal zone is the extreme variation in the environmental conditions brought about by the tidal cycle (Finke et al., 2007), and in many temperate systems this equates to a twice daily cycle of immersion. For aquatic organisms, this cyclic exposure to air amplifies the main abiotic stress factors (i.e. temperature and light) (Helmuth, 1999; Somero, 2002; Helmuth and Hofmann, 2001) and also 
adds desiccation stress (Harley, 2003; Harley and Helmuth, 2003). It is widely accepted that these abiotic stresses are the most significant factor in determining the upper range of an aquatic species (Nybakken, 2001).

In addition to these abiotic stresses, there are biotic stress factors resulting from species interactions such as competition, predation, and herbivory (Connell, 1961; Connell, 1972; Paine, 1974; Lubchenco, 1980; Bertness and Leonard, 1997). Due to the high diversity of species that can be found within the intertidal zone, these biotic interactions often involve multiple species (Wootton, 1994; Polis and Strong, 1996), making it difficult to predict the outcome of competitive interactions. While there are several mechanisms a species can utilise to enhance its competitive ability (e.g. mutualisms, commensalisms, or facilitations) (Menge, 1995), failure to capture an adequate level of resource will quickly result in the exclusion of a species from the intertidal community.

With the advent of global economies, the impact of introduced species is also becoming a significant factor in structuring intertidal communities (Ruiz et al., 1997; Strauss et al., 2006). Although species introductions are a naturally occurring process, human mediated dispersal vectors have accelerated the process (Carlton, 1985) and increased the introduction rate of exotic species (Mooney and Cleland, 2001; Wotton and Hewitt, 2004). Some ecosystems are unable to adapt quickly enough to these novel species and the consequences are even more severe. This is highlighted in the study by Hutson et al. (2005) that demonstrated Australian scallops (Pecten fumatus and Chlamys asperrima) do not recognise the introduced predatory seastar (Asterias amurensis) and subsequently display no escape response. This has resulted in elevated predation and a significant decline in local abundance of the scallops.

The impact of introduced species in the Mediterranean has been well documented, and presently over 500 alien fish, invertebrates and algal species can be found in various coastal habitats (Galil, 2005). Perhaps the most infamous of these intruders is the algae Caulerpa taxifolia (Vahl) 
C. Agardh which, due to its ability to form dense meadows on a variety of bottom types, has resulted in the localised replacement of native algal species (Coquillard et al., 2000; Nyberg and Wallentinus, 2005) and a reduction in species richness of up to $25 \%$ (Galil, 2005). It also uses harmful endotoxins as a defence mechanism against herbivory (Coquillard et al., 2000; Thoms et al., 2006) and is a significant threat to marine coastal biodiversity (Longpierre et al., 2005). Currently C. taxifolia is the only algal species listed as an 'Unwanted organism' under the New Zealand Biosecurity Act 1993.

There are currently 148 established marine species listed as introduced into New Zealand (NZ) and 20 of these are algae (Nelson, 1999). Of the 20, perhaps the most notable intruder is the laminarian kelp Undaria pinnatifida (Harvey) Suvingar. Undaria pinnatifida is native to China, Japan, and Korea and can occupy large amounts of space around the sublittoral fringe and can also create significant fouling on marine structures. There are conflicting reports regarding the ecological impact of this intruder and current evidence suggests there are both negative and positive effects for subtidal communities. It competes directly with many native canopy forming species and can lower community diversity through the competitive exclusion of such species (Coutts and Taylor, 2004; Thornber et al., 2004; Casas et al., 2004), however it may also increase spatial diversity via the colonisation of substrates unsuitable for native species (Forrest and Taylor, 2002). Recent studies indicate that $U$. pinnatifida is dominant in high energy, frequently disturbed areas as it can quickly colonise any newly created space but has difficulty becoming established in stable communities (Valentine and Johnson, 2003; Stuart, 2004).

The introduced intertidal alga Colpomenia bullosa (Saunders) Yamada is another species that could potentially impact on intertidal communities. The genus Colpomenia is a member of the Scytosiphonales, Phaeophyceae, and while there are currently four species of the genus Colpomenia in New Zealand-C. sinuosa (Roth) Derbes et Solier, C. peregrina (Sauvageau) Hamel, 
C. ecuticulata Parsons, and C.bullosa, only C. bullosa is listed as introduced (Parsons, 1982; Adams, 1994; Nelson, 1994; Nelson, 1999).

\subsection{Species background}

Many Colpomenia sp. have a heteromorphic life history with an upright gametophytic phase and a crustose sporophytic phase. The gametophyte thalli have a globular or saccate morphology that is solid at first and becomes hollow later (Adams, 1994). The thallus can range from several to many cell layers thick with inner cells being large and colorless, and becoming progressively smaller and more pigmented toward the periphery. The crustose sporophytic thalli has a prostrate growth form made up of tightly packed filaments (Clayton, 1979; Kogame and Yamagishi, 1997; Kogame and Masuda, 2001).

The different species of Colpomenia can be readily identified by the morphology of the gametophytic and sporophytic thalli. The gametophytic thallus of Colpomenia sinuosa is globular, and becomes expanded and deeply convoluted with age. It has a broad holdfast for attachment (Toste et al., 2003). It is usually $5-8 \mathrm{~cm}$ across and the thalli walls are more than five cell layers thick. The thalli surface is slightly roughened and dries to a brownish color. It is usually found in the mid-tidal zone attached on rocks or growing epiphytically on other algae.

The gametophyte of Colpomenia peregrina looks very similar to that of C. sinuosa early in development but older thalli lack the deeply convoluted appearance, with little to no divisions. The thalli sacs are thin and smooth (Oates, 1985). It also has a more narrow holdfast compared to C. sinuosa and is common on rock and other algae in the lower intertidal. It dries to a greenish color. Adams (1994) suggests that its narrow holdfast restricts C. peregrina to more sheltered bays and inlets however this needs to be investigated further before locality can be used as an identifying feature.

The crustose sporophytic phases of C. sinuosa and C. peregrina have 
been identified and described overseas (Vandermeulen et al., 1984; Toste et al., 2003; Cho et al., 2005) but they have not been identified in NZ. These studies identify the sporophyte as having a prostrate crustose thallus with plurilocular and / or unilocular sporangia as the main identifying feature but do not describe the morphological characteristics of the respective species. As identifying and describing the sporophytes of these species was not the primary role of this study, they will be listed as undescribed in New Zealand.

The gametophytic thallus of Colpomenia ecuticulata also has a smooth globular appearance but the walls are thinner and have a softer texture. The holdfast of C. ecuticulata differs from C. sinuosa and C. peregrina having rhizoids on the lower surface of the plant to add in attachment. The thallus dries to a greenish gold color and it is usually found in the upper subtidal. Adams (1994) reported that C. ecuticulata is restricted to the northern North Island and the Three Kings Islands and is generally uncommon in its abundance. The sporophytic phase is also undescribed in NZ.

The gametophytic thalli of Colpomenia bullosa are easily distinguished from the other Colpomenia. The thallus consists of one or more finger-like projections up to $10 \mathrm{~cm}$ tall arising from a common base (Fig 1.1 and 1.2). If there are multiple projections, they range in size with one or two of the larger older projections being mature and containing reproductive structures. The thallus has a firm texture and stalked rhizoids on the holdfast for attachment. The sporophytic phase of C. bullosa is a prostrate crustose thallus.

The sporophytic thallus has distinctive overlapping lobes on the upper surface and rhizoids on the lower surface. No endemic crustose species has this lobing pattern and, unlike other crustose species, the thallus is very easy to remove from the substrate. Anatomically, the tightly packed individual filaments that make up the thallus form a sweeping pattern that is also unique for a brown crustose species. The individual cells in the 


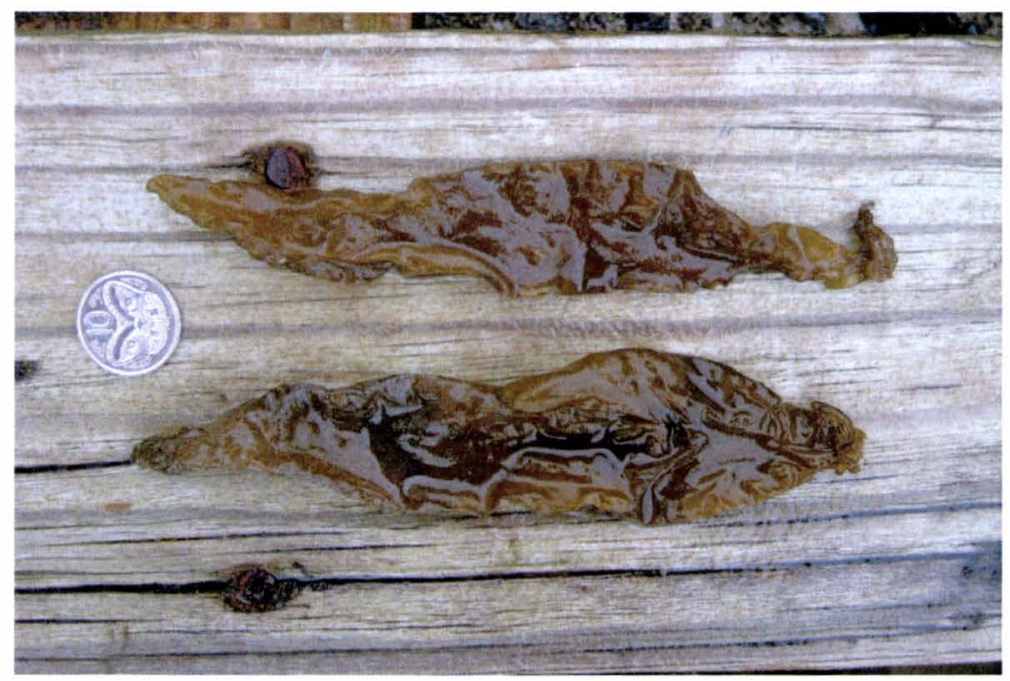

Figure 1.1: Gametophytic uprights of C. bullosa. The upper sample of thallus still has the holdfast attached and it is on the extreme right of the sample. The lower sample was removed from a holdfast containing multiple projections. The coin on the left of the image is approximately $20 \mathrm{~mm}$ in diameter.

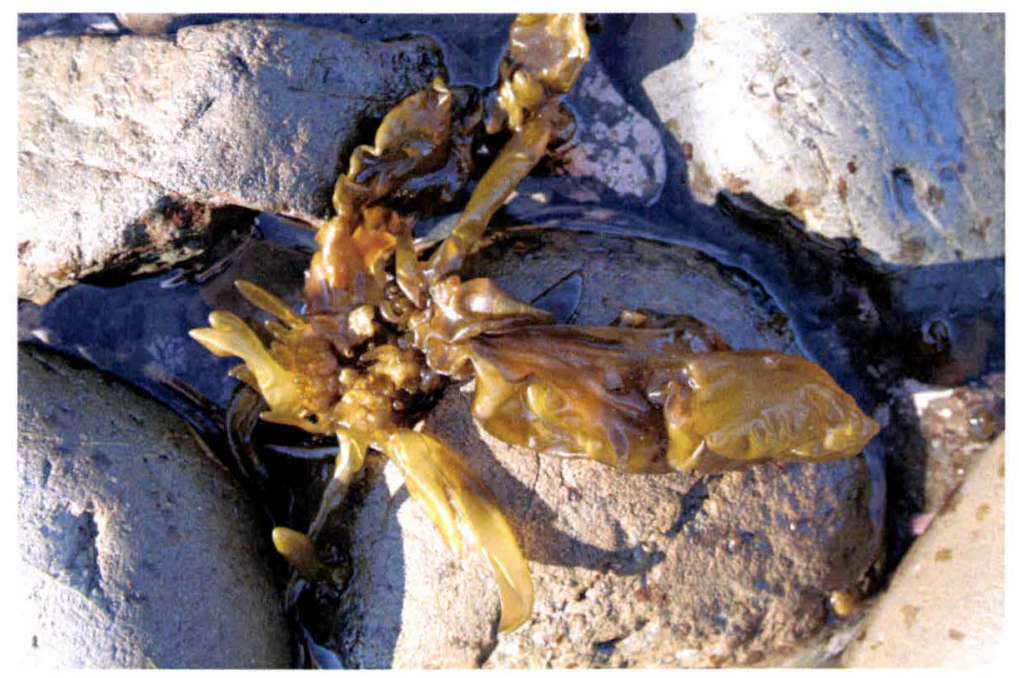

Figure 1.2: Gametophytic plant with multiple upright projections. Note the smaller projections arising from the same holdfast. 
filaments have one large chloroplast.

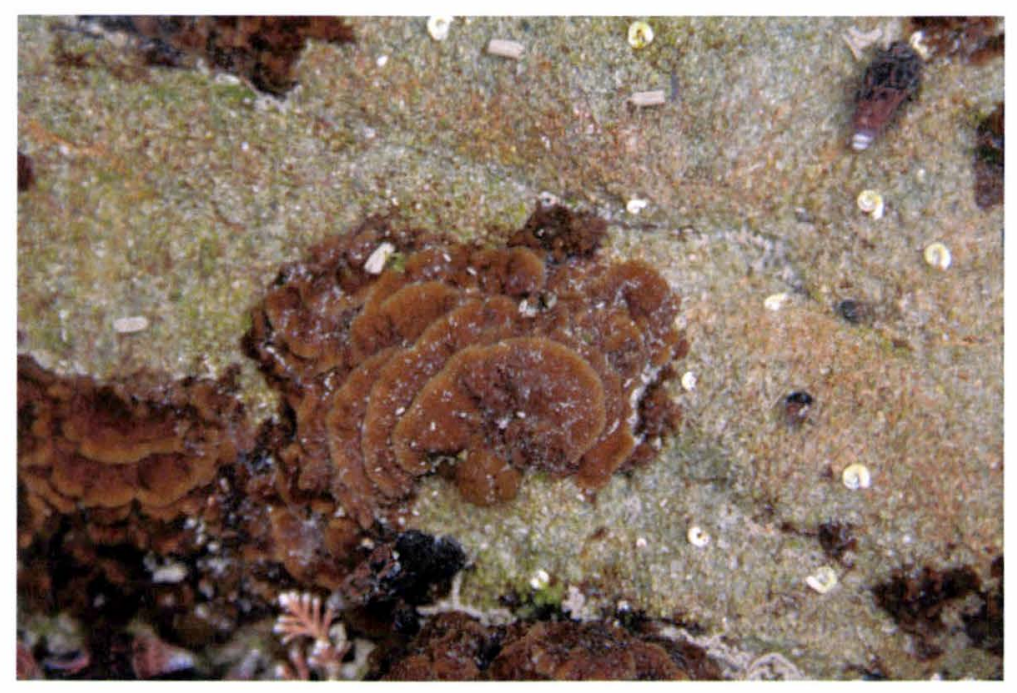

Figure 1.3: Sporophytic crustose $C$. bullosa. Note the distinctive overlapping lobe pattern that is absent from other native crustose species.

The gametophytic upright is often found in the same intertidal position as C. sinuosa and C. pergrina in the low intertidal or sublittoral fringe (Fig 1.4). Other algal species that share this position are Hormosira banksii, Corallina officinalis, and Cystophora sp. The sporophytic crustose phase appears to have a similar distribution to other crustose brown species and can be found throughout the intertial zone. It is currently unclear how the two phases are reproductively linked, but personal observations indicate that the upright gametophyte does not grow directly from the crustose sporophyte and the sporophytic crust can recycle through vegetative growth without having to go through the gametophytic phase.

There have been several name changes for the species since its intial discovery in New Zealand. When Parsons (1982) reported the discovery, he speculated that it had come from Japan and consequently named it as C.bullosa. In 1991 a specimen was discovered in a Chilean collection with the name Colopmenia durvilllei (Bory) Ramirez. Ramirez and Rojas (1991) proposed that C. bullosa was a later name for the same species. Adams 


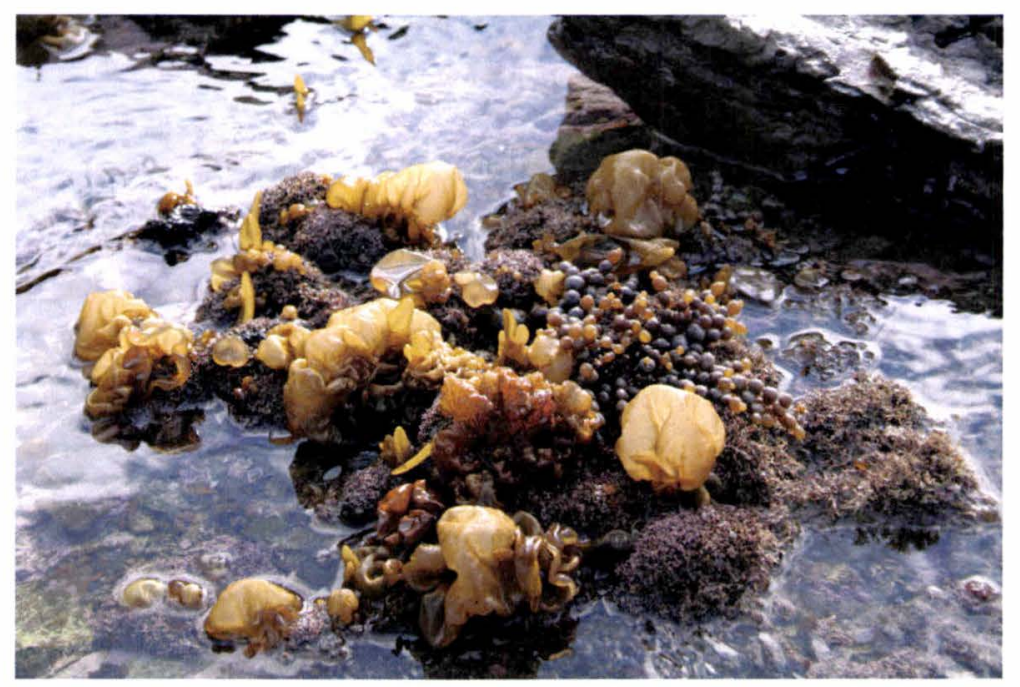

Figure 1.4: Colpomenia species in the lower intertidal. The upright finger-like projections are Colpomenia bullosa gametophytes and the saccate globular thalli are $C$. sinuosa. The $C$. bullosa gametophytes visible are new settlers less than 1 month old and would be expected to double in size while the larger C. sinuosa thalli are established and older specimens. Hormosira banksii and Corallina officinalis can also be seen in this picture. 
(1994) and Nelson (1994) decided to use this proposed nomenclature in their respective studies and suggested that the NZ specimens were synonymous with the Chilean species due to their Southern Hemisphere locality. Therefore they changed the name of the NZ entity from C. bullosa to C. durvillei.

A recent molecular study by Cho et al. (2005) compared $r c b \mathrm{~L}$ sequences from the tubular Colpomenia species in NZ with C. bullosa from Japan and found they were identical but no comparison was made between C. durvillei from Chile and C. bullosa from Japan. This comparison is needed to confirm the relationship between these species and fully resolve the nomenclature. Based on the results from Cho et al. (2005) for the rest of this study the tubular Colpomenia found in New Zealand will be referred to as Colpomenia bullosa.

The species was first described in NZ from a specimen collected in the Leigh Marine Reserve, North of Auckland, by Parsons (1982). Since this initial discovery, its distribution has expanded and the species can now be found in the Hauraki Gulf, Gisborne, Napier, and Wellington. Recently (Jan 2007) it was also discovered in the South Island with a single gametophytic upright found at Patons Rock, Nelson (pers. obs). This is the first confirmed report of the species in the South Island (pers. comm. Rissa Williams 2007). There are also some unconfirmed reports of it being found along the Wairarapa Coast but to date there have been no positive identifications or collections. These records show that the species is currently undergoing a range expansion since its initial discovery location in New Zealand.

Observations around Wellington indicate that both phases display some temporal variation in abundance (pers. obs) but is more pronounced in the upright phase. The gametophytic upright is present during the warmer periods of the year (Oct-Jan), when it forms distinct bands at the lower tidal levels but is completely absent in the colder period of year (AprSept). The sporophytic crust appears to be present throughout the year 
but shows a lower abundance in the warmest period (Feb-Mar) and then increases abundance again in the coolest period (May-Oct). Because of its year-round presence and longer abundance, it is likely that the crustose phase will have a greater long-term impact and be more important for the persistence of the species.

While there is no endemic or naturalised species with a similar morphology to the upright phase of C. bullosa, there are several species that are comparable to the crustose phase. Ralfsia verrucosa (Aresch) J. Ag., Ralfsia species (designated "Ralfsia-smooth"), and Diplura sp. (pers. comm. Joseph Buchanan) are the three species that are most likely to be confused with crustose C. bullosa but with practise they are easily distinguishable. All four species (C. bullosa, Ralfsia verrucosa, Ralfsia-smooth, and Diplura sp.) have a similar color and can all be found within the intertidal (pers. comm. Joe Buchanan) but C. bullosa has a distinctive growth pattern that results in overlapping lobes on the upper surface. This, and the other morphological features described earlier, enable both field and laboratory identification.

There are also endemic and naturalised species that co-occur with gametophytic C. bullosa and are the species most likely to be involved in ecological interactions. The main competitors for the upright phase are the other Colpomenia sp., Leathesia sp., Hormosira banksii, and several Cystophora species. An example of this can be seen in Fig 1.4. There are also several species commonly found co-occuring with upright C. bullosa, including Scytothamnus australis, Laurencia sp., and Corallina officinalis, but it is not clear how many of these species share the same ecological niche or are involved in competitive interactions with upright C. bullosa given their different morphologies. 


\subsection{Proposed Research}

This study is the first step in filling the knowledge gap surrounding this species and has three main aims. The first is to document the regional and local distribution of Colpomenia bullosa in the Wellington Region. This involves a regional survey to document the spread of this algae from its initial discovery location in Wellington Harbour, localised surveys to determine the intertidal range of the species, and a nearest neighbor survey to identify which endemic species are most at risk from this introduced species. This initial phase provides baseline data for the subsequent parts of the study.

The second aim of the study is to establish the physiological tolerance of Colpomenia bullosa to some of the abiotic stressors encountered in the intertidal. This part of the study measures the stress response of the photosystem using Pulsed Amplitude Modulated (PAM) fluorometry to establish the upper and lower thermal limits of the algae. PAM fluorometry is also used to assess the response of the algae to desiccation, changes in salinity, and rapid temperature change. This information, combined with the first part of the study, will help predict the potential habitats and areas most at risk from this introduced algae.

The final aim of this study is to investigate how Colpomenia bullosa becomes established in endemic intertidal communities. This phase of the study will determine the role of herbivores in the introduction process and how well C. bullosa competes with other algal species in the presence and absence of such herbivores. This information is important as it will assist in identifying the underlying mechanisms that C. bullosa uses to become established and will help in formulating any required management plans for this introduced alga.

The following chapters have been written as stand alone experiments and some repetition may occur with references and figures. All steps have been taken to minimise this but in some cases it was unavoidable. The ref- 
erences for each of the chapters are all listed in one complete list following the general discussion. 


\section{Chapter 2}

\section{Spatial and Temporal Variation of Colpomenia bullosa in the Wellington Region.}

\subsection{Introduction}

The negative impacts of introduced species have been well documented worldwide, and range from the localized extinction of endemic species (Fritts, 1998; Edgar et al., 2005; Qian and Ricklefs, 2006), to reductions in spatial diversity (Ross, 1991; Olden et al., 2004), to invasional meltdowns (Simberloff and Von Holle, 1999; Grosholz, 2005). The displacement or exclusion of native species can have cascading trophic effects and may cause ecosystem collapse should keystone species be affected (Paine, 1966; Paine, 1969; Lyons and Schwartz, 2001; Boudouresque and Verlaque, 2002). It is the goal of biosecurity programs to reduce these risks by detecting exotic species before they become established (Wotton and Hewitt, 2004; Schaffelke et al., 2006) and by not allowing introduced populations to reach problematic levels (Schaffelke et al., 2006). Once a population of an introduced species become established it can become almost impossible to control. 
After becoming established, an intruder may begin a range expansion (Carlton, 1996a; Grosholz and Ruiz, 1996) and spread beyond its initial introduction point (Kolar and Lodge, 2001; Lockwood et al., 2005). Often there is a time lag between introduction and range expansion due to time required to establish viable populations, and for sexually reproducing species (Hastings et al., 2005) this may require multiple introductions so that viable reproductive individuals come into contact with one another. This lag phase can vary depending on many factors and it can often take several years before a population is of sufficient size to allow range expansion (Mack et al., 2000).

Colpomenia bullosa (Saunders) Yamada is a recent arrival to New Zealand (NZ) and is possibly just beginning a range expansion. Colpomenia bullosa was first observed in the Leigh Marine Reserve, North of Auckland, in 1981 (Parsons, 1982) but current recordings indicate an expanding population as it can now be found in several North Island port areas including Auckland, Gisborne, Napier, and Wellington (Parsons, 1982; Adams, 1994; Nelson, 1999)(pers. obs). There are also some unconfirmed reports in coastal areas (i.e. Mahia and Wairarapa) between these locations and recently a single upright gametophytic plant was found at Patons Rock, Nelson (pers. comm. Erasmo Macaya-Horta 2006). This is the first record of the species from the South Island (pers. comm. Rissa Williams 2007).

Colpomenia bullosa has a heteromorphic life history with two clearly identifiable life history stages. There is an upright gametophytic phase in which the thallus forms round fluid filled finger-like projections that are between $10-15 \mathrm{~cm}$ in size and are brown in colour (Adams, 1994). There can be one or more uprights per holdfast and they form very conspicuous bands in the lower littoral zone (Adams, 1994; Nelson, 1999). The alternate phase is a sporophytic crustose phase which can be identified by its color and the unique lobing pattern visible on the upper surface of the thallus. The crustose phase can be found throughout the mid- to high- littoral zones and can occupy significant amounts of space. Currently there 
is anecdotal evidence that both phases show some seasonal variation in abundance (pers. comm. Joseph Buchanan, pers. obs.) but it is more pronounced in the upright phase which is only present during the warmer period of the year (Nov-Mar).

Although the taxonomy of New Zealand algae is poorly resolved and there are many species that have not been formally identified, there is little doubt that C. bullosa is a recent introduction to NZ. As mentioned above, the gametophytic upright has a distinctive morphology that is easily recognisable and although several other Colpomenia species appear in early species listings (Chapman, 1974; South and Adams, 1976; Adams and Nelson, 1985; Nelson and Adams, 1987), no species with a comparable morphology or description appears. Given its prolific abundance during certain times of the year, it is unlikely it would have gone unreported until 1982 (Parsons, 1982). The Algaebase database(www.algaebase.org) also lists C. bullosa as an introduced species in Europe and Australia, strengthing the case for it being an invader into NZ.

Although there are many studies highlighting the devastating consequences introduced species can have on native communities (e.g. Meinesz et al 1993, Bellan-Santini et al 1996, Berkman et al 1998, York et al 2006), very little is known about C. bullosa in NZ or any potential effects for intertidal communities. This is surprising given it was first described over 20 years ago (Parsons, 1982).

Assessing the potential impact of C. bullosa is further complicated by the alternate life history phases of this introduced algae. As the phases have very different morphologies they will likely have different effects on communities. The ephemeral upright is absent for a significant period of the year while the slow growing crustose phase can persist longterm. Both phases may interact with endemic intertidal communities and the outcomes of such interactions may significantly influence the community over time. As C. bullosa is found in multiple locations already, and there is little chance of restricting or controlling the spread, this species introduc- 
tion provides a chance to examine what effect an introduced species can have on indigenous communities and how such communities respond to such an event.

This chapter addresses questions regarding spatial and temporal variation in the abundance of $C$. bullosa and its patterns of co-occurrance with native species. Answering these questions will facilitate predictions as to the extent of the introduction in the Wellington region and identify the intertidal position commonly occupied by C. bullosa. They will also determine what species are most at risk from this introduced alga and its potential impacts.

\subsection{Methods}

\subsubsection{Spatial Variation Survey}

I used a nested survey design to examine the spatial distribution of crustose Colpomenia bullosa in the Wellington region. Based on the results of pilot surveys, five locations around Wellington were chosen: (1) Point Halswell, within Wellington Harbor; (2) Palmer Head, at the entrance to Wellington Harbor; (3) Owhiro Bay, on the Wellington South Coast; (4) Makara Beach (West Coast); (5) Porirua Harbor (West Coast). The general area of each location is shown in Fig. 2.1 and the GPS coordinates are listed in the Appendix.

Within each of the locations, two sites were selected a minimum of $200 \mathrm{~m}$ apart. The sites were topographically comparable to each other and had similar wave exposure, aspect, and littoral zone gradient. All the sites had large rocky substrate with a slope less than $10 \%$ which was checked using a Topcon AT-G7 Auto Level theodolite (Topcon theodolite). None of the survey sites were exposed to direct wave action and all sites had an intertidal zone of comparable length. This allowed direct comparisons in the coverage of C. bullosa between the various sites without needing to 
allow for confounding abiotic variables.

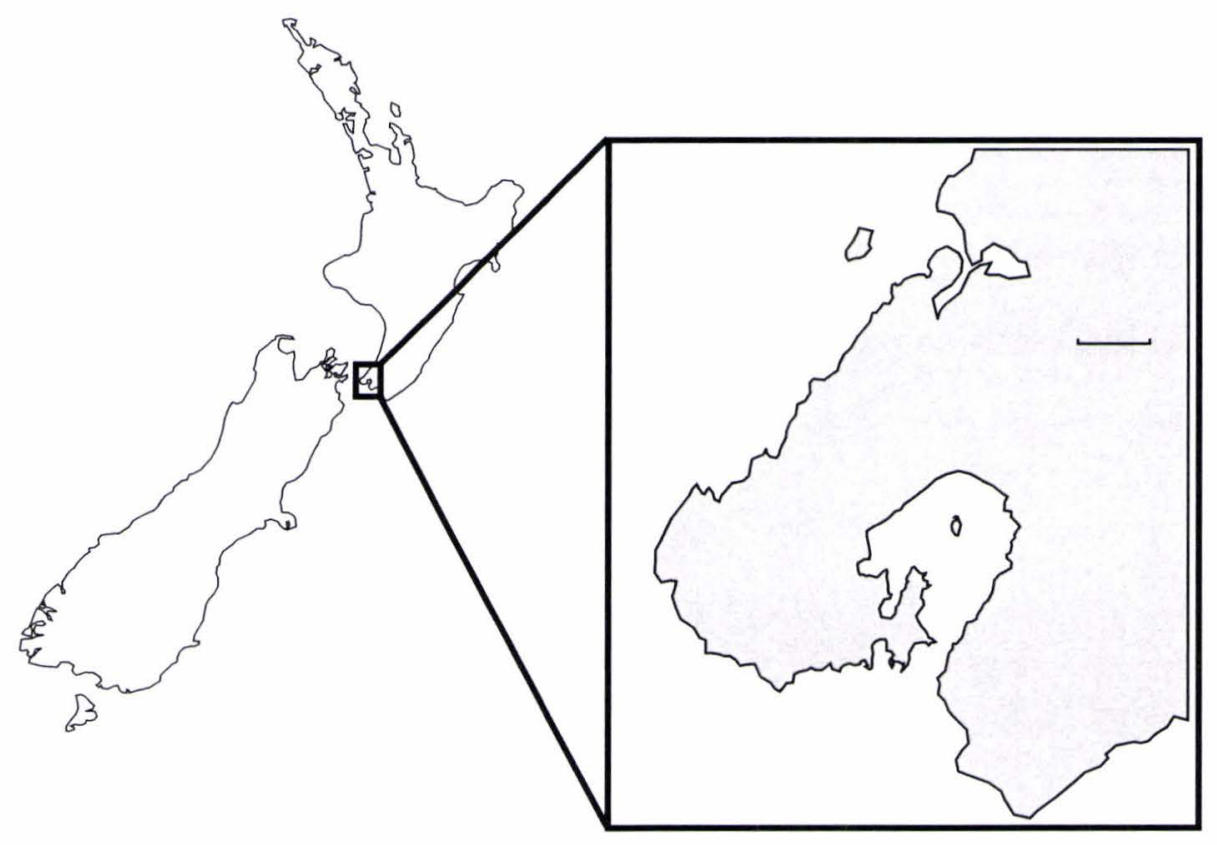

Figure 2.1: Distribution survey sampling locations. The numbers indicate the general location of the respective survey sites around the Wellington Region and the GPS coordinates for the exact locations are listed in the appendix. Location (1) Point Halswell, Location (2) Palmer Head, Location (3) Owhiro Bay, Location (4) Makara, and Location (5) Porirua Harbor.

At each of the sites the mean low and high water heights were marked using A-788 Splash Zone Compound (Z-Spar) marine epoxy. All of the survey sites had a mean low and high water level marked on the same day and all sites were marked \pm 15 mins of the low and high water time. Later the vertical distance between these markers was checked using the Topcon theodolite to ensure the tidal range was similar between all of the sites. After the mean high and low water levels were marked, these points were used to indicate the placement of transect lines.

Transect lines were laid parallel to the shore in the high-, mid-, and low-littoral zones. The 'High zone' transect was just below the mean high water level and the 'Low zone' transect was just above the mean low wa- 
ter level. The 'Mid zone' transect was approximately midway between the 'High' and 'Low' transect lines. Ten quadrats measuring 200mm X $200 \mathrm{~mm}$ were then placed along each transect line (five in pools and five on emergent rock) using randomly generated numbers. The random numbers were generated so that each quadrat was placed within a $2 \mathrm{~m}$ area and no two quadrats were closer than $0.5 \mathrm{~m}$. This was repeated along each of the transect lines.

The physical make-up of each quadrat had to meet specific requirements before the \% cover was recorded. Pilot surveys indicated that $C$. bullosa would not be found in sandy areas or on cobbles less than $50 \mathrm{~mm}$ diameter. Therefore, if more than $20 \%$ of the quadrat (selected randomly during the main survey) was of such substrate, the position was rejected and a new random number was generated. The same rejection process was applied if more than $40 \%$ of a pool quadrat was emergent rock and if more than $40 \%$ of an emergent rock quadrat was covered by water. Quadrats were continually placed along the transect using random numbers until the five pool and five emergent rock quadrats were obtained for each transect.

A visual estimation technique was used to estimate the \% cover of each species within the quadrats. I validated this approach against percent cover estimates obtained from a random point contact method. One hundred quadrats were randomly sited and the \% cover of the species within each quadrat was visually estimated. Then a clear Perspex sheet with 100 randomly sited points was overlaid on the quadrat and the species or substrate underneath each point was recorded. The same Perspex sheet was used in all visual estimation calibration quadrats and the visual estimation was always conducted first to prevent any bias from the point intercept result. The error between the visual estimate and point intercept was then tested using regression.

All sessile species found within the quadrat were recorded as \% covers; all mobile species were recorded as counts. Species identifications 
were made in the field as far as possible. If the specimen could not be identified, then it was collected, preserved, and identified in the lab by microscopy and sectioning if appropriate. Some of the species were identified as distinct species even though they have not yet been described. Such species included Ralfsia-"Smooth", Ralfsia-"Rough", "Smooth coralline", and "Ridged coralline". Uncommon or difficult to identify algal species were collected and pressed for future identification purposes.

Spatial variation in \% cover (or counts) were then analyzed using standard Nested ANOVA models with 'Tidal height' nested within 'Site' nested within 'Location'. All statistical analysis were performed using R (version 2.3.0 for Mac OSX) statistical package.

\subsubsection{Temporal Variation Survey}

To examine the temporal variation in abundance of C. bullosa, fixed quadrat surveys were used. During 2005 three sites with upright gametophytes of C.bullosa were identified and marked using Splash-zone marine epoxy compound: Site (6) Palmer Head, at the entrance to Wellington Harbor; Site (7) Island Bay, Wellington South Coast; and Site (8) Red Rocks, Wellington South Coast. These sites were deliberately placed to cature existing patches of C. bullosa and the GPS coordinates for each site were also plotted and listed in the Appendix. At each site, three permanent $2 \mathrm{~m} \times 2 \mathrm{~m}$ quadrats were established in the sub-littoral fringe (SLF), mid-littoral (ML) and high-littoral (HL) a minimum of $10 \mathrm{~m}$ apart. The corners of the plots were marked using Z-spar and labeled with colored tags. The plots were not cleared or manipulated in any way and were situated on rocky substrate with a minimum cobble size of $50 \mathrm{~mm}$.

The sites were surveyed monthly from November 2005 to November $2006(n=12)$. The number of upright $C$. bullosa gametophytes within each quadrat were recorded each survey, and once a plant was counted, a label was attached to the plant. Labels consisted of a colored cable tie placed 


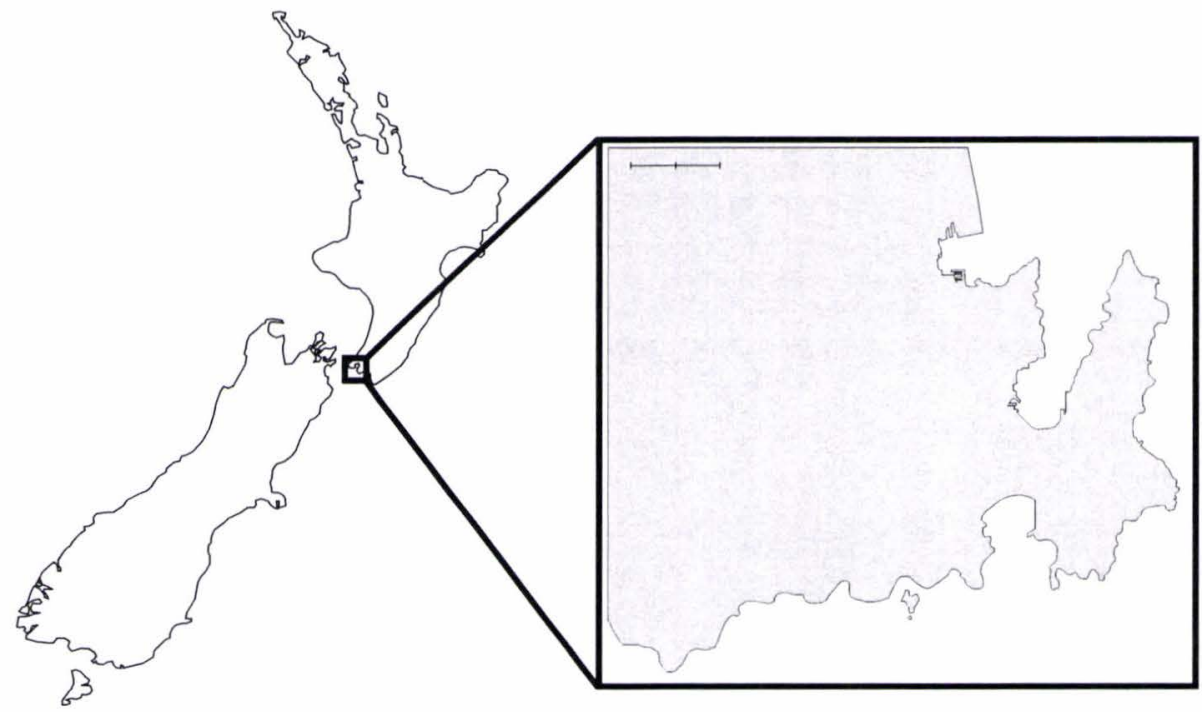

Figure 2.2: Location of the fixed quadrats around the Wellington region. Site (6) Palmer Head, Site (7) Island Bay, Site (8) Red Rocks. There were nine plots at each site- three in each littoral zone (HL, ML, SFL).

loosely around the base of one of the fluid filled projections. A disc of Zspar was also placed onto the substrate beside the plant with an unique identifying number scribed into the disc. This was to allow for the identification of lost plants. Labelling the individual plants also allowed for new settlers to be identified and counted.

For the crustose phase, the results were analyzed using a multi-factorial repeated measures ANOVA with Month as the repeated measure, Tidal height as an additional fixed factor, and \% cover as the measured response. The upright phase was analyzed using a repeated measures ANOVA with Month as the repeated measure. Tidal height was not assessed as the gametophyte was only found within one tidal level.

\subsubsection{Neighbouring Species Interaction Survey}

The neighbouring species interaction surveys refer to the crustose phase of C. bullosa only. A band transect design was used to investigate how crus- 
tose C. bullosa interacts with other crustose species within the intertidal. Eight sites around the Wellington Region were selected. The sites were topographically comparable to each other and had similar wave exposure aspect, orientation towards the sun, and tidal zone gradient. All the sites had large rocky substrate with a slope less than $10 \%$ which was checked using the Topcon theodolite. None of the survey sites were exposed to direct wave action and all featured a similar length intertidal zone.

Using the same tide markers laid out for the Nested Survey design, a $20 \mathrm{~m}$ transect was laid in the high littoral zone and all pools along the transect were surveyed. Emergent rock was not included as the previous surveys indicated C. bullosa was restricted to pools.

An area $250 \mathrm{~mm}$ either side of the transect was surveyed providing a $500 \mathrm{~mm}$ wide band and all C. bullosa crustose thalli larger than $50 \mathrm{~mm}$ in diameter were assessed for interactions at the growing edge. A compass was placed in the middle of the thalli and the interaction event occurring at the $\mathrm{N}$ E S W points was recorded. The interaction events were categorized in respect to C. bullosa and were placed into one of four groups- overgrowing neighboring species (Over), under or being overgrown by the neighboring species (Under), no available space (NAS) i.e. all of the available subtrate is occupied by C. bullosa and no other event can occur, and bare rock with no neighboring species or event occurring (BR). All the interaction events along the transect were recorded provided the individual thalli satisfied the above criteria.

The results were analyzed using a Monte Carlo permutations model that examined the observed vs. expected results under a Chi-squared distribution with alpha $=0.05$. The permutations test was performed 10000 times. 


\subsection{Results}

\subsubsection{Visual vs. Point Estimate \% Cover}

The visual estimate of \% cover for 100 quadrats was assessed for accuracy using regression with the visual estimate of \% cover plotted against the point intercept result from the perspex overlay (Fig. 2.3). The significant $\mathrm{R}^{2}$ of $0.92\left(\mathrm{~F}_{(1,97)}=2485, \mathrm{p}<0.001\right)$ indicated that the visual estimates were a close match to the point intercepts. The variation in the residual error was greater for the quadrats with high \% cover and the visual estimates tended to be higher for such quadrats.

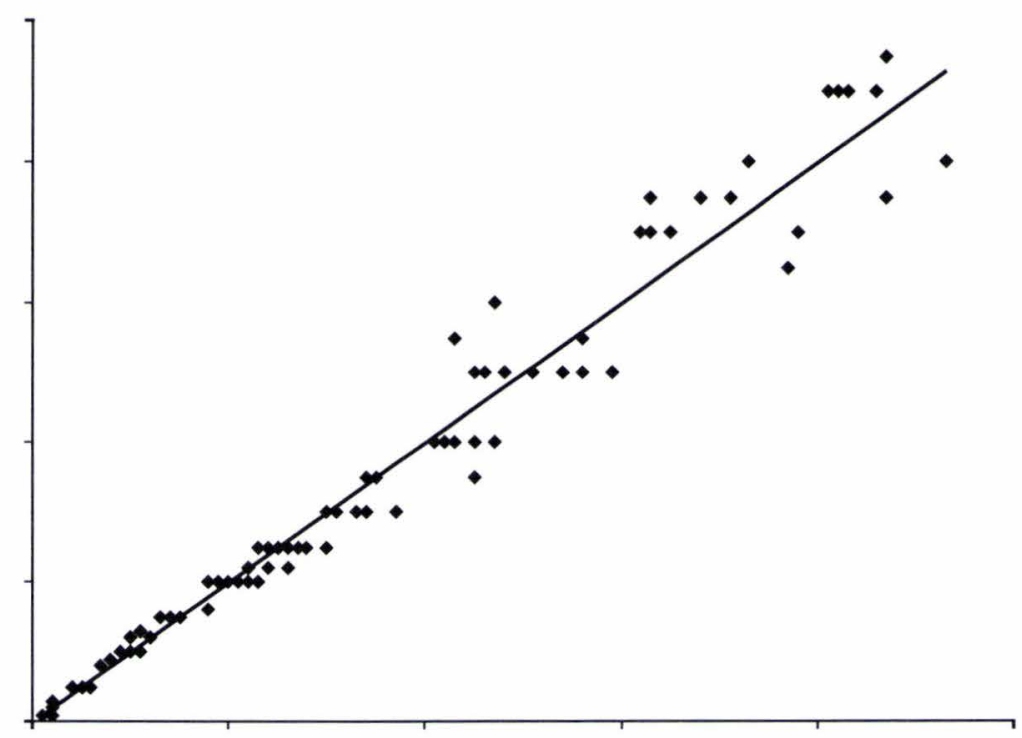

Figure 2.3: Visual estimation vs point intercept regression plot. The visual estimates of $\%$ cover were a close match to the point estimate $\%$ 's. $\mathrm{R}^{2}=$ $0.92(\mathrm{p}<0.001)$. 


\subsubsection{Spatial Variation Survey}

The Nested ANOVA indicated there was a significant difference in the abundance of crustose C. bullosa between the survey locations $(p<0.001)$ (Table 2.1). This result was investigated further using multi dimensional scaling and Kau Bay (Location 1) was found to group apart from the other locations (Fig. 2.4). Kau Bay had a significantly lower abundance of $C$. bullosa.

There was no difference between the Sites nested within Location $(p=0.978)$ but there was a significant effect from Tidal Height $(p<0.001)$ nested within Site within Location. There was also a significant effect from Habitat within Tidal Height after allowing for the Site and Location nesting $(\mathrm{p}<0.001)$ (Table 2.1). The highest \% cover of crustose C. bullosa was observed within pools in the highest littoral zone surveyed and coverage had reduced to zero by the low littoral zone. No significant amount of C. bullosa were found on emergent rock at any tidal level (Fig. 2.5).

Table 2.1: Nested ANOVA table. The order of the variables indicates the nesting order.

\begin{tabular}{|l|c|c|c|c|}
\hline Variation & Df & MS & F-value & P-value \\
\hline Location & 4 & 96.6 & 4.428 & $<0.001$ \\
Location:Site & 5 & 0.5 & 0.017 & 0.978 \\
Location:Site:Tidal Height & 18 & 51.8 & 2.374 & $<0.001$ \\
Location:Site:Tidal Height:Habitat & 28 & 113.9 & 5.219 & $<0.001$ \\
Residuals & 224 & 21.8 & & \\
\hline
\end{tabular}

The MDS and Nested Survey results correspond to the crustose phase of C. bullosa only as there was insufficient data gathered for the upright phase to allow for conclusive analysis. The upright phase had a very low intertidal to sublittoral distribution and these zones were not adequately covered during the surveys. 


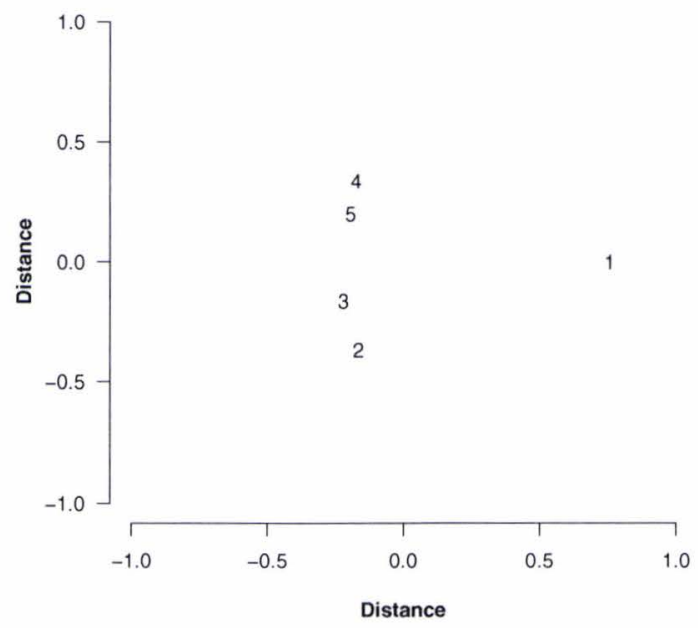

Figure 2.4: Multi Dimensional Scaling plot. The numbers refer to the survey locations with $1=$ Kau Bay, $2=$ Wahine Park, $3=$ Red Rocks, $4=$ Makara, and $5=$ Porirua Harbour. The axis label 'Distance' refers to the statistical distance between the locations and shows there is significant statistical distance between location 1 and the other locations.

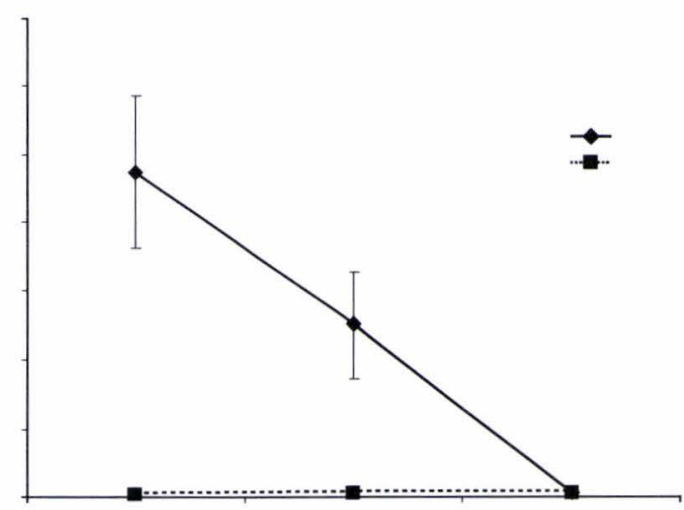

Figure 2.5: Tidal height: Habitat interaction plot. The \% cover of crustose C. bullosa is significantly different between the tidal heights and habitat. No crustose $C$. bullosa was found on emergent rock on any tidal height. 


\subsubsection{Crustose Species Abundance}

The crustose species found within the survey plots all showed significantly different patterns of distribution compared to crustose C. bullosa. In the high tidal zone pools, C. bullosa and 'Thin crustose coralline' had the highest percentage cover (approx. 12 and $14 \%$ respectively) relative to the other crustose species found in this zone however, C. bullosa had significantly higher cover compared to the other crustose brown algal species $(\mathrm{p}<0.001)$. The species with the next highest cover was Ralfsia-smooth species (3\% cover) but this was four times lower than that of C. bullosa. Two other Ralfsia species were found in the plots but neither had very high abundance cover (Fig. 2.6).

In the mid-littoral pools, C. bullosa was still the dominant brown crustose species but the dominant coralline species had switched from 'Thin crustose coralline' to the morphotype designated 'Ridged crustose coralline'. Unlike the other brown crustose species, C. bullosa showed a significant reduction in cover between the high- and mid-littoral zones and only covered approximately $5 \%$ of available space in the mid tidal zone.

In the low littoral pools, Diplura crust had become the dominant brown crustose species and C. bullosa was almost completely absent. The abundance of the Ralfsia spp. was not significantly different from the high or mid tidal levels and had similar abundance across all three tidal levels (Fig. 2.6).

\subsubsection{Temporal Variation Surveys}

The abundance of the upright C. bullosa gametophytes showed significant temporal variation $\left(\mathrm{F}_{(1,11)}=155.2, \mathrm{p}<0.001\right)$ with a peak in abundance in the spring / early summer (Oct-Jan) period. There were approximately 25 per plants per quadrat (Fig. 2.7) during this time, however, this was not sustained and by mid summer (Feb) no gametophytes were present in any of the plots. The gametophytes did not return until late winter 


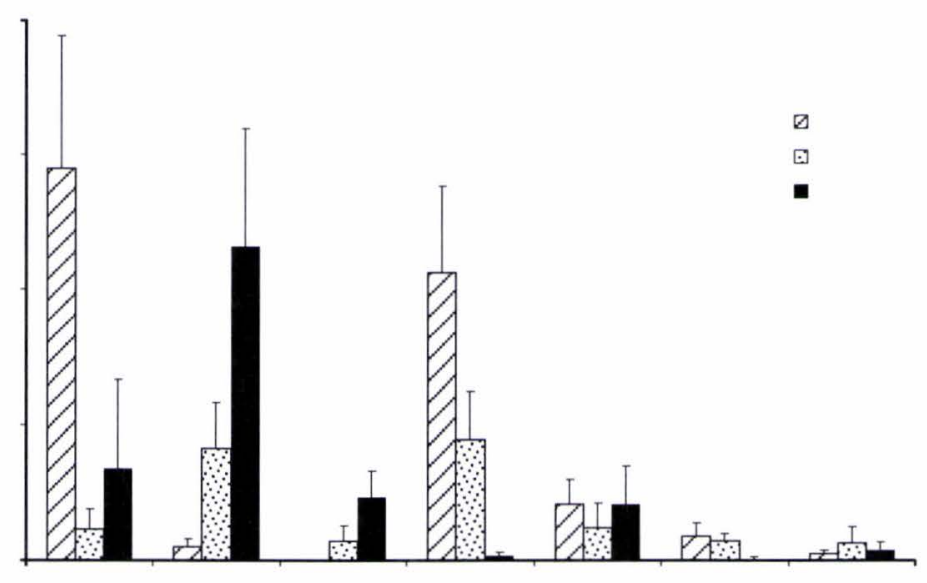

Figure 2.6: Percentage cover of crustose species within pools in the 3 tidal zones ( \pm 1SE). The key indicates the shading combinations for the respective tidal heights. High $=$ High mid littoral zone, $\mathrm{Mid}=$ Mid littoral zone, and Low $=$ Sub-littoral fringe.

/ early spring (Sept-Oct). The number of new settlers displayed a similar trend with the bulk of new plants occurring in one short period (Oct-Nov). Note that Fig. 2.7 refers to the low littoral zone only as the gametophytes were not found at any other tidal height.

The abundance of crustose C. bullosa showed little temporal variation during the survey period. There was no significant interaction between Month and Tidal height $\left(\mathrm{F}_{(22,288)}=0.334, \mathrm{p}=0.998\right)$ on crustose $C$. bullosa abundance. There was also no significant monthly variation $\left(\mathrm{F}_{(1,11)}=0.861\right.$, $\mathrm{p}=0.578$ ) however there was significant variation between the littoral zones monitored during the survey $\left(\mathrm{F}_{(2,22)}=1178.5, \mathrm{p}<0.001\right)$. The high littoral zone had the highest \% cover, followed by the mid- and then the lowlittoral zone (Fig. 2.8).

Figure 2.8 suggests some temporal variation in high littoral zone however statistical further testing confirms this is not significant. The high littoral zone displayed the most variation with \% cover peaking during spring (Dec) at approximately $16 \%$ and reducing to $14 \%$ during the mid 
summer period (Feb-Mar) but repeated measures ANOVA testing shows this reduction was not statistically significant $\left(\mathrm{F}_{(11,96)}=1.363, \mathrm{p}=0.203\right)$. The mid- and low-littoral zones had very little variation during the survey period but also had much lower \% cover overall (Fig. 2.8). As with the Nested survey, crustose C. bullosa was almost completely absent at the lowest tidal level.

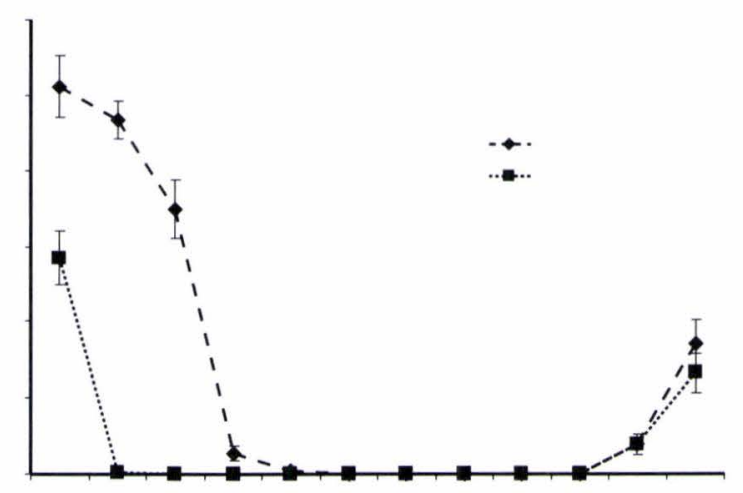

Figure 2.7: The abundance of gametophytic upright Colpomenia bullosa over 12 months at the low tidal level $( \pm 1$ SE.) The total number of uprights peaked during spring or the November / December period and the number of settlers peaked in early spring. No uprights were found in any of the plots between March and August.

\subsubsection{Neighbouring Species Interactions}

The low and mid tidal level transect surveys failed to yield enough data for analysis (i.e. C. bullosa was in such low abundance that obtaining suitable replication was not possible) so the following results are applicable to the high tidal zone only. The event categories Bare Rock (BR) and No Available Space (NAS) were also removed from the analysis as the 'zero' (signifying no observed event) caused a skewed distribution resulting in a failure of the required normality assumption for a valid permutations test. 


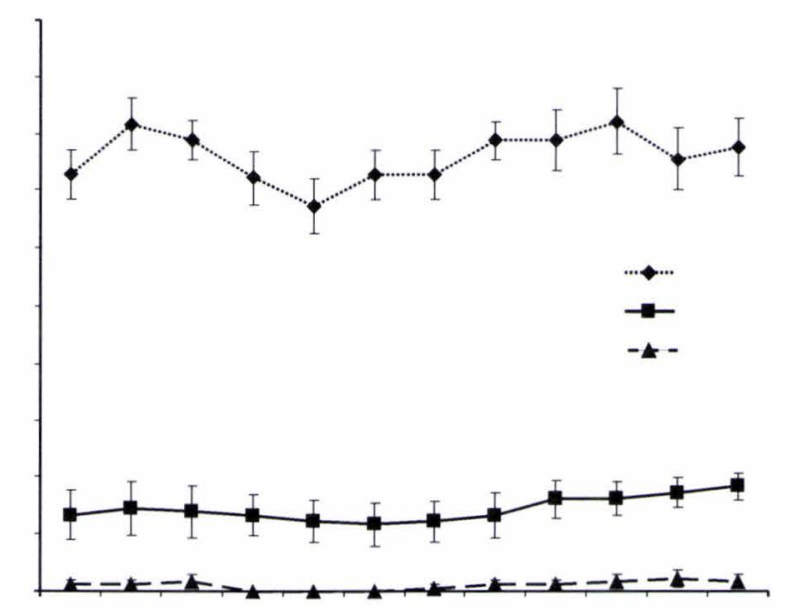

Figure 2.8: The \% cover of crustose Colpomenia bullosa over 12 months ( \pm 1SE). None of the observed monthly variation in \% cover was significant and the high zone had the highest \% cover out of the 3 tidal zones.

Out of the 418 events recorded, 109 were in the BR category and 163 were in the NAS category.

The observed frequency for the species interactions was found to be significantly different $\left(\chi_{(6)}^{2}=109.42, \mathrm{p}<0.001\right)$ from frequencies expected under a random distribution. These results were tested further using a permutations test which showed a significant difference in the observed vs. expected results $(\mathrm{p}<0.001$ with $\mathrm{r}=10000)$. The results indicate that the two more upright macroalgal species (Corallina officinalis and Hormosira banksii) overgrow C. bullosa more than what would expected under random conditions but C. bullosa seems to overgrow morphologically similar species more than what would be expected under random conditions. Due to the rarity of some of the species interacting, it should be noted that some of the groups have a limited number of observed interactions. The observed and expected frequencies are shown in Table 2.2. 
Table 2.2: Observed and Expected values for species interactions. The event 'Under' $=$ the respective species found underneath C.bullosa and 'Over' $=$ the respective species found growing over C.bullosa.

\begin{tabular}{|l|c|c|c|c|}
\hline \multirow{2}{*}{ Species } & \multicolumn{4}{c|}{ Event } \\
\cline { 2 - 5 } & \multicolumn{2}{|c|}{ Under } & \multicolumn{2}{c|}{ Over } \\
\cline { 2 - 6 } Corallina officinalis & Observed & Expected & Observed & Expected \\
Ridged Crustose Coralline & 7 & 23.6 & 27 & 7.4 \\
Thin Crustose Coralline & 83 & 7.6 & 3 & 2.4 \\
Hormosira banksii & 0 & 3.8 & 0 & 19.9 \\
Ralfsia confusa & 4 & 3.1 & 0 & 1.2 \\
Ralfsia rough & 8 & 6.1 & 0 & 1.0 \\
Ralfsia smooth & 5 & 3.8 & 0 & 1.9 \\
\hline
\end{tabular}

\subsection{Discussion}

Colpomenia bullosa appears to have spread extensively since its introduction to Wellington Harbour (Nelson, 1994). The crustose phase can now be found from Palmer Head to Porirua Harbour and although the surveys did not measure the abundance of the upright phase, the permanent quadrats indicated a high enough abundance to allow easy detection along the Wellington South Coast during certain times of the year. These results indicate that the species has undergone a range expansion since the discovery of the single gametophyte at Evans Bay in Wellington Harbour (Nelson, 1994).

The underlying mechanisms of this population expansion are not examined in this study but the most likely explanation is an anthropogenic vector. Both Makara (Location 4) and Porirua (Location 5) are upstream of the prevailing tidal stream so natural dispersal seems unlikely. Both are marked as safe havens for coastal shipping vessels however and, due to the high number of commercial and recreation vessels in the Wellington 
region, it is possible that one or more of the vessels transported plants or spores from Wellington harbour or the South Coast around to Makara and Porirua.

The intertidal distribution of crustose C. bullosa matched what would be expected from a crustose species (Dethier, 1994) with high abundance in the upper littoral zone declining closer to the sublittoral fringe. As crustose species are characteristic of high stress or highly disturbed environments (Lubchenco and Cubit, 1980; Steneck, 1986; Dethier, 1994; Somero, 2002) their high abundance in the upper littoral is not unexpected. Unusually though, none of the native brown crustose species were found in such abundance or exhibited the pronounced change in abundance observed in C. bullosa.

Crustose Colpomenia bullosa covered up to $14 \%$ of available space in high zone pools and all of the other brown crustose species surveyed had coverage lower than 5\% (Fig. 2.6). This high coverage was only matched by the thin crustose coralline species. The mechanisms driving this distribution are unclear at this stage but could be the result of abiotic factors (e.g. temperature, light, salinity, or desiccation) or biotic interactions (e.g. competition or grazing). Based the heteromorphic life history of C. bullosa and the observed distributions it is likely that different factors will be controlling the distributions of the respective phases.

As C. bullosa was not found on emergent rock at any tidal level, this would suggest desiccation tolerance may be an important abiotic factor that could influence distribution. Poor desiccation tolerance would be unusual for a crustose species as their morphology is expected to aid water retention and reduce desiccation stress (Hay, 1981; Taylor and Hay, 1984; Dudgeon et al., 1995). Further to this, the filamentous nature of the crustose C. bullosa thallus would be expected to provide some level of desiccation tolerance, yet it was not found on emergent rock even in the lower littoral zones. Due to the reduced desiccation times at such littoral levels C. bullosa would only require mild desiccation tolerance in order to survive 
(although biotic interactions may affect or exclude it). The tolerance of $C$. bullosa to abiotic stresses like temperature, light, salinity and desiccation will be examined in the following chapters.

The reduced abundance of crustose C. bullosa in the lower littoral zones could be the result of biotic factors that are ineffectual in the high littoral zone. Biotic factors have less influence in the high littoral zone due to the high levels of physiological stress and disturbance but become more influential in the lower littoral zones as the impact of stress and disturbance is reduced. These biotic factors can influence competitive outcomes and may result in a change of abundance for some species.

The interaction survey data suggests that crustose C. bullosa can overgrow and out compete morphologically similar species but it may not be able to continue this dominance in the lower littoral zones. If this is the case then it would explain why C. bullosa has a much higher abundance than the other crustose species in the high zone as it can overgrow and exclude them from the community, reducing their overall abundance. In the lower littoral zones, C. bullosa does not maintain this dominance and is overgrown by other species (crustose or other macroalgal species) causing the observed distribution.

It is unclear from the surveys what effect C. bullosa is having on the species it can overgrow. A recent study by Underwood (2006) found that some crustose species can withstand overgrow th by utilising nutrient translocation mechanisms. It is hypothesised that an overgrown species can survive using this strategy until the competitor is removed. How this theory applies to an overgrowing crustose species is unclear, as although C. bullosa is comparatively easy to remove from the substrate, it would take a substantial disturbance event to remove it and release the species being overgrown.

Further work also needs to be done on establishing the role and importance of the species most at risk from this introduced alga. Very little is known regarding the ecology of crustose species in NZ and what role they 
play in the intertidal community. There is evidence that some of the crustose coralline species are important for invertebrate settlement (Steneck, 1986; Johnson and Sutton, 1994; Moss, 1999) and provide a valuable food source for invertebrate juveniles (Steneck, 1982; Shepherd and Turner, 1985; Daume et al., 1999; McShane and Naylor, 1996). The trophic effects of removing these crustose species are unknown and will require further investigation but based on the survey results to date, the impacts are likely to be minimal as crustose C. bullosa has a very limited distribution (i.e. restricted to pools high in the littoral zone).

The permanent quadrat monitoring confirmed significant temporal variation in the upright gametophytic phase of C. bullosa but not for the sporophytic crustose phase. This was contrary to anecdotal observations but does support the suggestion of Dethier and Steneck (2001) that the crustose phase is used to survive stressful periods of the year and is more important for the long-term persistence of the species. Although not statistically significant, there was a reduction in crustose abundance in March, which could related to thermal stress. Traditionally this is the warmest period of the year and would increase the risk of photoinhibition considerably, possibly resulting in a reduction in abundance.

There is a lack of knowledge surrounding the ecology of C. bullosa in $\mathrm{NZ}$ and the temporal variation in gametophytic phase is difficult to explain, however there are several viable hypotheses. Several studies (e.g.Lubchenco and Cubit, 1980; Cubit, 1984; Korpinen et al., 2007) highlight the importance of grazing and seasonal abundance of ephemeral algal species. These studies suggest firstly, that grazing can control or reduce algal abundance for most of the year except during the late winter period when algal productivity is highest and secondly, that herbivory has the greatest effect on ephemeral algae around the sublittoral fringe (Korpinen et al., 2007). It is suggested that during this time the herbivores cannot graze the algae fast enough, resulting in an increased abundance for such species until productivity reduced and grazing pressure was able to suppress the 
species again.

An alternative explanation to grazing pressure is disturbance. The influence of disturbance in structuring intertidal communities has been studied extensively (e.g. Connell 1961, Dayton 1971, Paine 1974,Sousa 1979, Lubchenco 1980, Harley 2006 ) and, although it could potentially influence the abundance of both phases of C. bullosa, physical disturbance is more likely to act upon the upright phase. The upright gametophytes have a thin foliose thalli with a large surface area that is easily removed from the substrate. The large thalli would create significant drag from water movement and would therefore be susceptible to damage or total removal by heavy wave action (Blanchette, 1997).

The strength of wave action that would be required to remove C. bullosa from the substrate is unclear but the Cook Strait and Wellington area is a region of significant swell events. Although the ocean swell often does not impact directly onto the shore, and many of the significant swell events are during the June-August period, it may still have a significant effect on the intertidal community. With this in mind however, there were no significant storm events in the January-Febuary 2006 period that would account for the reduction in the upright phase observed in the permanent quadrats.

The permanent quadrat surveys also suggest a single pulse of recruitment or a specific germination trigger. The number of new plants peaked early in the growing season and there were no new plants recorded after this peak. Many species use diurnal cycles and temperature as reproductive cues and, although germination triggers have been studied in dinoflagellates (Anderson et al., 1987; Kremp and Anderson, 2000; McQuoid, 2005) it is unknown if such triggers exist for temperate macroalgal species. Further research is needed in this area before any conclusive statements regarding C. bullosa and its reproductive cycle can be made.

The results from the regression plot support the use of visual estimation as an accurate method of measuring percentage cover. Although the 
variation became larger when percentage cover was very high, the $R^{2}$ value indicates that the visual estimates and point intercepts were very closely matched. The visual estimation method allowed for a more extensive survey and greater coverage of the Wellington region. This increased sample size would reduce any overall error associated with the visual estimation technique as supported by Dethier et al. (1993) and Meese and Tomich (1992).

The site selection criteria for the nested survey was designed to examine the spatial variation of C. bullosa around the Wellington region but does not give an accurate representation of the abundance of C. bullosa in the Wellington region. It may lead to an over estimation of the actual abundance. Random selection of the sampling locations would have given a better representation but the methodology used here allowed a direct comparison between the locations without having to allow for additional physical or geographic factors. Upon consideration of both sampling methods, it was decided that the information gained from the direct comparisons would be more useful than random surveys.

The pilot survey data from which the site selection criteria was constructed indicated that sheltered areas of hard rocky substrate with a low gradient had the greatest cover of crustose species and would provide the best chance of detecting effects of C. bullosa. Given the diverse nature of the Wellington coast line, a survey using randomly sited sampling sites may have missed such locations and failed to detect the abundance or influence of this introduced species. Any future abundance surveys should take this into consideration when designing experiments based on the results from this study.

The lack of data regarding the gametophytic phase is also an issue that needs to be addressed. As it is the more recognisable phase, it is likely that it would be used for fast detection of this introduced species even though the crustose phase is more important for long term persistence. Although the nested survey indicated it had a more sub-littoral distribution with 
significant temporal variation, no data was collected with regard to spatial variation or its influence on neighbouring species. As the uprights were identified as having a sub-littoral distribution, surveys with the appropiate methodology could collect the required data relatively easily.

In summary, there appears to be some variation in the regional distribution of C. bullosa with the Wellington Harbor location having lower abundance that the other four sites. There is also significant variation in the intertidal distribution with the crustose phase restricted to pools high in the littoral zone and the upright phase found below the littoral fringe. Both phases show some temporal variation (although not statistically significant for the crustose phase) but this is more pronounced in the upright phase.

Although crustose C. bullosa can overgrow morphologically similar species in most competitive encounters, its highly restricted distribution means it is unlikely that there will be significant impacts for the community in general. While it may impact on high littoral pool communities, it is unclear what effect the removal or exclusion of the native crustose will have and this needs to be investigated further. 


\section{Chapter 3}

\section{Investigations into the physiological tolerance of Colpomenia bullosa.}

\subsection{Introduction}

It is widely accepted that abiotic factors are more influential in the higher intertidal (Connell, 1972; Bertness, 1981; Dring and Brown, 1982; Harley, 2003) and that community composition at these heights are driven by species' ability to tolerate stress (Bertness et al., 1992; Bertness and Hacker, 1994; Beukema and Flach, 1995; Somero, 2002). The tidal cycle is the primary cause of abiotic stress in the high intertidal (Stillman and Somero, 1996; Helmuth et al., 2002) followed closely by disturbance (Dayton, 1971; Taylor and Littler, 1982). These factors result in extreme fluctuation and constant change in the environmental conditions that species must withstand in order to survive.

The failure of an individual to adapt to or withstand the abiotic stresses of the intertidal may result in the elimination of that individual from the community (Sousa, 1979a; Witman, 1992; Dethier, 1994) and in turn reduce the impact of the respective species on the surrounding community. 
Furthermore, significant stress and disturbance events may also alter the community structure as they can reset the successional sequence (Connell, 1972; Kim and DeWreede, 1996; Foster et al., 2003) and provide the opportunity for new species to colonise areas through the removal of competitive dominants (Dayton, 1971; Sousa, 1979a; Paine and Levin, 1981; Sousa, 1984).

The ability to tolerate and withstand stress or disturbance is especially relevant for species living in the higher littoral zones as it is a mechanism to ensure survival in this highly variable environment (Wolcott, 1973; Davison and Pearson, 1996; Nielsen et al., 2006). In addition to longterm survival, stress and disturbance can create space in existing communities by removing less hardy species thereby allowing surviving species to increase in abundance (Sousa, 1979b). A high tolerance to stress or disturbance is also a potential vector for allowing introduced species to become established in native communities (Carlton, 1996b; Kolar and Lodge, 2001).

Previous work (Chapter 2) has shown that the crustose phase of the introduced algae Colpomenia bullosa is restricted to pools high in the intertidal and, unlike other intertidal crustose algae, is seldom found on emergent rock or outside pools. The surveys also showed that C. bullosa occupies large amounts of primary substrate in these high pools. Given that these pools are highly variable and physiologically demanding environments for marine species, it suggests crustose $C$. bullosa has a high stress tolerance and can withstand significant disturbance events, e.g. heavy wave action or sand scour, but is unable to withstand desiccation as it is never found on emergent rock. High stress tolerance and the ability to withstand disturbance are ideal traits to facilitate the establishment of an introduced species (Ashton et al., 2007).

If C. bullosa does have a high physiological tolerance then it will be reflected in photosystem functioning. Here, I investigate the physiological tolerance of C. bullosa and determine how this correlates to the observed 
distribution. There are three main components to this chapter. The initial component will address the question 'What is the physiological range of crustose Colpomenia bullosa with respect to temperature and light?' The set of experiments used to answer this question will establish the minimum and maximum temperatures that crustose C. bullosa tolerate over time, and how the photosystem responds to such temperatures. This component will also examine the effect of different light levels and salinities.

The second component will test the response of crustose C. bullosa to desiccation. As mentioned above, the survey data revealed that crustose C. bullosa was never found on emergent rock suggesting desiccation may play a factor in determining the distribution of this algae. Other studies (Oates, 1985; Beer and Eshel, 1983; Kawamitsu et al., 200) demonstrated that although some intertidal algae had reduced photosynthetic performance while desiccated or exposed, they were able to fully recover upon re-immersion. This has never been tested in C. bullosa. This experiment will examine how long crustose C. bullosa can tolerate desiccation before there is a reduction in photosynthetic performance and how well it recovers from desiccation.

The final part will examine the critical temperature at which permanent damage to the photosystem occurs and at what temperature there is a complete loss of photosythetic function. This will be conducted on both reproductive phases of C. bullosa.

\subsubsection{Pulsed Amplitude Modulated Fluorometry and Pho- tosystems}

When light energy (in the form of photons) enters the photosystem it can be sent down one of three pathways. In the first instance, the photons strike a reaction centre and promote an electron to a higher energy level. This excited electron is then passed along the electron transport chain and used in photochemistry. Energy gained via this pathway is known as the 
Photochemical Quantum Yield and can be used as a measure of efficiency for the photosystem. However as there are a maximum number of electrons that can move through the photosystem at any one time, and excess electrons can damage the photosystem, there are two alternative pathways that protect the photosystem. These are known as the de-excitation pathways and are used to dissipate excess electrons.

The first of these protective de-excitation pathways operates via the emission of chlorophyll $a$ fluorescence. If the excited electron is not passed along the electron transport chain, it will fall back to its original state and the energy will be released as fluorescence. This pathway is used to prevent the build up of excited electrons within the photosystem. The second protective pathway dissipates the excess light energy as heat. This second pathway acts in the medium- to long-term compared to the fluorescence pathway as it requires heat energy to be given off to the surrounding environment. These three pathways (one excitation and two de-excitation) are linked so that changes in one will be reflected in the other two. In general terms, fluorescence is highest when photochemical quantum yield and heat dissipation are lowest. A change in fluorescence will also reflect a change in photochemical quantum yield or the efficiency of the photosystem.

These pathways can be examined using Pulsed Amplitude Modulation (PAM) fluorometry. PAM fluorometry uses pulses of light with a known amount of light energy and measures fluorescence levels to assess photosystem health. Upon commencing PAM measurements, the initial fluorescence yield ( $\mathrm{Fo}$ ) of the sample is established and used as the baseline for fluorescence measurements. Then a saturating pulse of light is applied to a sample for 1 second. As the reaction centers become light saturated, the excess light energy is passed to the de-excitation pathways to protect the photosystem. Because the saturating pulse is only for 1 second, it is assumed that the heat dissipation pathway will not be activated and the excess energy will be given off as fluorescence. A PAM fluorometer measures 
this maximal fluorescence (Fm) and calculates a ratio between the fluorescence and the captured light energy (Eq. 3.1 and 3.2) (Genty et al., 1989; Walz, 2003). This ratio is known as the Maximum Quantum Yield (Yield) and can be used as an indicator for the efficiency of the photosystem.

$$
\begin{gathered}
\text { Yield }=(F m-F o) / F m \\
\text { Yield }=\Delta F / F m
\end{gathered}
$$

As the Yield is a ratio between fluorescence and captured light energy, its value ranges between zero and one. A Yield measurement of one indicates $100 \%$ efficiency with no fluorescence while a Yield of zero indicates no photosystem function. Higher land plants usually provide Yield measurements around .600 to .800 (Genty et al., 1990; Genty et al., 1990; Hormann et al., 1994; Saroussi and Beer, 2007) while symbiotic coral zooxanthellae can be as low as 400 (Schreiber et al., 1997; Winters et al., 2003). Generally as the photosystem becomes less efficient, initial fluorescence increases, the amount of light energy captured reduces, and causes a reduction in the Yield. Any abiotic stress factor can influence the efficiency of the photosystem and will be reflected in the Yield measurement.

There are many other photosynthetic parameters that can be examined using PAM fluorometry but this study will focus mainly on the maximum quantum yield measurement and the rETRmax measurement (rETRmax = relative Electron Transport Rate maximum). This defines the maximum number of electrons moving through the photosystem.

\subsection{Methods}

\subsubsection{Initial investigations}

Samples of established crustose Colpomenia bullosa were collected from a site labelled 'The Drain Pipe', Island Bay, Wellington (S40²0.992 E17447.001). 
All samples were collected from within the same area but different pools to reduce any influence that environmental conditions may have on the photosynthetic response of the samples. All were positively identified as C. bullosa before the experiment. Each sample was removed from the substrate using a plastic spatula and stored out of direct sunlight in seawater from the same pool. The samples were transported to the lab as soon as possible following removal.

Data loggers were also deployed at this site to record the daily temperature variation. Twelve data loggers were deployed in total. Six were placed into the high tidal pools around where the samples of crustose C. bullosa were collected and six placed on emergent rock adjacent to the pools. The data loggers were iButton DS-1912G temperature loggers that were set to record the temperature every $10 \mathrm{mins}$. The loggers were placed into thermally inert epoxy resin to allow for attachment to the substrate and were left in place for several months.

Once at the lab, the C. bullosa samples were placed into $18^{\circ} \mathrm{C} 1 \mu \mathrm{M}$ filtered seawater under $50 \mu \mathrm{mol} \mathrm{m}^{-1} \mathrm{~s}^{-1}(\mu \mathrm{E})$ white fluorescent light before being prepared for the experiment. The samples were in these conditions for less than one hour. The samples were cut into approximately $10 \mathrm{~mm}$ $\mathrm{X} 10 \mathrm{~mm}$ pieces and placed into $58 \mathrm{~mm}$ diameter plastic petri dishes with $30 \mathrm{mls}$ of $18^{\circ} \mathrm{C} 1 \mu \mathrm{M}$ filtered seawater. PAM measurements were taken of samples at this time to check photosystem functioning. The samples were then placed into the $18^{\circ} \mathrm{C}$ chamber under $50 \mu \mathrm{E}$ light for $24 \mathrm{hrs}$ with a $12: 12$ day/night cycle. This was to acclimate the samples and reduce any possible handling effects.

There were three light and four temperature treatments for the initial experiment. The light treatments were $50,100,150 \mu \mathrm{E}$ and the temperature treatments were $7,12,20,30^{\circ} \mathrm{C}$. Temperatures were achieved by continuously pumping liquid through closed coils embedded at each end of a thermally conducting slab. Warm liquid is pumped through one end of the slab and cold liquid is pumped through the other. A temperature gra- 
dient then develops between the different temperatures at the ends of the slab. For this experiment, the warm end of table was at $35^{\circ} \mathrm{C}$ and cold end was at $4^{\circ} \mathrm{C}$. The table was located in a controlled temperature room with ambient temperature of $4^{\circ} \mathrm{C} \pm 1^{\circ}$.

The three light levels used in the experiment were achieved using twin 58 watt fluorescent lights that were raised or lowered to either increase or decrease intensity to the required levels. The lights were switched on a 12:12 day / night cycle and were suspended directly above the samples. The controlled temperature room had no windows or light source other than the lights used in the experiment.

The samples were kept in complete darkness for 6 mins prior to PAM measurements being taken to allow the samples to dark adapt. PAM measurements were taken at the same time every $24 \mathrm{hrs}$ for 7 days after the samples were placed into the experimental treatments. The parameters recorded during the PAM measurements were rETRm (the maximum number of electrons moving through the photosystem) and Maximum Quantum Yield (an indicator of photosystem efficiency). New filtered seawater was added to the petri dishes after the PAM measurements had been taken and was at the same temperature as the respective treatments. Salinity was also monitored within each petri dish to prevent any osmotic stress. Any samples that died during the experiment were not replaced.

All PAM measurements in this chapter were taken with a Walz Mseries Imaging-PAM fluorometer (I-PAM) unit.

The results were analyzed using a repeated measures ANOVA with Time as the repeated measure, Temperature and Light as additional fixed factors, and Yield and rETRmax as the response variables. All statistical analysis for this chapter were performed using $\mathrm{R}$ (version 2.3.0 for Mac OXS) statistical package. 


\subsubsection{Follow-up experiment}

This experiment was an extension of the one described above, using the same protocols and PAM measurements, but temperature treatments were $21,24,27$, and $30^{\circ} \mathrm{C}$. The three light levels remained the same $(50,100$, $150 \mu \mathrm{E}$ ) and the samples of crustose C. bullosa were also collected from 'The Drain Pipe', Island Bay, Wellington.

These results were also tested using a repeated measures ANOVA with Time as the repeated measure, Temperature and Light as additional fixed factors, and Yield and rETRmax as the response variables.

\subsubsection{Response to salinity variation}

This experiment was designed to test the response of crustose Colpomenia bullosa to different salinities. Established crustose thallus was collected from 'The Drain Pipe', Island Bay, Wellington, using a plastic spatula and placed into a clear zip lock bag with water collected from the same pool. The bag was then stored out of direct sunlight and transported immediately back to lab.

At the lab, the samples were cut into $10 \mathrm{~mm} \times 10 \mathrm{~mm}$ pieces and PAM measurements were taken. The samples were then cultured as previously described. After 24hrs PAM measurements were taken again and the samples were randomly assigned to one of four treatments. The treatments were 10,30, and 50 practical salinity units (psu) salinity and a control treatment of natural sea water at $35 p s u$ filtered to $1 \mu \mathrm{M}$. The salinities were achieved by mixing distilled water with Instant Ocean aquarium salt in the required concentrations to achieve the various salinities.

The samples were then placed into $58 \mathrm{~mm}$ plastic petri dishes with $30 \mathrm{ml}$ of the respective solutions and placed under $50 \mu \mathrm{E}$ light on a 12:12 day / night cycle at $18^{\circ} \mathrm{C}$. PAM measurements were taken every $24 \mathrm{hrs}$ and the water was changed at this time also. New salt solution was made daily for all of the salinity treatments but although the natural seawater was 
changed daily, it came from the same batch of filtered water.

The experiment was left to run for seven days. All PAM measurements were taken using dark adapted samples. Any samples that died during the experiment period were not replaced. The results were analyzed using a repeated measures ANOVA with Time as the repeated measure, Salinity as an additional fixed factor, and Yield as the response.

\subsubsection{Recovery from desiccation exposure}

This experiment was designed to test the length of time crustose Colpomenia bullosa can tolerate desiccation before there is a permanent reduction in photosynthetic efficiency. Established crustose thallus was collected from Moa Point, Wellington ( $441^{\circ} 21.000 \mathrm{E} 174^{\circ} 48.620$ ). The thallus was removed from rocky substrate using a plastic spatula and placed into a clear plastic zip lock bag with water collected from the same pool. The bag was then stored out of direct sunlight and transported immediately back to lab.

In the lab, the samples were cut into $10 \mathrm{~mm} \times 10 \mathrm{~mm}$ pieces and had PAM measurements taken. The samples were then stored as described previously. After 24hrs PAM measurements were taken again and the samples were randomly assigned to one of five time treatments $(2,4,6,8$, and $10 \mathrm{hrs}$ ). The samples were then blotted dry and placed into dry $58 \mathrm{~mm}$ plastic petri dishes. The samples were then kept in the dry petri dish for the respective time treatments at $18^{\circ} \mathrm{C}$ under $150 \mu \mathrm{E}$ light. There were five replicates per time treatment.

At the end of the time treatment PAM measurements were taken and then the sample was placed back into $18^{\circ} \mathrm{C} 1 \mu \mathrm{m}$ filtered natural seawater under the same $150 \mu \mathrm{E}$ light. Subsequent PAM measurements were taken every 60mins until the PAM parameters returned to pre-emersion levels or remained unchanged for three consecutive measurement periods. All PAM measurements were performed on dark adapted samples.

Each of the time treatments was treated as a separate experiment and 
analyzed independently using both a repeated measures ANOVA and a standard one-way ANOVA. Time was the only factor used in all tests and Yield was the response variable. Although standard ANOVA testing does not allow for the effect of repeated measures and is technically an incorrect test, it does allow for post hoc testing that cannot be performed under the repeated measures test. I believe the value of the post hoc tests out weights the disadvantages associated with the standard ANOVA and justifies its use.

\subsubsection{Thylakoid membrane integrity}

This experiment was designed to assess the maximum temperature $C$. bullosa could tolerate before permanent damage to the thylakoid membrane occurs. Samples of the sporophytic crustose thallus and the gametophytic upright were collected from several locations within Wahine Park, Wellington (S41²0.900 E174 49.560$)$. Samples of crustose thalli were removed from rocky substrate using a plastic spatula while the uprights were removed from the substrate by hand. The samples were then placed into clear plastic zip lock bags out of direct sunlight with unfiltered seawater. The samples were taken straight to the lab after collection.

At the lab, PAM measurements were taken within one hour of sample collection to determine cell health. If the maximum quantum yield was below .600 at this stage, the sample was discarded. The samples were then cleaned and stored as previously described for $24 \mathrm{hrs}$.

After $24 \mathrm{hrs}$ a $30 \mathrm{~mm} \times 30 \mathrm{~mm}$ piece was cut from each sample ( $\mathrm{n}=7$ total)and pinned onto expanded polyurethane foam inside a clear plastic container. Filtered natural seawater $(1 \mu \mathrm{m})$ was circulated into the container from a water bath via a 65 watt aquarium pump. At the start of the experiment the water temperature was $18^{\circ} \mathrm{C}$. The water was circulated through from the water bath to the plastic container and back at a rate of 1.2 litres per minute. This flow rate caused the water in the plastic con- 
tainer to be replaced 3.5 times every minute. The samples were $2 \mathrm{~mm}$ below the surface of the water in the plastic container.

The plastic container was then placed inside the I-PAM unit with circulating water temperature set at $18^{\circ} \mathrm{C}$. Samples were left until the initial fluorescence yield (Fo) was stable and then left for a further $5 \mathrm{mins}$. A saturating light pulse was then applied to samples. Samples were monitored until Fo stablised and reached the level measured before saturating pulse was applied. If this did not occur then sample was discarded, replaced with another, and process started again. This ensured that the sample was healthy and that the photosystem was fully functional.

Once the sample had stablised then the temperature of the water bath was raised. The Fo value was recorded for every $\frac{1}{2}$ degree temperature rise. Time was also recorded to ensure that the temperature rise was constant. The temperature was raised until the Fo measurement peaked and declined. At this point another saturating pulse was applied to the sample.

The Fo value was then plotted against temperature and fitted lines were added to the plot to establish the Critical Temperature (Tc) and Peak Fluorescence (Tp) values. The Tc value is the point at which permanent damage occurs to the thylakoid membrane and there is irreversible reduction in maximum quantum yield. The Tp temperature is the point at which there is a complete loss of photosynthesis and maximum quantum yield becomes zero. The Tc and Tp value were calculated for each sample individually using Sigma Plot 8.0.

The Tc and Tp values for the different reproductive phases (crustose and upright) were then analyzed and compared using small sample $t-$ testing. 


\subsection{Results}

\subsubsection{Field measurements of temperature}

During the entire period that the loggers were deployed (Aug-Dec) the maximum pool temperature was recorded on the 19th of December at 1420 and reached $25.7^{\circ} \mathrm{C}$. The minimum temperature recorded was on the $23 \mathrm{rd}$ of August at 0540 and was $9.3^{\circ} \mathrm{C}$. The daily mean maximum temperature was $16.3 \pm 4.6^{\circ} \mathrm{C}(95 \% \mathrm{CI})$ for the Aug-Dec period and the daily mean minimum was $11.3 \pm 1.8^{\circ} \mathrm{C}(95 \% \mathrm{CI})$.

The recorded temperatures for the 26th September 2006 are shown in Fig. 3.1 and show the typical daily temperature variation over 24 hrs. Over the $24 \mathrm{hrs}$ the minimum temperature of $\left(10^{\circ} \mathrm{C}\right)$ was slightly lower than the ambient sea temperature $\left(12^{\circ} \mathrm{C}\right)$ and the maximum temperature reached, $\left(20.5^{\circ} \mathrm{C}\right)$ was much higher than the ambient sea temperature. This temperature was reached just after midday. There was scattered cloud cover with no significant wind but it was generally fine and sunny on the day these measurements were recorded.

\subsubsection{Initial investigations}

During the first five days of the experiment, the three light levels and the temperature treatments 7-, 12-, and $20^{\circ} \mathrm{C}$ had no significant effect on the yield measurement (3.2). By day five the low light treatment $(50 \mu \mathrm{E})$ provided the highest Yield measurements and remained this way until the conclusion of the experiment. All of the light and temperature treatments showed a significant reduction in Yield over the seven days of the experiment but the $30^{\circ} \mathrm{C}$ treatment had the greatest effect.

A repeated measures ANOVA found no significant interaction between Light, Temperature, and Date $(p=0.335)$ for the Yield measurement, however there were some significant 2-way interactions between Temperature and Light $(\mathrm{p}<0.001)$ and Temperature and Date $(\mathrm{p}<0.001)$ (Table 3.1). The 


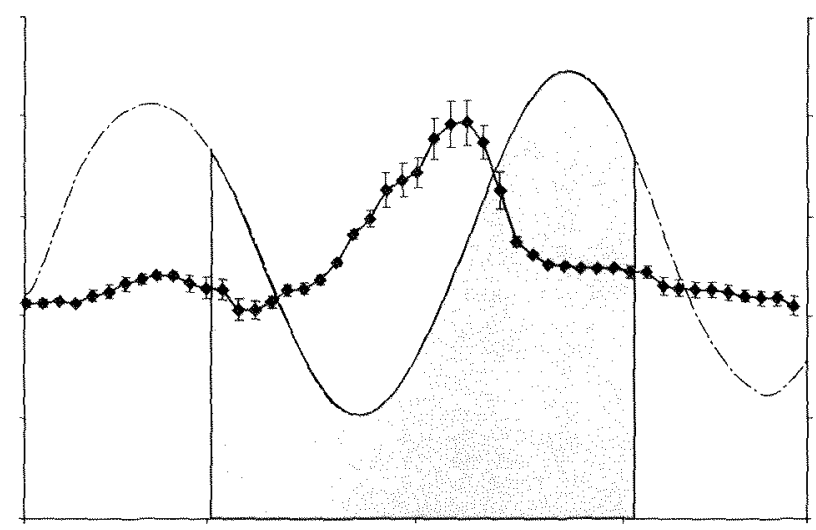

Figure 3.1: Intertidal pool temperature $( \pm 1 S E)$ during a 24 h period. The solid line signifies the temperature and the dashed line signifies the tidal variation. The shaded area indicates daylight hours with sunrise occurring at 0608 and sunset occurring at 1823 on the 26th September 2006. The influence of solar heating on the pool temperature can be seen by the constant temperature rise during the tidal cycle until the tidal flush lowers the pool temperature. The pool was situated in the high littoral zone with fine and sunny weather during the $24 \mathrm{~h}$ measurement period. 
Yield measurement showed a significant decline after $24 \mathrm{hrs}$ at $30^{\circ} \mathrm{C}$ across all three light treatments and by day seven the samples at this temperature had very little photosynthetic activity (Fig. 3.2).

The rETRmax measurements displayed greater variation compared to the Yield measurements but there was a significant three-way interaction between Light, Temperature, and Date $(p<0.001)$ (Table 3.2). The overall trend for $\mathrm{rETRmax}$ was similar to the Yield with the $30^{\circ} \mathrm{C}$ treatment having the greatest effect by reducing rETRmax to 0 by the end of the experiment period (Fig. 3.2). The low light treatment caused a significant increase in rETRmax for the 7,12 , and $20^{\circ} \mathrm{C}$ treatments midway through the experiment but this rise was not sustained and had reduced by the end of the experiment.

Table 3.1: Repeated Measures ANOVA table for Yield measurements taken during initial investigations.

\begin{tabular}{|l|c|c|c|}
\hline Variation & Df & F-value & P-value \\
\hline Light & 2 & 2.935 & 0.055 \\
Temperature & 3 & 141.5 & $<0.001$ \\
Date & 5 & 64.23 & $<0.001$ \\
Light*Temperature & 6 & 6.238 & $<0.001$ \\
Light*Date & 10 & 1.943 & 0.055 \\
Temperature*Date & 15 & 12.607 & $<0.001$ \\
Light*Temperature*Date & 30 & 1.108 & 0.335 \\
\hline
\end{tabular}

\subsubsection{Follow-up experiment}

In the second tolerance experiment, a repeated measures ANOVA found a significant 3-way interaction between Light, Temperature, and Date $(p<0.001)$ for the Yield measurements (Table 3.3). The temperature treatment of $30^{\circ} \mathrm{C}$ had the same effect as in the previous experiment with Yield reducing sharply after only $24 \mathrm{hrs}$ in all three light treatments. A similar reduction 

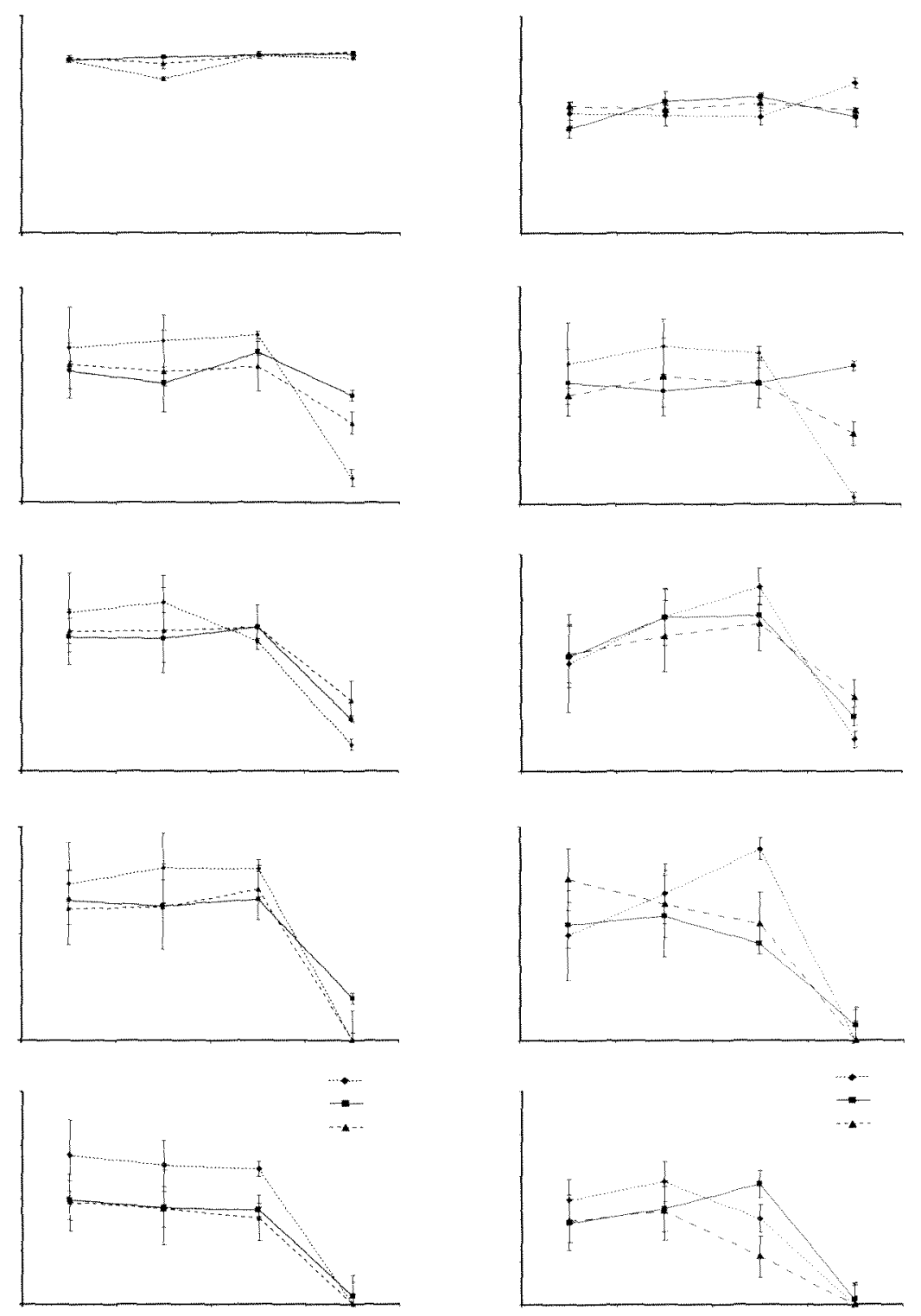

Figure 3.2: Yield and rETRmax measurements for seven days at 7-, 12-, 20-, and $30^{\circ} \mathbf{C} \pm \mathbf{1 S E}$. The 50, 100, and 150 refer to the light level and are measured in $\mu \mathrm{mol} \mathrm{m}^{-1} \mathrm{~s}^{-1}(\mu \mathrm{E})$. There is a significant decline in Yield after one day at $30^{\circ} \mathrm{C}$ and by the end of the seven day period, the samples at $30^{\circ} \mathrm{C}$ have very limited photosystem function. This trend is reflected in the rETRmax measurements. 
Table 3.2: Repeated Measures ANOVA table for rETRmax measurements taken during initial investigations.

\begin{tabular}{|l|c|c|c|}
\hline Variation & Df & F-value & P-value \\
\hline Light & 2 & 1.221 & 0.297 \\
Temperature & 3 & 91.565 & $<0.001$ \\
Date & 5 & 23.455 & $<0.001$ \\
Light*Temperature & 6 & 4.247 & 0.004 \\
Light*Date & 10 & 1.319 & 0.234 \\
Temperature*Date & 15 & 9.984 & $<0.001$ \\
Light*Temperature*Date & 30 & 3.086 & $<0.001$ \\
\hline
\end{tabular}

was also observed in the $27^{\circ} \mathrm{C} / 100 \mu \mathrm{E}$ treatment but the decline did not continue and the stablised for the rest of the experiment period. By the end of the experimental period there was a significant reduction in Yield for the 27 and $30^{\circ} \mathrm{C}$ treatments in all three light treatments with the $30^{\circ} \mathrm{C}$ treatment having the greatest effect (Fig. 3.3). The 21 - and $24^{\circ} \mathrm{C}$ treatments showed no significant decline in Yield over the experiment period.

As with the initial experiment, there was a significant three-way interaction between Light, Temperature, and Time $(p<0.001)$ (Table 3.4) for the rETRmax measurements (Fig. 3.3). The $30^{\circ} \mathrm{C}$ treatment had the greatest effect causing a reduction in rETRmax across all three light treatments and by the end of the seven day experiment period, the samples were photosynthetically inactive. The $27^{\circ} \mathrm{C}$ treatment also caused a significant reduction in $\mathrm{rETR}$ max by day five and this affected the mid $(100 \mu \mathrm{E})$ light treatment first. The 21 - and $24^{\circ} \mathrm{C}$ treatments showed no significant decline in rETRmax over the experiment period.

\subsubsection{Response to salinity variation}

The response of crustose $C$. bullosa to the different salinities is shown in Fig. 3.4. The repeated measures ANOVA indicated no significant inter- 

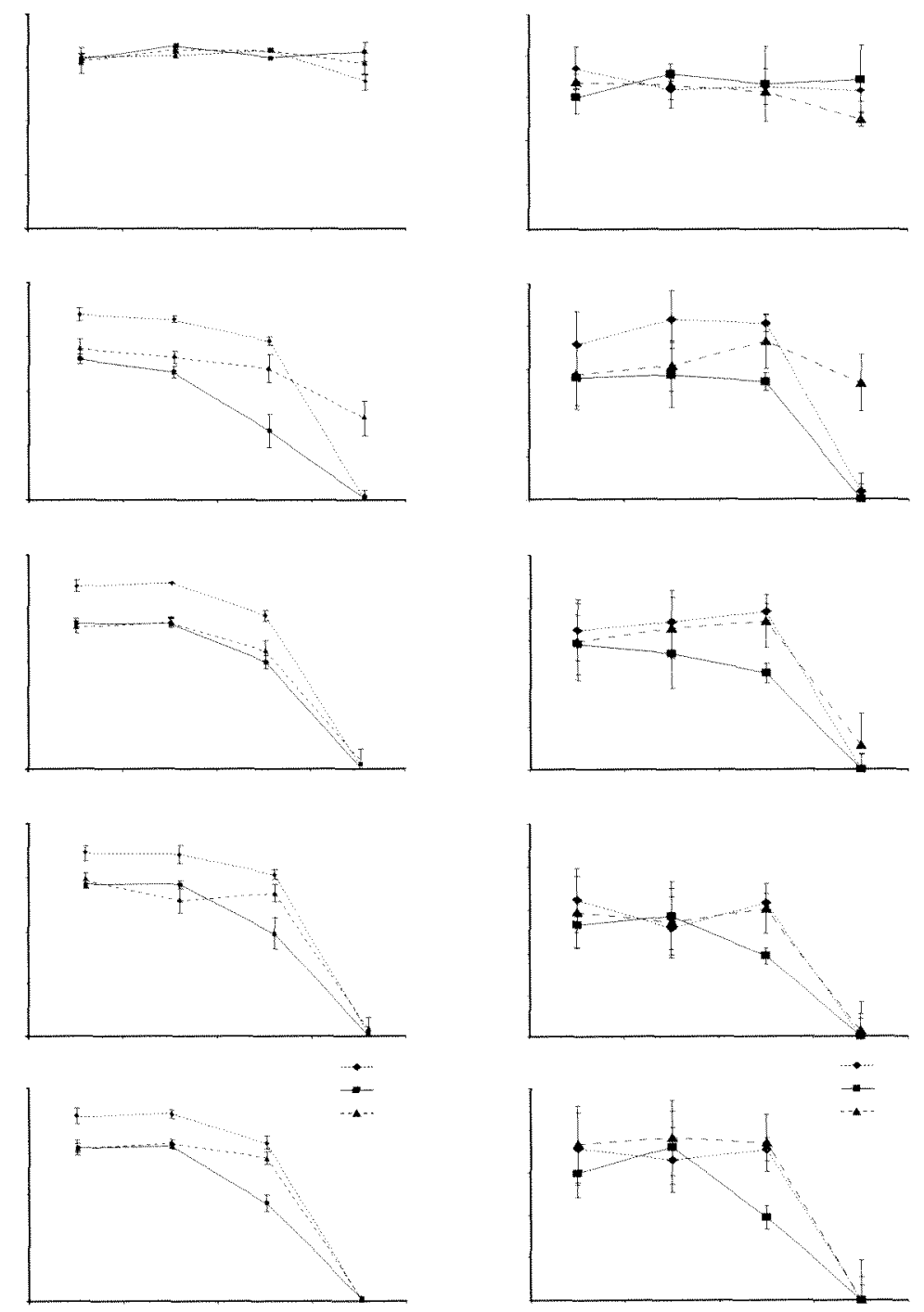

Figure 3.3: Yield and rETRmax measurements for seven days at 20-, 24,27-, and $30^{\circ} \mathrm{C} \pm \mathbf{1 S E}$. The 50,100, and 150 refer to the light level and are measured in $\mu \mathrm{mol} \mathrm{m}^{-1} \mathrm{~s}^{-1}(\mu \mathrm{E})$. There was a significant decline in Yield and rETRmax for the $27-$ and $30^{\circ} \mathrm{C}$ treatments after one day but only the $30^{\circ} \mathrm{C}$ treatment continued to complete photosystem shutdown. 
Table 3.3: Repeated Measures ANOVA table for Yield measures in second tolerance experiment.

\begin{tabular}{|l|c|c|c|}
\hline Variation & Df & F-value & P-value \\
\hline Light & 2 & 112.299 & $<0.001$ \\
Temperature & 3 & 1040.376 & $<0.001$ \\
Date & 5 & 64.853 & $<0.001$ \\
Light ${ }^{*}$ Temperature & 6 & 61.849 & $<0.001$ \\
Light*Date & 10 & 25.747 & $<0.001$ \\
Temperature*Date & 15 & 13.078 & $<0.001$ \\
Light*Temperature*Date & 30 & 5.736 & $<0.001$ \\
\hline
\end{tabular}

Table 3.4: Repeated Measures ANOVA table for rETRmax measurements in second tolerance experiment.

\begin{tabular}{|l|c|c|c|}
\hline Variation & Df & F-value & P-value \\
\hline Light & 2 & 11.548 & $<0.001$ \\
Temperature & 3 & 289.395 & $<0.001$ \\
Date & 5 & 38.178 & $<0.001$ \\
Light*Temperature & 6 & 9.223 & $<0.001$ \\
Light*Date & 10 & 8.607 & $<0.001$ \\
Temperature*Date & 15 & 16.351 & $<0.001$ \\
Light*Temperature*Date & 30 & 3.966 & $<0.001$ \\
\hline
\end{tabular}


action between salinity and time $\left(\mathrm{F}_{(12,99)}=1.590, \mathrm{p}=0.107\right)$ but the effects of salinity $\left(\mathrm{F}_{(3,99)}=20.213, \mathrm{p}<0.001\right)$ and time $\left(\mathrm{F}_{(4,99)}=10.109, \mathrm{p}<0.001\right)$ were both highly significant. The Yield dropped during the first $24 \mathrm{hrs}$ in all of the salinity manipulations after which it stablised and remained constant for the rest of the experiment period. This trend was not observed in the natural seawater control treatment (35psu) which showed no significant change in Yield over the experiment period.

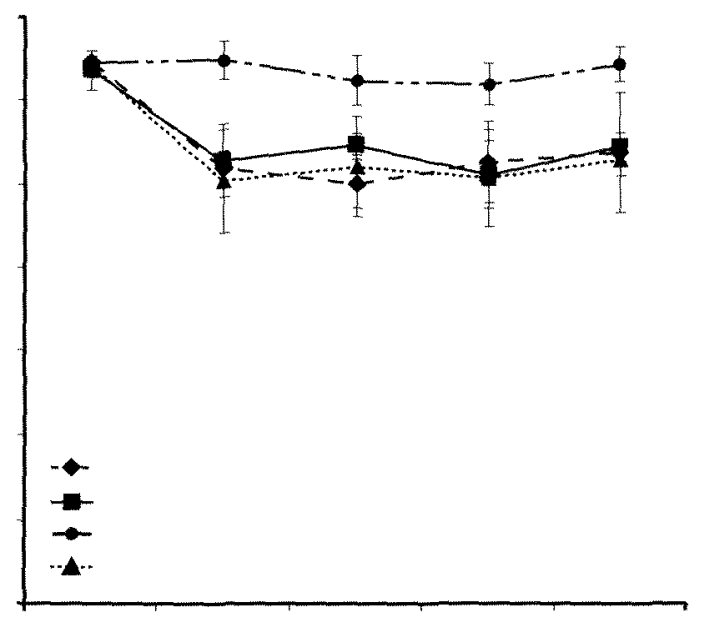

Figure 3.4: Yield measurements for seven days at 10-, 30-, 35-, and 50psu \pm 1 SE. After the initial reduction in the 10-, 30-, and 50 psu treatments, the Yield stablished and did not show any further significant variation. The natural seawater treatment of 35 psu did not show any significant variation during the experiment period.

\subsubsection{Recovery from desiccation exposure}

The repeated measures ANOVA testing showed a significant decline in Yield for all of the desiccation treatments (Table 3.5). A similar trend was observed in the standard ANOVA testing results except in the 10hr desiccation treatment which indicated no statistical difference between the 
Yield measurements $(p=0.051)$ at the $5 \%$ level.

Table 3.5: ANOVA results for recovery experiments. The results of the repeated measures and standard ANOVA tests are listed with df and Fvalues.

\begin{tabular}{|l|c|c|c|c|c|c|}
\hline & & & \multicolumn{4}{|c|}{ ANOVA Test } \\
\cline { 4 - 8 } & & & Repeated Measures & \multicolumn{2}{c|}{ Standard } \\
\cline { 4 - 8 } Treatment & Variation & Df & F-value & P-value & F-value & P-value \\
\hline 2 Hours & Time & $(5,24)$ & 7.00 & $<0.001$ & 3.179 & 0.024 \\
4 Hours & Time & $(5,24)$ & 24.03 & $<0.001$ & 5.491 & 0.001 \\
6 Hours & Time & $(5,24)$ & 62.66 & $<0.001$ & 56.882 & $<0.001$ \\
8 Hours & Time & $(5,24)$ & 25.033 & $<0.001$ & 15.897 & $<0.001$ \\
10 Hours & Time & $(5,24)$ & 6.005 & 0.004 & 2.611 & 0.051 \\
\hline
\end{tabular}

The use of standard ANOVA testing allowed for post hoc Tukey testing for each of the desiccation treatments. The Yield returned to pre-treatment levels within two hours of re-immersion for the two hour (Time 0 vs. $2 \mathrm{hrs}$ re-immersion, $\mathrm{p}=0.992$ ) and four hour (Time 0 vs. 2hrs re-immersion, $\mathrm{p}=0.991$ ) drying treatments. Measurements were ceased six hours after re-immersion as there had been no significant change in Yield.

In the six hour treatment the Yield measurement had not returned to pre-treatment levels four hours after re-immersion (Time 0 vs. 4 hrs reimmersion, $\mathrm{p}=0.043$ ) and required a further two hours of immersion before it reached pre-treatment conditions (Time 0 vs. 6hrs re-immersion, $\mathrm{p}=0.970$ ).

The Yield measurement never recovered to pre-treatment levels for the eight hour desiccation treatment (Time 0 vs. all immersion measurements, $\mathrm{p}<0.001$ in all cases). Although the graph (Fig. 3.5) indicates some level of recovery, this was not statistically significant and did not reach pretreatment levels.

The Yield measurements for the ten hour desiccation treatment were highly variable following re-immersion and had recovered statistically to 
pre-treatment levels within four hours of re-immersion (Time 0 vs. 4 hrs reimmersion, $p=0.101)$. There was no statistically significant variation after this time point (Time 0 vs. 6hrs re-immersion, $p=0.072$, Time 0 vs. 8 hrs re-immersion, $p=0.163$, and Time 0 vs. 10 hrs re-immersion, $p=0.181$ ) and measurements were suspended 10hrs after re-immersion (Fig. 3.5).

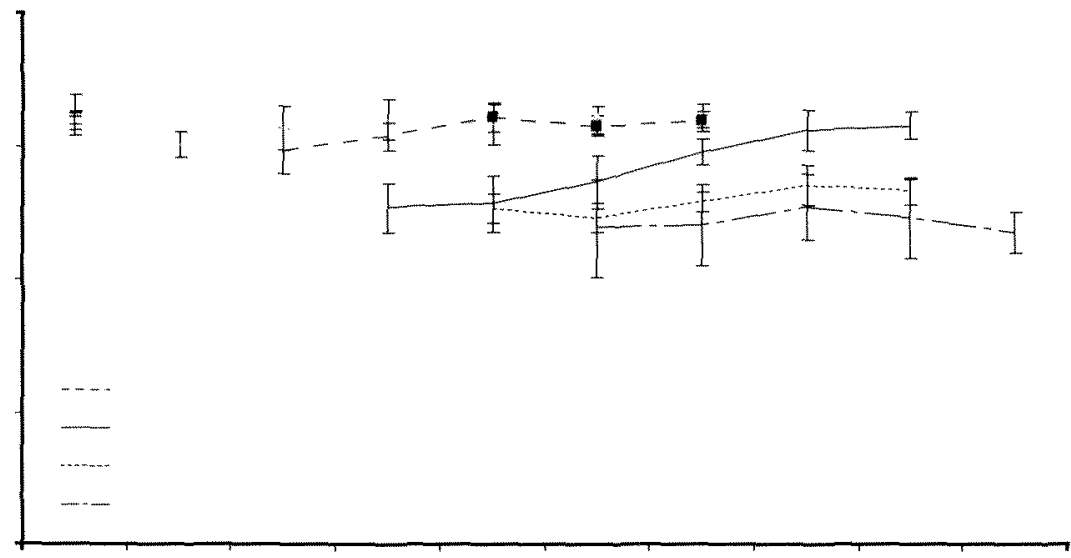

Figure 3.5: Yield measurements following desiccation \pm 1 SE. The different time treatments are shown in the lower left of the plot and number indicates the desiccation time in hours. The two and four hour emmersion yield values recovered to pre-treatment yield quickly and the six hour treatment recovered after eight hours. The eight and ten hour emmersion treatments did not recover to the pre-treatment values and displayed larger variation in the measured values compared to the shorter desiccation treatments.

\subsubsection{Thylakoid membrane integrity}

For crustose Colpomenia bullosa thalli the critical temperature (Tc) was $40.3^{\circ} \mathrm{C}$ and the temperature for peak fluorescence ( $\mathrm{Tp}$ ) was $46^{\circ} \mathrm{C}$. For the upright gametophytic thalli the Tc was $38.6^{\circ} \mathrm{C}$ and the Tp was $42.9^{\circ} \mathrm{C}$ (Fig. 3.6). A Students T-test revealed a significant difference between both the Tc and 
Tp values for the crustose and upright thalli $(p=0.017$ and $p=0.037$ respectively).

The range between $\mathrm{Tc}$ and $\mathrm{Tp}$ was also different for the two types of thalli. There was $5.7^{\circ} \mathrm{C}$ difference between $\mathrm{Tc}$ and $\mathrm{Tp}$ for the crustose thalli while it was only $3.4^{\circ} \mathrm{C}$ for the upright thalli.

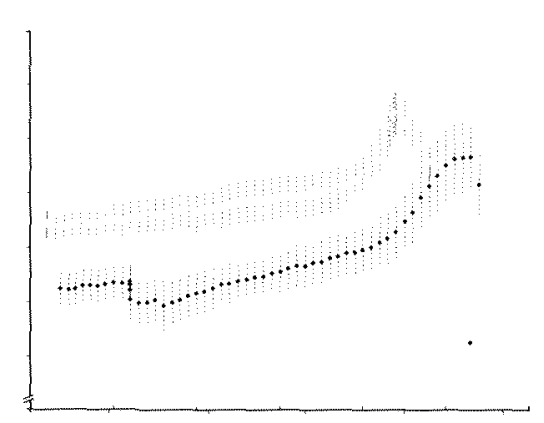

Figure 3.6: Determination of critical temperature levels for thylakoid membrane integrity. The plot on the left shows Fo measurements for the upright and crustose thalli ( $\pm 1 \mathrm{SE}$ ) with no fitting lines while the plot on the right shows the same data but has the fitting lines shown on the plot. The arrows indicate the Tc and Tp positions on the plot. Temperature in shown above the $\mathrm{x}$-axis and Time is shown below.

\subsection{Discussion}

Crustose C. bullosa has an upper thermal tolerance around $27^{\circ} \mathrm{C}$ and if the ambient temperature rises above this there is a reduction in photosynthetic performance. The lower thermal tolerance of crustose C. bullosa was not determined but there was no significant reduction in photosynthetic performance at $7^{\circ} \mathrm{C}$ and it is unlikely that intertidal pools would ever become colder than this. The membrane integrity experiment indicated permanent damage to the photosystem started occuring at $40.3^{\circ} \mathrm{C}$ and $38.6^{\circ} \mathrm{C}$ for the crustose and upright phases respectively. 
The temperature data from the high tidal pools where crustose C. bullosa is commonly found reveals that temperatures in the mid twenties are not uncommon, suggesting C. bullosa may be living at the edge of its thermal tolerance for some period of the year. The temperature data also highlights the effect of the tidal flush on the temperature of these high tidal pools. During the 24 hour measurement period, the pools required over six hours to reach the maximum recorded temperature but the tidal flush reduced the temperature back to the ambient sea temperature relatively quickly once the incoming tide reached the pool. Given the length of time required to heat the pools, it is unclear if the pools would ever reach the point at which permanent damage to the photosystem would occur.

Another factor that should also be considered is the effects of substrate amelioration on temperature. All of these experiments were conducted with established thalli that had been removed from the substrate but it is possible that the substrate may act as a buffer against the effects of temperature in the high tidal pools. Although the pool water will heat up faster than the substrate, the prostrate nature of the crustose thallus means that it will have significant contact with the substrate as well as the water. The thermal inertia of the substrate causes a less rapid temperature rise and may offer some protection to the crustose thallus. This should be considered in future temperature tolerance experiments.

All three of the salinity manipulation experiments initially showed a reduction in yield, however, this stablised after $24 \mathrm{hrs}$ and remained unchanged for the rest of the experiment. This was in contrast to the natural sea water treatment that showed no significant change in yield over the experiment period. Instant Ocean sea salt is widely used to create synthetic sea water and manipulate salinity (e.g.Murphy et al., 2003) so it is unclear if these results are due to an experimental artifact or are an actual response to changing salinity.

Osmotic acclimation is considered to be a relatively rapid process (Kirst, 1989) that can take minutes for micro-algae to several hours in macro-algal 
species (Hasegawa et al., 2000). The process of acclimation utilises a feedback loop involving turgor pressure and osmolyte concentration where the species must first respond to the rapid water loss / gain due to the osmotic gradient and then adjust the osmotic solute concentrations until the new equilibrium is reached (Kirst, 1989; Hasegawa et al., 2000; Murphy et al., 2003). Passive partial turgor pressure regulation combined with flexible cell walls are the most likely mechanisms for intertidal species to deal with salinity variation (Dickson and Kirst, 1987; Kirst, 1989; Bisson et al., 2006). While the osmotic acclimation range of marine algae is highly variable, some species are able to tolerate salinity up to six times that of natural seawater (Brand, 1984; Moberg et al., 1997; Allen et al., 2003).

From the results of the salinity experiment it is unclear if C. bullosa was fully osmo-acclimated. Once a species has fully osmo-acclimated then the photosynthetic yield should return to pre-stress levels (Kirst, 1989; Torquemada et al., 2005) but this was not observed in this experiment. These results (Fig. 3.4) suggest partial acclimation as the Yield measurement stabilises after the initial decline and remains unchanged for the rest of the experimental period. Kirst (1989) hypothesizes that when a species is at the limit of its salinity tolerance, growth and metabolic function can be sacrificed in order to maintain the osmotic balance. Such a response would be reflected in a reduced photosynthetic yield and is a way of ensuring survival during adverse conditions.

Although the partial osmo-acclimation response is plausible it requires further examination. Crustose species are hypothsised to be characteristic of the highly stressful and variable upper littoral zones where salinities can fluctuate up to 20psu (e.g.Goss-Custard et al., 1979; Kirst, 1989; Gordillo et al., 2002) yet C. bullosa showed reduced photosynthetic performance at 30psu, a fluctuation of approx. 7psu from natural seawater. As samples in all of the salinity treatments survived the entire experiment period, further work is needed to determine if the reduced pho- 
tosynthetic performance is the standard osmo-acclimation response of $C$. bullosa to changes in salinity. Alternatively the observed photosystem response could be due to the artifical seawater and salts used to manipulate the salinities.

The desiccation experiment demonstrates that crustose C. bullosa can only tolerate short term desiccation and has slow recovery. Previous studies have shown that most photosynthetic recovery occurs during the first two hours following re-immersion (Davison and Pearson, 1996) and there will be little subsequent recovery past 14hrs (Dring and Brown, 1982; Brown, 1997). The long recovery time shown by C. bullosa would mean that it would not recover from prolonged desiccation between tidal cycles and would suffer further damage upon subsequent emersion exposure.

As desiccation and water loss will increase the osmolyte concentration within cells (Wegmann, 1986; Hasegawa et al., 2000), potentially disrupting the flow of electrons along the electron transport chain (Hader et al., 2002), any further water loss will have compounding effects. When the osmotic stress is combined with other intertidal sublethal stresses (i.e. temperature or light) the risk of permanent damage to the photosystem or plant cells increases significantly. Should this occur, the competitive abilities of the plant may be compromised as more resources are committed to damage repair than growth, and could result in localised exclusion.

The constant temperature and light regime used in the tolerance experiments means the results are not particularly relevant from an ecological perspective but they do provide important information about the tolerance of the photosystem. The next set of experiments should focus on the higher temperature range but use cyclic high and low temperature exposure as this would better mimic natural conditions and test the cumulative effects of sub-lethal stress events. This would test the recovery ability of C. bullosa and help predict its potential range better.

The different light levels appeared to have no effect on crustose C. bullos $a$ in any of the tolerance experiments. The light levels used were chosen 
as they were comparable to the light conditions experienced by crustose $C$. bullosa under field conditions. Crustose species will experience light conditions far below ambient levels as they are usually covered by a layer of fine sediment and are often shaded by more upright neighboring species (Underwood, 2006). Light levels are further attenuated by water turbidity resulting in: (1) much reduced light reaching the photosystem and (2) species that are acclimated to operate under low light conditions (Davison and Pearson, 1996). These factors were taken into consideration and justify the selection of the levels used for the experiments.

A desiccation experiment and tolerance experiments could not be conducted for the upright phase due to logistical and experimental constraints. Other studies (e.g.Oates, 1985; Oates, 1986; Oates, 1988) have concluded that saccate species prevent desiccation via the fluid stored within the thallus. Therefore in order to conduct the desiccation experiment, whole intact plants were required and these proved difficult to obtain. The upright plants are difficult to remove from the substrate intact and maintaining the internal fluid level during transport was problematic. Further more, measuring this internal fluid level was not possible without destroying the plant. Compounding these problems, the uprights could not be kept alive under laboratory conditions for the length of time required to conduct the tolerance experiment.

These experiments also need to be carried out on juvenile or young plants to better understand the role of physiological tolerance in controlling the distribution of C. bullosa. This is required as several studies have found contrasting differences in tolerance between juvenile and adult plants. For example, a study by Davison et al. (1993) found that the zygotes of some brown algae have reduced germination sucess when exposed to high light and temperature. However, Rodrigo and Robaina (1997) showed that younger plants had better salinity and temperature tolerance. As all of the experiments conducted in this chapter were conducted only on established or adult samples it is difficult to predict the physiological tolerance 
of juvenile C. bullosa (crust or upright) and will require further examination.

In summary, this chapter set out to investigate the physiological tolerance of C. bullosa and how this correlates with the observed distribution. The initial experiments established that crustose C. bullosa can tolerance short term exposure up to $25^{\circ} \mathrm{C}$, above which there is a decline in photosynthetic efficiency. As the data loggers show high littoral pool temperatures around the mid twenties are not uncommon, crustose C. bullosa may be living at the edge of its thermal tolerance for some periods of the year. While the tolerance experiments show crustose C. bullosa is capable of surviving throughout the littoral zone, subsequent experiments found crustose C. bullosa has poor desiccation tolerance and does not fully recover from desiccation exposure $>6 \mathrm{hrs}$. This provides some explanation as to why crustose C. bullosa is not found on emergent rock but does not account for its absence in the lower littoral zones. As these zones have lower desiccation exposure, these results suggest that crustose C. bullosa should be able to survive. This will be experimentally examined in the next chapter.

The final experiments found crustose C. bullosa could tolerate large variations in salinity despite a reduction in photosynthetic efficiency accross all salinity treatments. The gametophytic upright and sporophytic crust were also found to have significantly different critical short term exposure temperatures with the photosystem of the crustose phase able to tolerate higher temperatures before permanent damage occurred. This shows some support for Dethier's (1994) hypothesis that the crustose phase is an adaptation for surviving stressful periods during the year. 


\section{Chapter 4}

\section{Habitat manipulations and the influence of molluscan herbivores on the abundance of crustose Colpomenia bullosa.}

\subsection{Introduction}

Some of the most fundamental questions in ecology involve understanding why species live where they do and what prevents them from living elsewhere. Individual organisms can be influenced by behaviour, dispersal, inter- and intra-specific interactions, temperature and physiological constraints (Connell, 1961; Dayton, 1975; Gaines and Roughgarden, 1985; Gaines and Bertness, 1992; Stillman and Somero, 1996; Gaylord and Gaines, 2000) while at the community level, the same individuals must also adapt to space and resource availability, community dynamics, and community change (Paine, 1974; Lubchenco, 1978; Paine, 1980; Belsky, 1992; Martins et al., 2007). These factors result in the ecological paradox that all species are so specialized that they are almost always ab- 
sent from almost everywhere (Townsend et al., 2002).

The work in the previous chapters has highlighted that the crustose phase of the introduced alga Colpomenia bullosa has a highly restricted distribution but can tolerate short term exposure to temperatures between $7-25^{\circ} \mathrm{C}$ under a wide range of light conditions. Although physiologically capable of living throughout the littoral zone, the observed distribution indicates there must be other factors involved in determining the distribution of this alga.

Disturbance is one factor (Levin and Paine, 1974; Farrell, 1989) that can structure the community in various ways depending on the severity and frequency of the disturbance events (Turner et al., 1998; Schiel and Lilley, 2007). Disturbance can range from high frequency-low severity to low frequency-high severity (Steneck et al., 1991) and will impact the community in different ways as species have adapted to exploit such events (Plante and Wilde, 2004). For introduced and invasive species, disturbance provides an oportunity to capture previously occupied space and become established in new communities. This can be seen in the introduced laminarian kelp Undaria pinnatifida, which requires physical disturbance to become established and has difficulty reaching significant abundance without these events (Valentine and Johnson, 2003).

Crustose C. bullosa is commonly found in high littoral pools (see 2.3.2) that are exposed to significant disturbance factors (e.g. thermal stress, light, sand scour, and wave action) but no studies have examined if it is able to benefit from such events. Crustose species are generally found in highly disturbed or stressful environments (Dethier, 1981; Steneck et al., 1991; Dethier and Steneck, 2001) but the surveys in Chapter 2 showed $C$. bullosa has a significantly greater abundance in these pools compared to other morphologically similar species, suggesting it may be adapted to, or at least tolerate, the environmental conditions in these pools better than the native crustose species.

Another possible factor influencing species distributions is competi- 
tion (Menge, 1976; Schoener, 1983; Paine and Trimble, 2004; Menge and Sutherland, 1987). Typical competition models propose three possible mechanisms a species can employ to capture space- (1) expansion into unoccupied space, (2) capturing previously occupied space that becomes vacant following mortality or disturbance, or (3) direct overgrowth of neighbouring species (Schoener, 1983). There are many examples of introduced species employing these strategies (e.g. Caulerpa taxifolia (Coquillard et al., 2000; Nyberg and Wallentinus, 2005; Thoms et al., 2006), Sargassum muticum (Britton-Simmons, 2004; Sánchez et al., 2005; Sánchez and Fernández, 2005), and the zebra mussel Dreissena polymorpha (MacIsaac, 1996; Gurevitch and Padilla, 2004; Strayer and Malcom, 2006)) and often a combination of these mechanisms are employed during the invasion process.

Enhanced competitive abilities will allow an introduced species to become established quicker. However, they can also be assisted through the establishment process via facilitation (Bertness and Shumway, 1993; Bertness and Ellison, 1987; Callaway and Walker, 1997; Bruno et al., 2003). Facilitation, direct or indirect, can provide enhanced resource capture and increase the probability of long-term persistence of the introduced species (Turner, 1983). The influence of grazers in the littoral community and their role as facilitators in trophic interactions is well known (Kim, 1997; Wootton, 1994) with the three way interaction between barnacles, limpets, and algae receiving lots of attention (e.g.Dungan, 1986; Wootton, 1992; Zabin and Altieri, 2007). Various studies have identified limpets as a habitat facilitators, capable of transforming habitat and making it suitable for colonization by other species (e.g.Arrontes et al., 2004). Dethier (1994) also hypothesised that crustose speces are often reliant on facilitators to prevent overgrowth from more upright species.

If the facilitator is removed from the system then this may influence the outcome of competitive interactions (Hacker et al., 1999) and could lead to competitive reversals. There is evidence of such reversals occurring in 
crustose coralline algae (Lubchenco, 1978; Steneck, 1986; Steneck et al., 1991) with one study (Steneck, 1986) attributing a reversal to a change in grazer composition at the different tidal height. A competitive reversal could account for the observed reduction in crustose C. bullosa at the lower tidal heights as grazing pressure from molluscan herbivores decreases.

This chapter will examine some of the mechanisms that determine the observed distribution of crustose C. bullosa. The findings of the first and second chapters suggest that $C$. bullosa is always found in high littoral zone pools (see 2.3.2), possibly due to its low desiccation tolerance (see 3.3.5) and inability to compete against the more upright macroalgal species present in the lower littoral zones. The initial experiments will test these findings in a natural setting addressing the questions 'can crustose C. bullosa survive in different littoral zones?' and 'can crustose C. bullosa survive on emergent rock in the littoral zone?'.

The second set of experiments will examine the influence of, and possible facilitation by, molluscan herbivores on C. bullosa. The main question addressed by these experiments is 'do molluscan herbivores facilitate the survival of crustose C. bullosa?'. This experiment will also evaluate whether molluscan herbivores influence the outcome of competitive interactions between crustose C. bullosa and morphologically similar species. Specifically 'does the outcome of competitive interactions between crustose C. bullosa and morphologically similar species change in the absence of molluscan herbivores?'.

\subsection{Methods}

\subsubsection{Habitat manipulation / Survival analysis}

Three sites were identified along the South Coast of Wellington for the transplant experiment (Fig.4.1): Site (9) between Gibraltar Rock and Palmer Head at the entrance of Wellington Harbor; Site (10) Waitaha Cove, Lyall 
Bay; and Site (11) inshore from The Sirens Rocks formation between Owhiro Bay and Island Bay. The GPS co-ordinates for each site are listed in the Appendix. The sites were topographically comparable and had similar substrate composition. At each site five transect lines were laid perpendicular to the water between the high and low littoral zones. The transect lines were a minimum of $20 \mathrm{~m}$ apart.

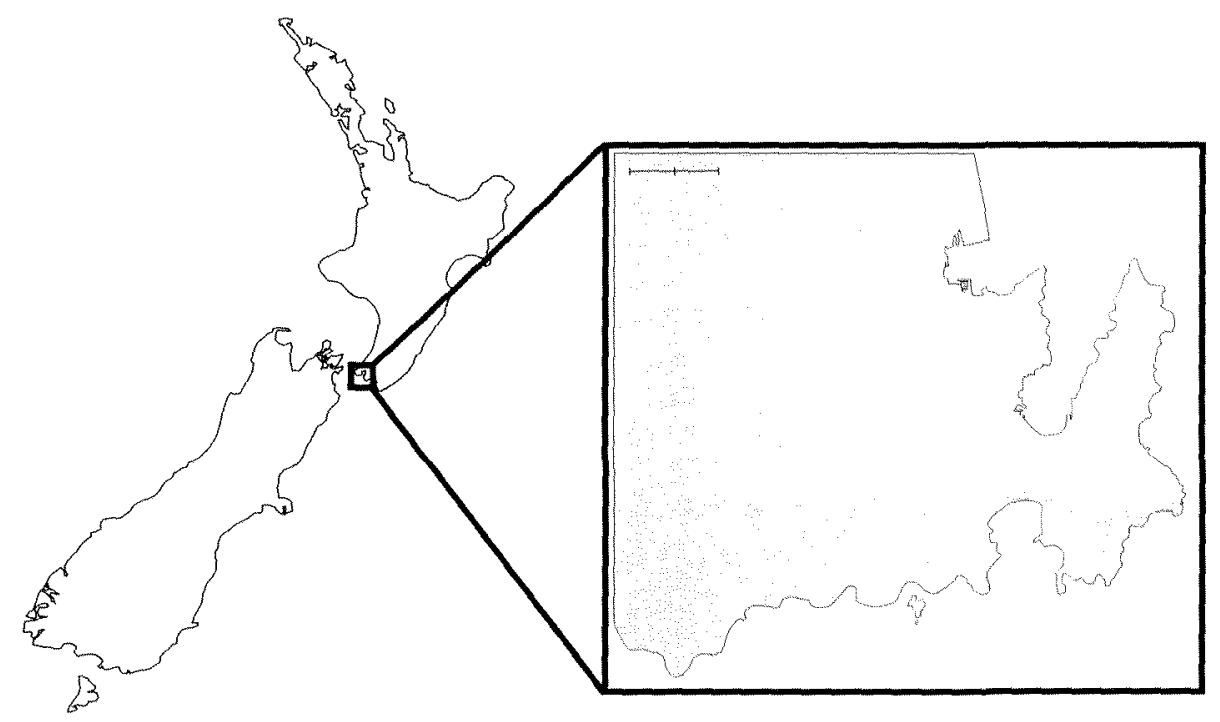

Figure 4.1: Location of transplant experiment sites on Wellington South Coast. The experiment sites are indicated by the bold numbers. Site (9) Gibraltar Rock at Palmer Head. Site (10) Waitaha Cove and Site (11) The Sirens Rocks formation. The shaded area of the map indicates land with Cook Strait at the bottom of the map.

Patches of existing and established crustose C.bullosa were identified within the area around the site. A large piece of substrate from within a patch was then broken away using a battery powered rotary hammer drill, concrete chisel, and a hammer. This piece of substrate was then broken into seven equally sized pieces approximately $30 \mathrm{~mm}$ in diameter that had similar crustose C. bullosa coverage. The large piece of substrate was separated so that each of the smaller pieces had at least one growing edge from the crustose thallus as pilot studies indicated this enhanced survival. 
The removal location was also marked and the remaining crustose $C$. bullosa was photographed. This area was used as a control treatment to examine any possible experimental or handling effects and was monitored throughout the experimental period. A control treatment was used whenever samples were collected from a new area. At Site (9), all of the transplanted samples came from one area therefore only one control treatment was monitored within this location. At Sites (10) and (11) there were two control treatment areas monitored for the three transect lines.

Six of the smaller pieces of substrate were then randomly assigned to one of three tidal level treatments (High, Mid, or Low) resulting in two samples per tidal level. The seventh piece of substrate was used as a further control treatment and this was re-attached in its original position. The samples were attached to the substrate using A-788 Splash Zone Compound (Z-Spar) marine epoxy compound. Care was taken to ensure that no Z-spar came into contact with the C. bullosa crust.

At each tidal level, one sample was placed into a pool and one was placed adjacent to the pool on emergent or exposed rock. The samples were approximately the same size and were positioned so they would receive similar light and wave exposure. This process was performed for each transect line resulting in seven manipulated samples per transect (six treatments and one control) with five transect lines for each site. The samples were transplanted during low water to ensure the emergent rock tramsplants would be exposed during the tidal cycle.

The samples were monitored and photographed monthly for five months. The images were then downloaded into Imagel picture analysis software where the health of the thalli was assessed. This was achieved by comparing the color and physical condition of the thalli against the original image and control treatments. The samples were classified as 'Alive' or 'Dead' and the results were fitted to Weibull survival curves (Pinder III et al., 1978). They were then analysed using a parametric survival analysis. 
All analyses were conducted using R (version 2.3.0 for MacOSX) statistical package.

\subsubsection{Grazer exclusion manipulation}

To test the influence of molluscan herbivores on C. bullosa, five sites were identified along the Wellington South Coast (Fig. 4.2) that had comparable levels of crustose C. bullosa \% cover and similar topography: Site (12), Palmer Head; Site (13), Moa Point; Site (14), The Drain Pipe, Island Bay; Site (15), The Sirens Rocks formation; Site (16), Red Rocks. The GPS coordinates for each site are listed in the Appendix. The sites were located approximately $2 \mathrm{~km}$ apart and the experiment was set up in September 2006 and was left running until February 2007.

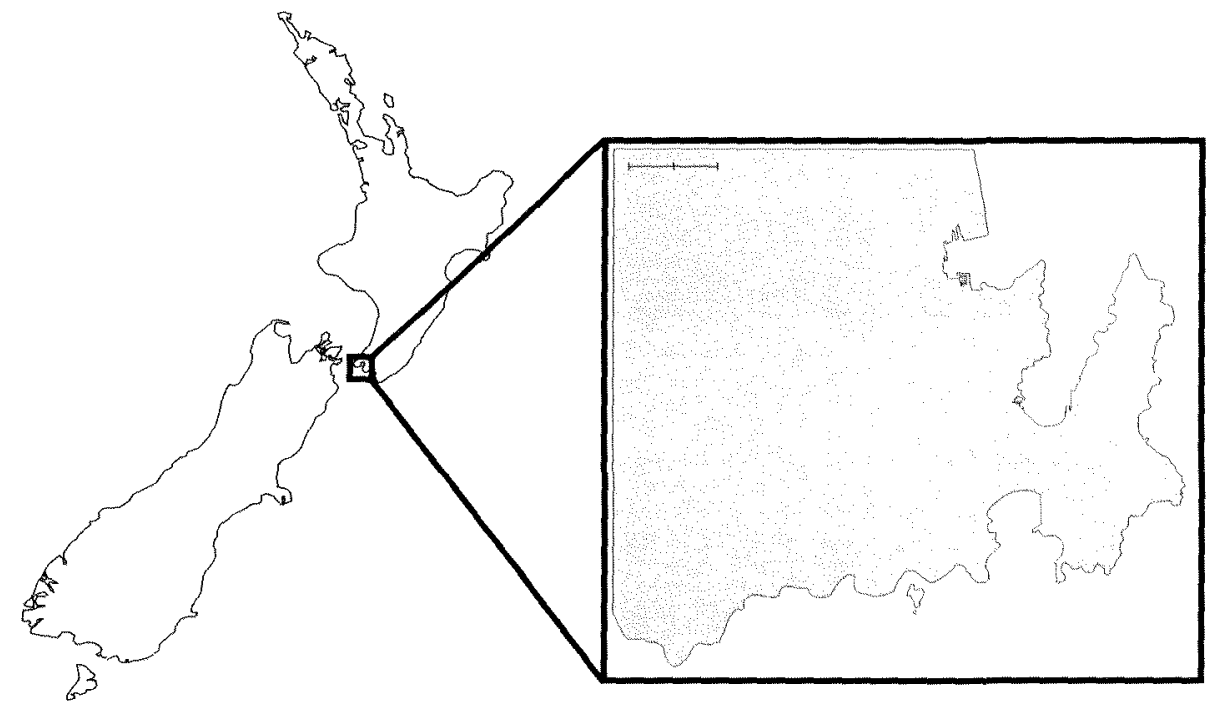

Figure 4.2: Location of herbivore manipulation experiment sites on the Wellington South Coast. Site (12) Palmer Head, Site (13) Moa Point, Site (14) The Drain Pipe, Site (15) The Sirens Rock formation, and Site (16) Red Rocks. The shaded area of the map indicates land with Wellington City located in the central part of the map.

The earlier survey work showed that the crustose phase of C. bullosa was restricted to high intertidal pools so this manipulation was performed 
in these pools. Due to the experimental difficulties in constructing exclusion plots under water, the exclusion plots were constructed beforehand and then secured into position underwater.

The exclusion plots were constructed using untreated pine timber strips $7 \mathrm{~mm}$ thick by $30 \mathrm{~mm}$ wide and $200 \mathrm{~mm}$ long. Four timber strips were joined to form a square frame using cut down galvanized nail plates. The nail plates were used on the underside of the frame and the timber strips were joined width-ways. The frames were then sanded and painted with copper anti-fouling paint. This was left to dry for $6 \mathrm{hrs}$ and then a second coat of paint was applied. This construction method provided an exclusion barrier $230 \mathrm{~mm}$ by $230 \mathrm{~mm}$ long and $30 \mathrm{~mm}$ wide. Twenty frames were constructed with ten left unpainted for use as grazer accessible treatments.

Within each site, two pools were chosen and the experimental plots were fixed into position. An area $250 \mathrm{~mm}$ by $250 \mathrm{~mm}$ was marked out and the perimeter of this area was scraped clean using a chisel and wire brush. Z-Spar was then applied to the undersurface of the frame to create a gapproof seal with the substrate and the frame was placed into position. ZSpar was then used to fill any remaining gaps and the area was flushed with fresh seawater to remove any debris and Z-spar residue. The frame was also secured onto the substrate with stainless steel bolts. This method allowed any damaged frames to be repaired or replaced during the experiment.

In addition to the exclusion plot, three other plots were created as control treatments. The first control treatment was exactly the same as the exclusion plot except the timber frame was not painted with copper exclusion paint. The second control treatment was a $250 \mathrm{~mm}$ by $250 \mathrm{~mm}$ area with a $30 \mathrm{~mm}$ wide band of Z-Spar around the perimeter. The third control was a $250 \mathrm{~mm}$ by $250 \mathrm{~mm}$ area that had the perimeter cleared and the corners marked with Z-Spar. All four treatments were in the same pool and were applied on the same day. Due to the tidal cycle limiting available work hours per day, it took one week to install the plots at all the 
experimental sites.

After $24 \mathrm{hrs}$ all the plots were checked for holes or damage and to ensure the frame was adequately attached to the substrate. At this point all of the molluscan grazers were removed and the plots were photographed. The \% cover of the species within the plots was also recorded. At each of the five experimental sites this protocol was repeated to give a total of ten exclusion plots. The plots were photographed monthly from September 2006 until February 2007.

The results were analyzed using a repeated measures ANOVA test with Month as the repeated measure, Site as a fixed factor, and \% cover as the response variable.

\subsubsection{Competition manipulation}

In an extension of the experiment outlined above, another experiment was conducted at the same sites (Fig. 4.2). Due to the slow growth rates of crustose species, competition between the various species had to be artifically manipulated. Morphologically similar species were moved into positions where they would directly compete with $C$. bullosa for resources and space. This was performed in the presence and absence of grazers and was conducted in high tidal pools.

Twenty timber frames were constructed using the same method outlined above and ten were painted with copper anti-fouling paint. At each of the five sites, two high tidal pools were selected and two $250 \mathrm{~mm}$ by $250 \mathrm{~mm}$ areas were completely cleared using a wire brush and plastic scraper within each pool. One cleared patch had an unpainted frame attached to it and the other had a painted frame attached. Both frames were attached using the same method outlined above.

The three crustose algal species that most commonly interacted with $C$. bullosa in high tidal pools were identified (Thin crustose coralline, Ralfsiasmooth, and Ralfsia-rough). Pieces of substrate with these species attached 
were collected in a similar fashion to the transplant experiment and then attached to the substrate within the timber frames. The pieces of substrate were attached using Z-Spar using the same precautions outlined above.

Beside each piece of substrate, a similar sized piece of substrate covered with C. bullosa was attached as close as possible. The margin between the two species was then scraped away so that there was a gap approximately $5 \mathrm{~mm}$ wide between the two species. This was performed for each pair of species (C. bullosa and one of the collected crustose species). The quadrat was then flushed with seawater, photographed, and no further manipulations were performed on the quadrat. The gap between the species was monitored and photographed every month from September 2006 to February 2007.

The results were analyzed using a standard $2 \times 4$ factorial ANOVA with Accessibility and Species as fixed factors and Growth as the response variable.

\subsection{Results}

\subsubsection{Habitat manipulation / Survival analysis}

Two of the emergent rock transplants were lost in one of the transect lines at Site two so this transect was removed from the analysis. This resulted in a total of fourteen replicates for each treatment.

The High littoral zone transplants had the highest survival rate for the pool transplants (Fig. 4.3) with 11 of the 14 samples surviving to the end of the experiment period. The high mortality occurred between the two and three month surveys and was similar to the mortality experienced in the control treatment. The Mid and Low pool transplants had a gradual decline over the experiment period with one or two transplants dying every month. By the end of the experiment period half of the original transplants survived in the Mid littoral pools and just under half survived in the Low 
littoral pools. The mortality rate for these two zones was above the control treatment mortality.

The emergent rock transplants had significantly higher mortality compared to the pool transplants in all three tidal levels with no transplants surviving to the end of the experiment period. The High littoral transplant had the most dramatic effect with total mortality within one month of the experiment starting. The Mid and Low littoral transplants survived the first month with relatively low mortality but then suffered much higher mortality after this time point. By the fourth month no transplants survived in the Mid littoral zone while two transplants survived past the four month mark in the Low littoral zone but did not survive to the end of the experiment at five months.

These results for the pool transplants are shown in Fig. 4.3 and Fig. 4.5 for the emergent rock transplants. Figures 4.4 and 4.6 show the data with Weibull survival curves fitted. There are four curves fitted on each plotthe three tidal heights and one overall.

The fitted curves in Fig. 4.6 are all of similar shape and fall into the type III survival curve category. The fitted curves in Fig. 4.4 are a mix of type I and II shaped curves.

\subsubsection{Grazer exclusion manipulation}

Initially the herbivore exclusion plots became covered in a layer of fine sediment that started to accumulate immediately after the exclusion barrier was put into place. This layer of sediment was absent from the grazer accessible plots and continued to build up over the experiment period. The exclusion plots were always covered with this layer of sediment despite several significant swell events, which instead appeared to increase the sediment loading of the plots. Figure 4.7 shows one of the exclusion plots after 24 hrs and already a fine layer of sediment can be seen covering the plot. 


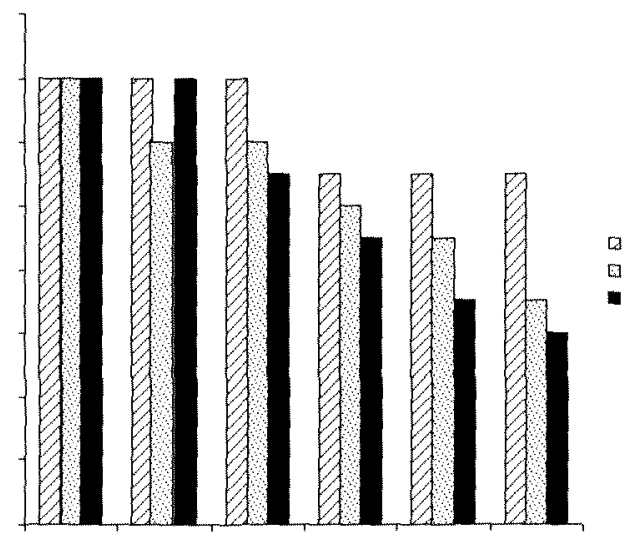

Figure 4.3: Survival of thalli transplanted into pools. Survival was greatest in the high zone with all of the mortality occurring between months two and three. The Mid and Low zones had relatively constant mortality after the second month with one or two plants dying each month.

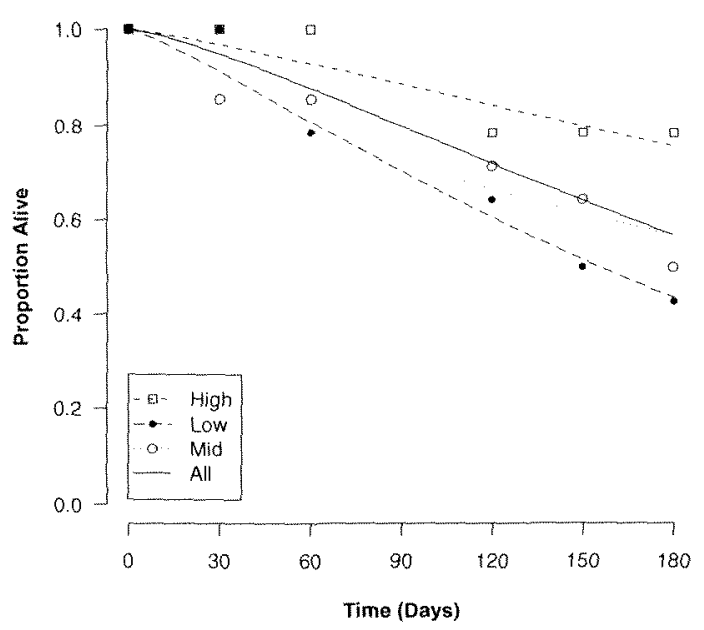

Figure 4.4: Weibull survival curves fitted onto the pool transplants. The curves from the three zones had a similar shape and are shown by the dashed lines. The curves are consistent with a type I and II survival response. 


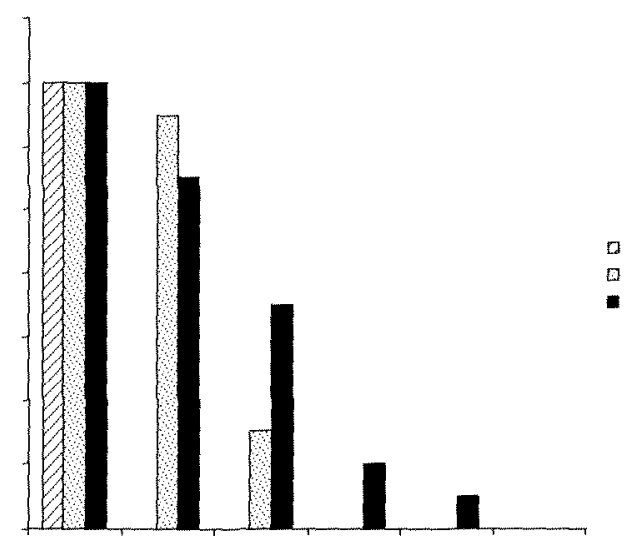

Figure 4.5: Survival of thallus transplanted onto emergent rock. The Low zone transplants had the greatest survival however no transplant from any of the zones survived longer than four months and none of the transplants from the high zone survived the first month.

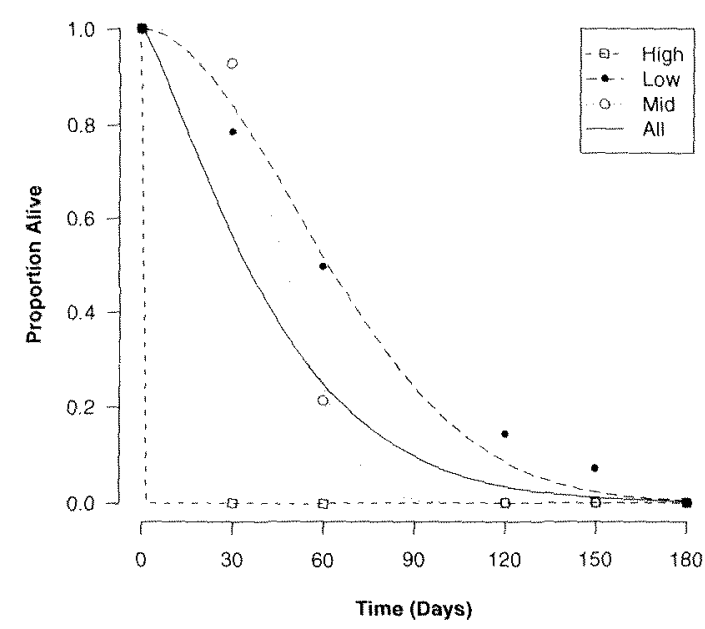

Figure 4.6: Weibull survival curves fitted to the emergent rock transplants. The shape of the combined curve is consistent with a type III survival response. The survival curves from the Mid and Low zones also follow this shape but the curve for the High zone is distorted poor survival rate. 
After three months the plots had significant filamentous algal cover (e.g. Enteromorha sp. and Chaetomorpha sp.) and some foliose algae (i.e. Ulva sp. and Colpomenia sp.) had started to develop. Some crustose C. bullosa was still visible but it was covered in a layer of fine sediment and the more upright algal species had started to over grow and smother it. The sediment build up was much thicker around the holdfast areas of algae and had become harder to remove. By this stage there was no exposed substrate in any of the plots. Figure 4.8 is the same plot as shown in Fig. 4.7 after three months and is representative of all the exclusion plots.

Although the crustose C. bullosa was smothered by the more upright species, it was still present in the plots. It was clearly visible if the sediment and upright species were cleared away however the health and functioning of the thallus was not checked as this would have required disturbing the plots. The thallus had become lighter in colour and appeared to have maintained its thickness.

After five months there was very little visible C. bullosa. The short filamentous algae had given way to larger filamentous and more foliose algal species (e.g. Enteromorpha intestinalis, Corallina officinalis, and Hormosira banksii) and these species had completely covered the C. bullosa. The sediment build up had continued and was now very thick (3-4mm) and established around the algal holdfasts. Any available substrate was also covered in sediment. Figure 4.9 is the same plot as Fig.'s 4.7 and 4.8 and is representative of all the exclusion plots.

As mentioned above, crustose $C$. bullosa was still present in the plots but it was now completely covered. The C. bullosa thallus had become overgrown by the holdfasts of the more upright species however it could still be observed if the sediment and upright algae was removed. Although the health of the thallus was not measured, it had become darker and lacked the definitive lobing pattern observed at the start of the experiment.

Statistical analysis of these results found no significant interaction be- 
tween Site and Month $(\mathrm{p}=0.6528)$ (Table 4.1). The main effect of Month was significant $(p<0.001)$ but Site was not $(p=0.097)$. Figure 4.10 shows how the dominant algal morphotype changed during the experiment period.

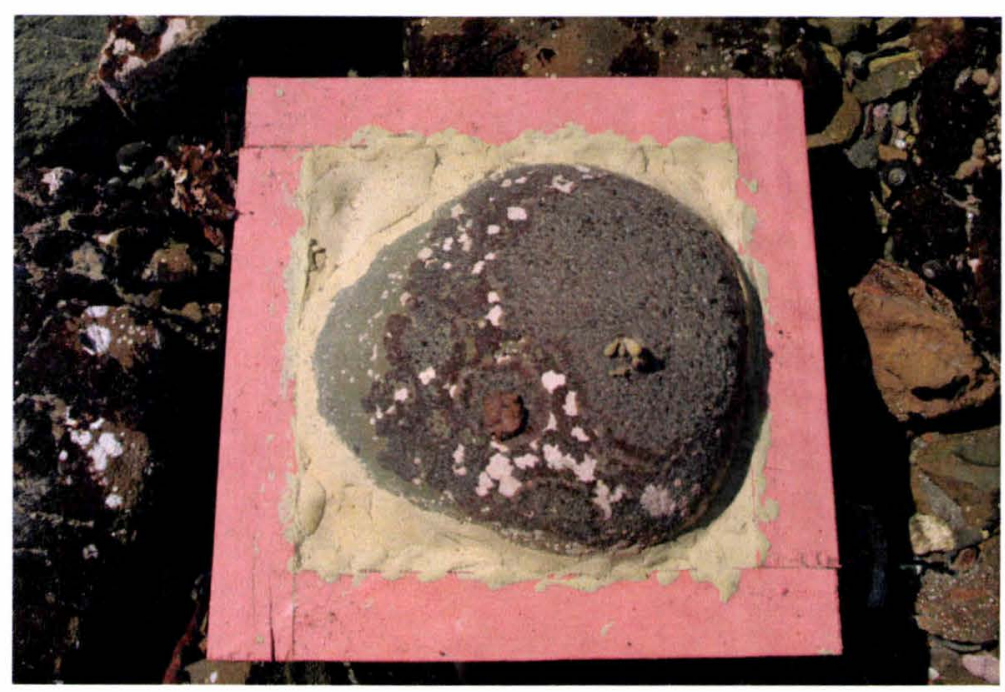

Figure 4.7: Exclusion plot after 24hrs. Most of the available substrate in the plot is covered by crustose C. bullosa with two small macroalgal species. Note that the exclusion plot has only been in place for $24 \mathrm{hrs}$ but there is already a fine layer of sediment covering the plot.

Table 4.1: Exclusion plot repeated measures ANOVA table.

\begin{tabular}{|l|c|c|c|}
\hline Variation & Df & F-value & P-value \\
\hline Site & 4 & 2.041 & 0.097 \\
Month & 4 & 18.952 & $<0.001$ \\
Site*Month & 16 & 0.826 & 0.6528 \\
\hline
\end{tabular}

\subsubsection{Competition manipulation}

The growth rate in the competition experiments was not influenced by the experimental factors. There was no significant interaction between 


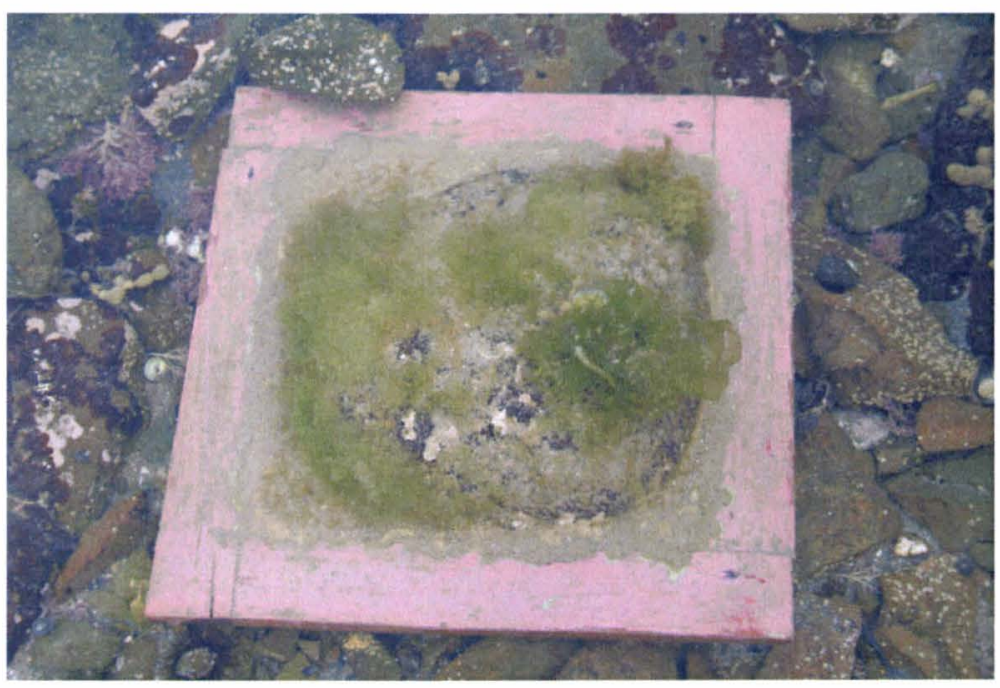

Figure 4.8: Exclusion plot after 3 months. The plot has very high sedimentation and there is significant filamentous algal growth throughout the plot. There is also a small amount of foliose algal growth with very little exposed C. bullosa.

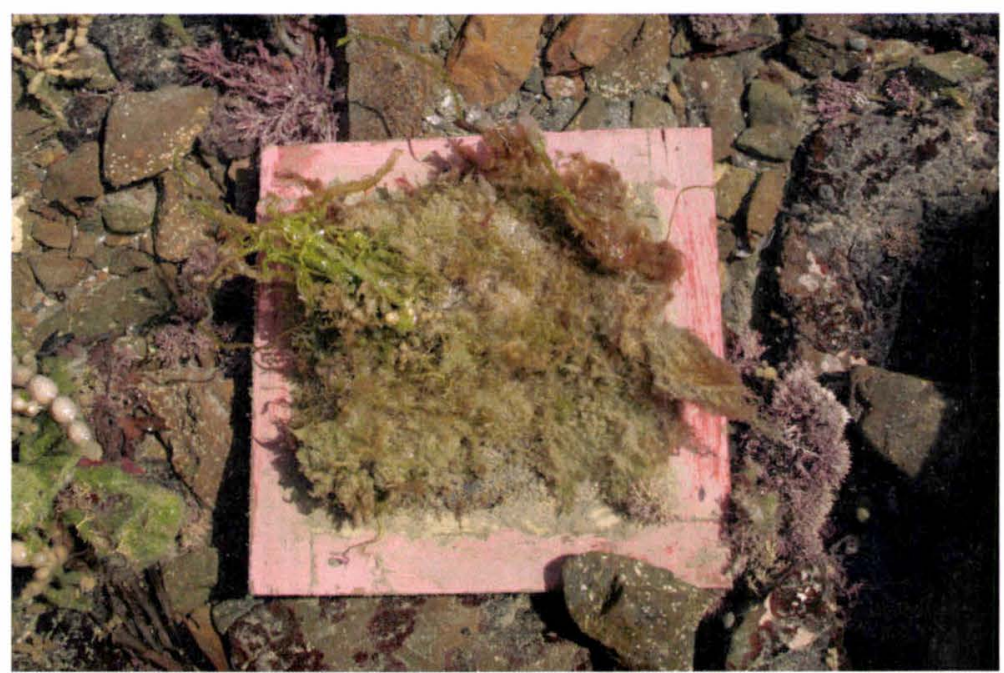

Figure 4.9: Exclusion plot after 5 months. All exposed substrate within the plot has been covered in filamentous or foliose algae. A thick layer of sediment can be observed close to the substrate and around the holdfasts of the algae. No crustose C. bullosa can be seen in the plot. 


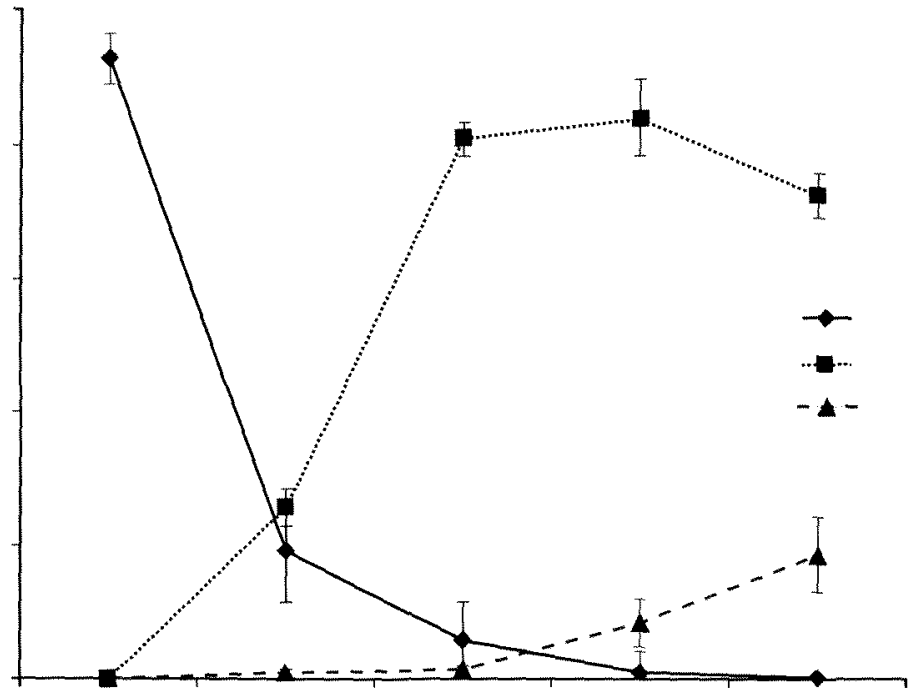

Figure 4.10: Species cover in herbivore exclusion plots ( \pm 1SE). The coverage of C. bullosa quickly declines and is almost completely absent by December. The coverage by the more foliose species starts to significantly increase around this time also. 
Accessibility and Species $\left(\mathrm{F}_{(3,72)} 0.842, \mathrm{p}=0.4754\right)$ or main effects of Access $\left(F_{(1,72)}=0.138, p=0.711\right)$ and Species $\left(F_{(3,72)}=1.137, p=0.475\right)$ on the growth rate. Neither grazer accessibility or the competing species had an effect on the growth rate of C. bullosa. Further examination of the accessibility treatment using paired t-testing confirmed that there was no significant difference in growth between the grazer accessible and grazer excluded plots $\left(\mathfrak{t}_{(39)}=-0.377, \mathrm{p}=0.7079\right)$ (Fig. 4.11).

The growth measurement in Fig. 4.11 is plotted in respect to C. bullosa. A positive value indicates that $C$. bullosa closed the gap by the observed amount while a negative value indicates that the other species closed the gap. Although not significant, $C$. bullosa showed higher average growth than the other crustose species in the majority of the treatments but no statistical trend was detected between the different accessibility treatments.

The influence of molluscan grazers on competition could not be tested due to insufficient data. In many cases the growing edge of the respective thalli did not touch so determining a competitive outcome was not possible.

\subsection{Discussion}

The transplant experiments suport the conclusions reached in Chapter three (see 3.3.5) that crustose C. bullosa has a poor desiccation tolerance. None of the high littoral zone emergent rock transplants survived the first month and even in the low littoral, where desiccation stress is much reduced, none of the transplants survived longer than four months. This is surprising as the desiccation exposure time is significantly reduced in these lower zones and it is expected that it would be within the tolerance indicated by the experiments in Chapter three (3.3.5 indicated crustose C. bullosa could recover from four to six hour desiccation exposure). As wave action can significantly reduce the duration of emersion time in the lower littoral zones (Harley and Helmuth, 2003) the C. bullosa transplants were 


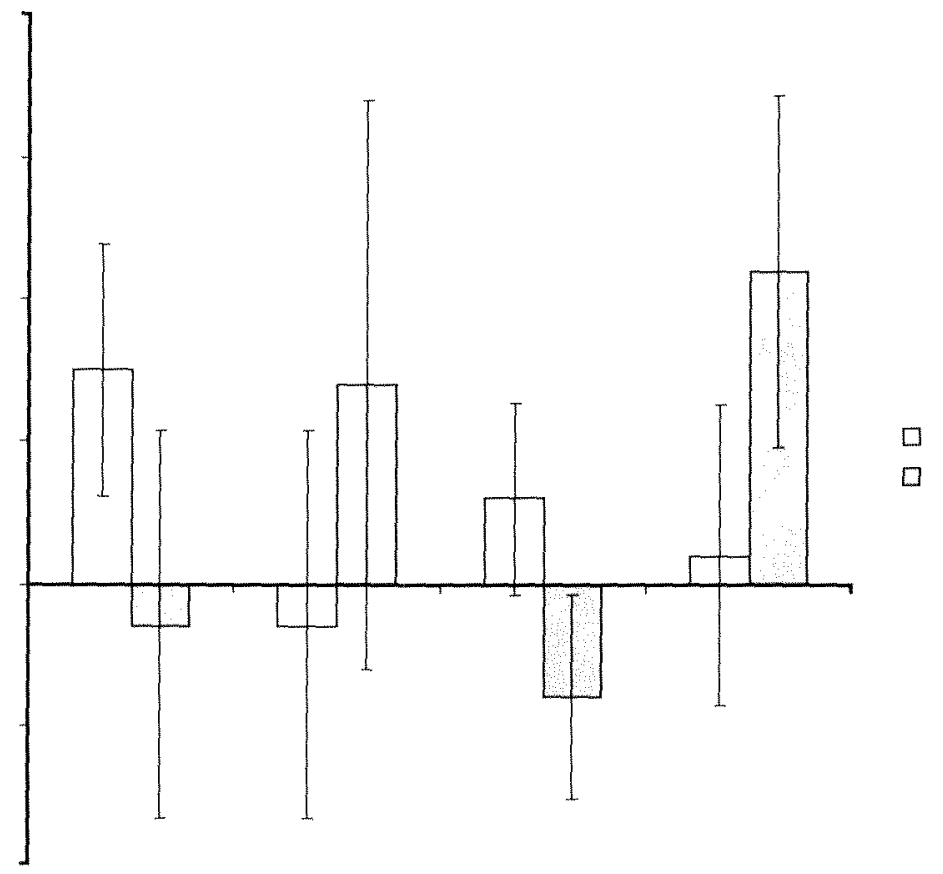

Figure 4.11: Species growth rate in the presence and absence of molluscan grazers ( \pm 1SE). A positive value indicates $C$. bullosa growth and a negative value indicates growth by the labeled species. No significant differences between growth rate and herbivore access were detected. 
expected to survive at these lower levels.

One possible explanation for the poor survival rate is the synergistic effects of the other sublethal stress factors associated with desiccation. The experiments in Chapter three only examined the effect of desiccation stress but the natural environment there are other factors present (e.g. light, temperature, salinity) that could potentially influence survival. For example, as desiccation occurs the intracellular osmotic potential increases due to water loss (Kirst, 1989) so any stress factor that causes further water loss (e.g. temperature) would also increase this osmotic potential causing intracellular salinity stress also.

The pool transplants indicate that crustose C. bullosa is physiologically capable of surviving in the lower littoral zones however other factors biotic factors may start to become more influential. The survival curves for the lower littoral zones are consistent with a type I response suggesting time dependent mortality. Many of the transplanted samples survived at least two months before significant mortality started to occur and this could have been the result of overgrowth or shading by neighboring species, changes in grazing pressure, or temporal changes in community composition. As the samples were transplanted into the areas, these influences often have an associated time lag before their effects become apparent resulting in the observed survival curve.

If overgrowth or shading was a significant factor in restricting crustose C. bullosa to the upper littoral zone, then it may have increased survival in lower littoral zones with frequent disturbance. As factors like temperature, light, salinity etc. are less influencial in the lower littoral zones, the advantages associated with tolerating disturbance from these factors is reduced but the prostrate nature of the crustose thallus would enhance survival during the disturbance events (i.e. boulder rolling, wave action, sand scour). These disturbance events would remove the more up-right macro species reducing the overgrowth and shading effects.

It is unclear how C. bullosa responds or tolerates overgrowth and re- 
quires more investigation. Crustose species are often among the first colonisers of empty space and, although they are frequently overgrown, they remain abundant with little adverse effect. Airoldi (2000) proposes two possible mechanisms for this. The first is via the translocation of photosynthate products (as mentioned earlier) and the second suggests there is increased lateral growth along the uncovered margins. These responses were not tested in this study but it raises the possibility that tolerance is more important than competition in structuring crustose communities.

The grazer exclusion experiments support the conclusion by Dethier (1994) that crustose species are poor competitors and are often reliant on grazers or physical disturbance to prevent overgrowth. Grazers remove sediment and detritus (Anderson and Underwood, 1997; Harley, 2006b) which can lower photosynthetic output and smother the plant but they have also been found to reduce algal settlement and lower reproductive success (Seapy and Littler, 1982; Airoldi, 1998; Schiel et al., 2006). As crustose C. bullosa quickly becomes smothered in sediment and overgrown by neighbouring species in the absence of grazers, the benefits associated with grazer presence would appear to outweigh any disadvantages.

The exclusion plots also suggest grazers may facilitate the establishment and survival of C. bullosa by consuming potential competitors. There is some historical support for such facilitation in crustose species (e.g.Steneck et al., 1991; Airoldi, 2000; Dethier and Steneck, 2001) with studies showing crustose species may be grazer-resistant but are also often grazer dependent. Dethier's (1981) study investigating the effect of herbivory on the brown crust Ralfsia californica found limpets did not directly graze the thallus but removed potential competitors and settlers from the thallus surface instead. In the absence of grazers, R. californica was unable to compete and became overgrown by more upright macroalgal species. This study demonstrated a similar effect with $C$. bullosa becoming over grown and smothered when grazers were absent.

The disadvantages of grazers (i.e. thallus damage from grazing) and 
physical effects of grazing on crustose C. bullosa still need to be quantified and assessed. If herbivores directly graze and consume the thallus of crustose C. bullosa, fast recovery from this damage may enhance the competitive abilities of this introduced alga. Steneck (1991) hypothesizes that a lateral growth response is important for recovery following high intensity / low frequency disturbance while a vertical growth response is important for persistence during low intensity / high frequency disturbance. He goes further to suggest crustose species with fast lateral growth usually have thin thalli and species with fast vertical growth have thicker, sometimes multilayered, thalli.

The thallus of crustose C. bullosa is much thicker than the other crustose species found in high littoral pools and, assuming Steneck's hypothesis is correct, may offer some protection against the low intensity / high frequency disturbance exerted by grazers. Such a trait could help explain the significantly higher observed abundance of C. bullosa and may also account for the multi-layered thallus often observed in crustose C. bullosa.

There are several areas that require further investigation to further understand how this introduced algae interacts with the native intertidal community. All of the experiments conducted here used established or existing crustose thalli and did not examine how a younger juvenile thallus might respond to the same effects. Such a comparison is needed as the survival response of juvenile crust may differ from established due to differences in physiological tolerance and acclimation abilities and the survival of spores / newly established thallus will have consequences for long term persistance.

The lack of data with regard to the gametophytic upright also needs to be addressed. Although the upright does not persist long term and is unlikely to have a long lasting impact on the community, determining what factors control its abundance will help understand how it interacts with neighbouring species.

The results of the competition and scrape away experiments were dis- 
appointing and maybe the result of inadequate response time rather than experimental design. Previous studies have indicated crustose species have growth rates between $2.9-3.9 \mathrm{~mm}$ per month or up to $20 \mathrm{~mm}$ per year (Steneck et al., 1991; Matsuda, 2004). The 7-month experimental period was thought to be of adequate length to detect an effect but the results suggest this was not the case. If these experiments had been left to run longer there may have been a more significant result and any future experiments involving such manipulations should allow more time.

This chapter confirms that crustose C. bullosa has a poor desiccation tolerance and has poor survival on emergent rock, even in the lowest littoral zones. The tranplant experiments also revealed that crustose C. bullosa can survive in pools throughout the littoral zone but its longterm survival in the lower zones may be restricted by biotic factors. The exclusion experiments indicated there was some form of facilitation for crustose C. bullosa by molluscan grazers and in the absence of these grazers, the crustose thallus quickly became overgrown and smothered. This facilitation may be absent in the lower littoral zones due to the change in grazer composition and could result in the observed reduced suvivorship of C. bullosa. 


\section{Chapter 5}

\section{Conclusion}

This study set out to address the knowledge gap surrounding C. bullosa in NZ. Despite being discovered in NZ over 20 years ago almost nothing is known about its current littoral distribution or any ecological effects it may be having on the natural marine community. Historical records and surveys have identified the species in several North Island port areas but this is the first known study that has attempted to quantify any spatial and temporal abundance.

The nested analysis indicated the location within Wellington harbour (Site 1, Fig. 2.1) had lower abundance of crustose C. bullosa compared to the other four locations. This result shows that C. bullosa has spread significantly since its initial discovery within Wellington harbour but it should be noted that this survey focused on areas presumed to contain suitable habitat only. It does not indicate the actual abundance of C. bullosa around Wellington.

Crustose species are thought to be charatertistic of highly stressful and disturbed environments (Dethier, 1994; Steneck, 1986; Airoldi, 2000) and crustose C. bullosa shows some support for this paradigm. It appears to be restricted to pools in the upper litoral zone, which show highly variable and stressful abiotic conditions, but unusually it has a poor desiccation tolerance. The experiments in Chapter three show it has slow recovery from 
emersion exposure longer than four hours and it does not recover from exposure lasting longer than six hours. This was highlighted further by the transplant experiments in Chapter four that demonstrated poor survival even in the lowest littoral zone where emersion times are much reduced.

This is surprising as the prostrate filamentous nature of the thallus is thought to aid water retention and prevent desiccation (Dethier, 1981). It is probable that there are other sublethal abiotic factors acting in conjunction with desiccation to limit the distribution of C. bullosa. Water loss can damage cell structures, increase the risk of photoinhibition, and disrupt the electron transport chain within the photosystem.

This study also found evidence that the establishment and survival of crustose C. bullosa is facilitated by molluscan herbivores. There is historical evidence of crustose species relying on facilitations for survival (e.g.Dethier and Steneck, 2001) and often in the absence of facilitators, crustose species quickly become overgrown and smothered. Although the C. bullosa thallus became completely covered in the absence of molluscan grazers during this study, the impacts of this may not be as significant as initially thought. Airoldi (2000) and Underwood (2006) propose that crustose species can withstand long periods of over growth via translocation mechanisms and would only require a portion of the thallus to be exposed to ensure survival. This would allow survival until the overgrowing or shading species is removed.

This facilitation may also help explain the significantly higher abundance of crustose C. bullosa in the upper littoral zone compared to the other crustose species surveyed. Although crustose C. bullosa can overgrow morphologically similar species, it does not appear to maintain its high abundance in the lower littoral zones. This could be due to a number of factors but one possible explanation is a reduction in the strength of the facilitation as the grazer species composition changes, resulting in crustose C. bullosa being unable to maintain competitive and is subsequently overgrown. Unfortunately the experiments designed to examine this further 
failed to yield a result so a more conclusive position cannot be reached.

\subsection{Future directions}

The lack of data for the gametophytic upright is a concern and needs to be addressed. Because the upright phase has such a distinctive morphology it is likely that it would be that used for any future monitoring and control programs. For these types of programs to be effective, more information is needed regarding its littoral / sub-littoral distribution, potential habitats and tolerance, and what affect it may have on native species and communities.

The results of this study also need to be tested outside the Wellington region to determine if they can be used in formulating a predictive distribution model. Current models based on the Wellington data would conclude the crustose phase is restricted to high littoral pools and the upright has a low littoral / sublittoral distribution. Testing these predictions will further aid any monitoring and control programs that are put in place for this introduced algae.

The experimental analysis of competitve abilities of crustose C. bullosa should also be repeated. This is required to establish if it does overgrow any native crustose species and what conditions can influence the outcome of these competitive encounters. If crustose C. bullosa does overgrow native species then the role of these species will need to be determined to further understand what effect this introduced alga is having.

\subsection{Conclusion}

In summary, crustose C. bullosa appears to be restricted to high littoral pools due to a combination of its poor desiccation tolerance and an inability to compete against more upright macroalgal species. There is also evidence that $C$. bullosa is assisted through the establishment and survival 
process via facilitation by molluscan herbivores. This facilitation allows it to overgrow morphologically similar species and maintain space in the long term.

The gametophytic upright has a sublittoral distribution and, unlike the sporophytic crust, displays significant temporal variation in abundance as it is only present during the period between Sept-Jan. The lack of data surrounding the gametophytic upright does require some attention but given the highly restricted distribution of the crust and emphermal nature of the upright, it does not appear that C. bullosa is having a significant effect on the intertidal communities around Wellington. 


\section{Appendix: GPS Table}

GPS waypoints for all of the experiment locations used in this study.

\begin{tabular}{|c|c|c|c|}
\hline Site & Southing & Easting & Site Description \\
\hline Nested Site 1 & $41^{\circ} 17.550$ & $174^{\circ} 50.010$ & $\begin{array}{l}\text { Kau Bay, Wellington Har- } \\
\text { bour. }\end{array}$ \\
\hline Nested Site 2 & $41^{\circ} 20.900$ & $174^{\circ} 49.560$ & $\begin{array}{l}\text { Palmer Head, entrance to } \\
\text { Wellington Harbour. }\end{array}$ \\
\hline Nested Site 3 & $41^{\circ} 21.312$ & $174^{\circ} 45.085$ & $\begin{array}{l}\text { Owhiro Bay, Wellington } \\
\text { South Coast. }\end{array}$ \\
\hline Nested Site 4 & $41^{\circ} 13.375$ & $174^{\circ} 41.928$ & $\begin{array}{l}\text { Makara Beach, Wellington } \\
\text { West Coast. }\end{array}$ \\
\hline Nested Site 5 & $41^{\circ} 5.487$ & $174^{\circ} 51.212$ & $\begin{array}{l}\text { Porirua Harbor Mouth, } \\
\text { Wellington West Coast. }\end{array}$ \\
\hline Fixed Quadrat Site 6 & $41^{\circ} 20.985$ & $174^{\circ} 49.555$ & $\begin{array}{l}\text { Palmer Head, entrance to } \\
\text { Wellington Harbour. }\end{array}$ \\
\hline Fixed Quadrat Site 7 & $41^{\circ} 20.688$ & $174^{\circ} 46.785$ & $\begin{array}{l}\text { Island Bay, Wellington } \\
\text { South Coast. }\end{array}$ \\
\hline Fixed Quadrat Site 8 & $41^{\circ} 21.056$ & $174^{\circ} 43.909$ & $\begin{array}{l}\text { Red Rocks, Wellington } \\
\text { South Coast. }\end{array}$ \\
\hline Transplant Site 9 & $41^{\circ} 20.900$ & $174^{\circ} 49.560$ & $\begin{array}{l}\text { Palmer Head, entrance to } \\
\text { Wellington Harbour. }\end{array}$ \\
\hline Transplant Site 10 & $41^{\circ} 20.900$ & $174^{\circ} 47.640$ & $\begin{array}{l}\text { Waitaha Cove, Western } \\
\text { side of Lyall Bay. }\end{array}$ \\
\hline
\end{tabular}




\begin{tabular}{|c|c|c|c|}
\hline Transplant Site 11 & $41^{\circ} 21.320$ & $174^{\circ} 45.900$ & $\begin{array}{l}\text { Sirens Rocks, between Is- } \\
\text { land Bay and Owhiro Bay, } \\
\text { Wellington South Coast. }\end{array}$ \\
\hline Exclusion Site 12 & $41^{\circ} 20.900$ & $174^{\circ} 49.560$ & $\begin{array}{l}\text { Gibraltar Rock, Palmer } \\
\text { Head, entrance to Welling- } \\
\text { ton Harbour. }\end{array}$ \\
\hline Exclusion Site 13 & $41^{\circ} 21.000$ & $174^{\circ} 48.620$ & $\begin{array}{l}\text { Moa Point, Western side } \\
\text { of Moa Point headland, } \\
\text { Wellington South Coast. }\end{array}$ \\
\hline Exclusion Site 14 & $41^{\circ} 20.992$ & $174^{\circ} 47.001$ & $\begin{array}{l}\text { Drain Pipe, Eastern side } \\
\text { of Island Bay, Wellington } \\
\text { South Coast. }\end{array}$ \\
\hline Exclusion Site 15 & $41^{\circ} 21.310$ & $174^{\circ} 45.810$ & $\begin{array}{l}\text { Sirens Rocks, Between Is- } \\
\text { land Bay and Owhiro Bay, } \\
\text { Wellington South Coast. }\end{array}$ \\
\hline Exclusion Site 16 & $41^{\circ} 21.320$ & $174^{\circ} 44.012$ & $\begin{array}{l}\text { Red Rocks, Wellington } \\
\text { South Coast. }\end{array}$ \\
\hline Band Transect Location 1 & $41^{\circ} 17.550$ & 17450.010 & $\begin{array}{l}\text { Kau Bay, Wellington Har- } \\
\text { bour. }\end{array}$ \\
\hline Band Transect Location 2 & $41^{\circ} 20.900$ & $174^{\circ} 49.560$ & $\begin{array}{l}\text { Palmer Head, entrance to } \\
\text { Wellington Harbour. }\end{array}$ \\
\hline Band Transect Location 3 & $41^{\circ} 21.000$ & $174^{\circ} 48.620$ & $\begin{array}{l}\text { Moa Point, Western side } \\
\text { of Moa Point headland, } \\
\text { Wellington South Coast. }\end{array}$ \\
\hline Band Transect Location 4 & $41^{\circ} 21.000$ & $174^{\circ} 47.640$ & $\begin{array}{l}\text { Waitaha Cove, Western } \\
\text { side of Lyall Bay. }\end{array}$ \\
\hline Band Transect Location 5 & $41^{\circ} 20.992$ & $174^{\circ} 47.001$ & $\begin{array}{l}\text { Drain Pipe, Eastern side } \\
\text { of Island Bay, Wellington } \\
\text { South Coast. }\end{array}$ \\
\hline
\end{tabular}


Band Transect Location $6 \quad 41^{\circ} 21.310 \quad 174^{\circ} 45.810$ Sirens Rocks, Between Island Bay and Owhiro Bay, Wellington South Coast.

Band Transect Location $7 \quad 41^{\circ} 21.312 \quad 174^{\circ} 45.085$ Owhiro Bay, Wellington South Coast.

Band Transect Location $8 \quad 41^{\circ} 21.320 \quad 174^{\circ} 44.012$ Red Rocks, Wellington South Coast. 


\section{Bibliography}

Adams, N., 1994: Seaweeds of New Zealand: An illustrated Guide. Canterbury University Press.

Adams, N. M. and W. A. Nelson, 1985: The marine algae of the Three Kings Islands: a list of species. National Museum of New Zealand.

Airoldi, L., 1998: Roles of disturbance, sediment stress, and substratum retention on spatial dominance in algal turf. Ecology, 79, 2759-2770.

Airoldi, L., 2000: Effects of disturbance, life histories, and overgrowth on coexistence of algal crusts and turfs. Ecology, 81, 798-814.

Allen, J., K. Krauss, and R. Hauff, 2003: Factors limiting the intertidal distribution of the mangrove species Xylocarpus granatum. Oecologia, 135, $110-121$.

Anderson, D. M., C. D. Taylor, and E. V. Armbrust, 1987: The effects of darkness and anaerobiosis on dinoflagellate cyst germination. Limnology and Oceanography, 32, 340-351.

Anderson, M. and A. Underwood, 1997: Effects of gastropod grazers on recruitment and succession of an estuarine assemblage: a multivariate and univariate approach. Oecologia, 109, 442-453.

Arrontes, J., F. Arenas, C. Fernandez, J. M. Rico, J. Oliveros, B. Martinez, R. M. Viejo, and D. Alvarez, 2004: Effect of grazing by limpets on mid- 
shore species assemblages in northern Spain. Marine Ecology Progress Series, 277, 117-133.

Ashton, G., K. Willis, M. Burrows, and E. Cook, 2007: Environmental tolerance of Caprella mutica: implications for its distribution as a marine non-native species. Marine Environmental Research, 64, 305-312.

Beer, S. and A. Eshel, 1983: Photosynthesis of Ulva sp: effects of desiccation when exposed to air. Journal of Experimental Marine Biology and Ecology, 70, 91-97.

Bellan-Santini, D., P. M. Arnaud, G. Bellan, and M. Verlaque, 1996: The influence of the introduced tropical alga Caulerpa taxifolia on the biodiversity of the Mediterranean marine biota. Journal of the Marine Biological Association of the United Kingdom, 76, 235-237.

Belsky, A. J., 1992: Effects of grazing, competition, disturbance, and fire on species composition and diversity in grassland communities. Journal of Vegetation Science, 3, 187-200.

Berkman, P. A., M. A. Haltuch, E. Tichich, D. Garton, G. W. Kennedy, J. E. Gannon, S. D. Mackey, J. Fuller, and D. Liebenthal, 1998: Zebra mussels invade Lake Erie muds. Nature, 393, 27-28.

Bertness, M., 1981: Predation, physical stress, and the organization of a tropical rocky intertidal hermit crab community. Ecology, 62, 411-425.

Bertness, M. D. and A. M. Ellison, 1987: Determinants of pattern in a New England salt marsh plant community. Ecological Applications, 57, 129-147.

Bertness, M. D., L. Gough, and S. W. Shumway, 1992: Salt tolerances and the distribution of fugitive salt marsh plants. Ecology, 73, 1842-1851.

Bertness, M. D. and S. D. Hacker, 1994: Physical stress and positive associations among marsh plants. American Naturalist, 144, 363-372. 
Bertness, M. D. and G. H. Leonard, 1997: The role of positive interactions in communities: lessons from intertidal habitats. Ecology, 78, 1976-1989.

Bertness, M. D. and S. W. Shumway, 1993: Competition and facilitation in marsh communities. American Naturalist, 142, 718-724.

Beukema, J. and E. Flach, 1995: Factors controlling the upper and lower limits of the intertidal distribution of two Corophium species in the Wadden Sea. Marine Ecology Progress Series, 125, 117-126.

Bisson, M., M. Beilby, and V. Shepherd, 2006: Electrophysiology of turgor regulation in marine siphonous green algae. Journal of Membrane Biology, 211, 1-14.

Blanchette, C. A., 1997: Size and survival of intertidal plants in response to wave action: A case study with Fucus gardneri. Ecology, 78, 1563.

Boudouresque, C. F. and M. Verlaque, 2002: Biological pollution in the Mediterranean Sea: invasive versus introduced macrophytes. Marine PolIution Bulletin, 44, 32-38.

Brand, L., 1984: The salinity tolerance of forty-six marine phytoplankton isolates. Estuarine, Coastal, and Shelf Science, 18, 543-556.

Britton-Simmons, K. H., 2004: Direct and indirect effects of the introduced alga Sargassum muticum on benthic subtidal communities of Washington State. Marine Ecology Progress Series, 277, 61-78.

Brown, B. E., 1997: Coral bleaching: causes and consequences. Coral Reefs, 16, S129-S138.

Bruno, J., J. Stachowicz, and M. D. Bertness, 2003: Inclusion of facilitation into ecological theory. Trends in Ecology \& Evolution, 18, 119-125.

Callaway, R. M. and L. R. Walker, 1997: Competition and facilitation: a synthetic approach to interactions in plant communities. Ecology, 78, 1958-1965. 
Carlton, J. T., 1985: Transoceanic and interoceanic dispersal of coastal marine organisms: the biology of ballast water. Oceanography and Marine Biology Annual Review, 23, 313-371.

Carlton, J. T., 1996a: Biological invasions and cryptogenic species. Ecology, 77, 1653-1655.

Carlton, J. T., 1996b: Pattern, process, and prediction in marine invasion ecology. Biological Conservation, 78, 97-106.

Casas, G., R. Scrosati, and M. L. Piriz, 2004: The invasive kelp Undaria pinnatifida (Phaeophyta, Laminariales) reduces native seaweed diversity in Nuevo Gulf (Patagonia, Argentina). Biological Invasions, 6, 411-416.

Chapman, V., 1974: The marine algae of New Zealand. Lehre J. Cramer.

Cho, G. Y., S. M. Boo, W. Nelson, and M. N. Clayton, 2005: Genealogical partioning and phylogeography of Colpomenia peregrina (Scytosiphonaceae, Phaeophyceae), based on plastid $r b c l$ and nuclear robosomal dna internal transcribed spacer sequences. Phycologia, 44, 103-111.

Clayton, M. N., 1979: The life history and sexual reproduction of Colpomenia peregrina (Scytosiphonaceae, Phaeophyta) in Australia. European Journal of Phycology, 14, 1-10.

Connell, J. H., 1961: The influence of interspecific competition and other factors on the distribution of the barnacle Chthamalus stellatus. Ecology, $42,710-723$.

Connell, J. H., 1972: Community interactions on marine rocky intertidal shores. Annual Review of Ecology and Systematics, 3, 169-192.

Coquillard, P., T. Thibaut, D. Hill, J. Gueugnot, C. Mazel, and Y. Coquillard, 2000: Simulation of the mollusc Ascoglossa Elysia subornata population dynamics: application to the potential biocontrol of Caulerpa taxifolia growth in the Mediterranean Sea. Ecological Modelling, 135, 1-16. 
Coutts, A. D. M. and M. D. Taylor, 2004: A preliminary investigation of biodiversity risks associated with biofouling on merchant vessels in New Zealand. New Zealand Journal of Marine and Freshwater Research, 38, 215-229.

Cubit, J. D., 1984: Herbivory and the seasonal abundance of algae on a high intertidal rocky shore. Ecology, 65, 1904-1917.

Daume, S., S. Brand-Gardner, and W. Woelkerling, 1999: Settlement of abalone larvae (Haliotis laevigata Donovan) in response to non-geniculate coralline red algae (Corallinales, Rhodophyta). Journal of Experimental Marine Biology and Ecology, 234, 125-143.

Davison, I. R., L. E. Johnson, and S. H. Brawley, 1993: Sublethal stress in the intertidal zone: tidal emersion inhibits photosynthesis and retards development in embryos of the brown alga Pelvetia fastigiata. Oecologia, 96, 483-492.

Davison, I. R. and G. A. Pearson, 1996: Stress tolerance in intertidal seaweeds. Journal of Phycology, 32, 197-211.

Dayton, P. K., 1971: Competition, disturbance, and community organization; the provision and subsequent utilization of space in a rocky intertidal community. Ecological Monographs, 41, 351-389.

Dayton, P. K., 1975: Experimental evaluation of ecological dominance in a rocky intertidal algal community. Ecological Monographs, 45, 137-159.

Dethier, M. and R. Steneck, 2001: Growth and persistence of diverse intertidal crusts: survival of the slow in a fast-paced world. Marine Ecology Progress Series, 223, 89-100.

Dethier, M. N., 1981: Heteromorphic algal life histories: the seasonal pattern and response to herbivory of the brown crust, Ralfsia californica. Oecologia, 49, 333-339. 
Dethier, M. N., 1994: The ecology of intertidal algal crusts: variation within a functional group. Journal of Experimental Marine Biology and Ecology, 177, 37-71.

Dethier, M. N., E. S. Graham, S. Cohen, and L. M. Tear, 1993: Visual versus random-point percent cover estimations: 'objective' is not always better. Marine Ecology Progress Series, 96, 93-100.

Dickson, D. and G. Kirst, 1987: Osmotic adjustment in marine eukaryotic algae: the role of inorganic ions, quaternary ammonium, tertiary sulponium and carbohydrate solutes. I. Diatoms and a Rhodophyte. New Phytologist, 106, 645-655.

Dring, M. and F. Brown, 1982: Photosynthesis of intertidal brown algae during and after periods of emersion: a renewed search for physiological causes of zonation. Marine Ecology Progress Series, 8, 301-308.

Dudgeon, S. R., J. E. Kübler, R. L. Vadas, and I. Davison, 1995: Physiological responses to environmental variation in intertidal red algae: does thallus morphology matter? Marine Ecology Progress Series, 117, 193-206.

Dungan, M. L., 1986: Three-way interactions: barnacles, limpets, and algae in a sonoran desert rocky intertidal zone. American Naturalist, 127, 292-316.

Edgar, G. J., C. R. Samson, and N. S. Barrett, 2005: Species extinction in the marine environment: Tasmania as a regional example of overlooked losses in biodiversity. Conservation Biology, 19, 1294-1300.

Farrell, T., 1989: Succession in a rocky intertidal community: the importance of disturbance size and position within a disturbed patch. Journal of Experimental Marine Biology and Ecology, 128, 57-73.

Finke, G. R., S. A. Navarrete, and F. Bozinovic, 2007: Tidal regimes of temperate coasts and their influences on aerial exposure for intertidal organisms. Marine Ecology Progress Series, 343, 57-62. 
Forrest, B. M. and M. D. Taylor, 2002: Assessing invasion impact: survey design considerations and implications for management of an invasive marine plant. Biological Invasions, 4, 375-386.

Foster, M., E. W. Nigg, L. M. Kiguchi, D. D. Hardin, and J. S. Pearse, 2003: Temporal variation and succession in an algal-dominated high intertidal assemblage. Journal of Experimental Marine Biology and Ecology, 289, 15-39.

Fritts, T. H., 1998: The role of introduced species in the degradation of island ecosystems: a case history of Guam. Annual Review of Ecology and Systematics, 29, 113-140.

Gaines, S. and J. Roughgarden, 1985: Larval settlement rate: a leading determinant of structure in an ecological community of the marine intertidal zone. Proceeding of the National Academy of Science, U.S.A., 82, 3703-3711.

Gaines, S. D. and M. D. Bertness, 1992: Dispersal of juveniles and variable recruitment in sessile marine species. Nature, 360, 579-580.

Galil, B., 2005: Loss or gain? invasive aliens and biodiversity in the Mediterranean Sea. Marine Pollution Bulletin, 55, 314-322.

Gaylord, B. and S. Gaines, 2000: Temperature or transport? range limits in marine species mediated solely by flow. American Naturalist, 155, 769 789.

Genty, B., J. Briantais, and N. Baker, 1989: The relationship between the quantum yield of photosynthetic electron transport and quenching of cholorphyll fluorescence. Biochimica et Biophysica Acta, 990, 87-92.

Genty, B., J. Harbinson, J.-M. Briantais, and N. Baker, 1990: The relationship between non-photochemical quenching of chlorophyll fluorescence and the rate of photosystem II photochemistry in leaves. Photosynthesis Research, 25, 249-257. 
Genty, B., J. Wonders, and N. Baker, 1990: Non-photochemical quenching of fo in leaves is emission wavelength dependent: consequences for quenching analysis and its interpretation. Photosynthesis Research, 26, 133-139.

Gordillo, F., M. Dring, and G. Savidge, 2002: Nitrate and phosphate uptake characteristics of three species of brown algae cultured at low salinity. Marine Ecology Progress Series, 234, 111-118.

Goss-Custard, S., J. Jones, J. Kitching, and T. Norton, 1979: Tide pools of Carrigathorna and Barloge Creek. Philosophical Transactions of the Royal Society of London. B, 287, 1-44.

Grosholz, E. D., 2005: Recent biological invasion may hasten invasional meltdown by acclerating historical introductions. Proceeding of the $\mathrm{Na}$ tional Academy of Sciences, 102, 1088-1091.

Grosholz, E. D. and G. M. Ruiz, 1996: Predicting the impact of introduced marine species: lessons from the multiple invasions of the European green crab Carcinus maenas. Biological Conservation, 78, 59-66.

Gurevitch, J. and D. K. Padilla, 2004: Are invasive species a major cause of extinctions? Trends in Ecology and Evolution, 19, 470-474.

Hacker, S. D., M. D. Bertness, S. D. Hacker, and M. D. Bertness, 1999: Experimental evidence for factors maintaining plant species diversity in a New England salt marsh. Ecology, 80, 2064-2073.

Hader, D., M. Lebert, R. Sinha, E. Barbieri, and E. Helbling, 2002: Role of protctive and repair mechanisms in the inhibition of photosynthesis in marine macroalgae. Photochemical and Photobiological Sciences, 2002, 809 814.

Harley, C., 2006a: Effects of physical ecosystem engineering and herbivory on intertidal community structure. Marine Ecology Progress Series, $317,29-39$. 
Harley, C. D. and B. S. Helmuth, 2003: Local- and regional-scale effects of wave exposure, thermal stress, and absolute versus effective shore level on patterns of intertidal zonation. Limnology and Oceanography, 48, 14981508.

Harley, C. D. G., 2003: Abiotic stress and herbivory interact to set range limits across a two-dimensional stress gradient. Ecology, 84, 1477.

Harley, D., 2006b: Effects of physical ecosystem engineering and herbivory on intertidal community structure. Marine Ecology Progress Series, $317,29-39$.

Hasegawa, P. M., R. A. Bressan, J.-K. Zhu, and H. J. Bohnert, 2000: Plant cellular and molecular responses to high salinity. Annual Review of Plant Physiology and Molecular Biology, 51, 463-499.

Hastings, A., K. Cuddington, K. F. Davis, C. J. Dugaw, S. Elmendorf, A. Freestone, S. Harrison, M. Holland, J. Lambrinos, U. Malvadkar, B. A. Melbourne, K. Moore, C. Taylor, and D. Thomson, 2005: The spatial spread of invasions: new developments in theory and evidence. Ecology Letters, 8, 91-101.

Hay, M. E., 1981: The functional morphology of turf-forming seaweeds: persistence in stressful marine habitats. Ecology, 62, 739-750.

Helmuth, B., 1999: Thermal ecology of rocky intertidla mussels: quantifying body temperatures using climatological data. Ecology, 80, 15-34.

Helmuth, B., C. D. Harley, P. M. Halpin, M. O'Donnell, G. E. Hofmann, and C. A. Blanchette, 2002: Climate change and latitudinal patterns of intertidal thermal stress. Science, 298, 1015-1017.

Helmuth, B. and G. Hofmann, 2001: Microhabitats, thermal heterogeneity, and patterns of physiological stress in the rocky intertidal zone. Biological Bulletin, 201, 374-384. 
Hormann, H., C. Neubauer, and U. Schreiber, 1994: On the relationship between chlorophyll fluorescence quenching and the quantum yield of electron transport in isolated thylakoids. Photosynthesis Research, 40, 93106.

Hutson, K., D. Ross, R. Day, and J. Ahern, 2005: Australian scallops do not recognise the introduced predatory seastar Asterias amurensis. Marine Ecology Progress Series, 298, 305-309.

Johnson, C. and D. Sutton, 1994: Bacteria on the surface of crustose coralline algae induce metamorphosis of the crown-of-thorns starfish Acanthaster planci. Marine Biology, 120, 305-310.

Kawamitsu, Y., T. Driscoll, and J. Boyer, 200: Photosynthesis during desiccation in an intertidal alga and a land plant. Plant Cell Physiology, 41, 344-353.

Kim, J. H., 1997: The role of herbivory, direct, and indirect interactions, in algal succession. Journal of Experimental Marine Biology and Ecology, 217, 119-135.

Kim, J. H. and R. E. DeWreede, 1996: Effects of size and season of disturbance on algae patch recovery in a rocky intertidal community. Marine Ecology Progress Series, 133, 217-228.

Kirst, G., 1989: Salinity tolerance of eukaryotic marine algae. Annual Review of Plant Physiology and Plant Molecular Biology, 40, 31-53.

Kogame, K. and M. Masuda, 2001: Crustose sporophytes of Colpomenia bullosa (Scytosiphonaceae, Phaeophyceae) in nature. Cryptogamie Algologie, 22, 201-208.

Kogame, K. and Y. Yamagishi, 1997: The life history and phenology of Colpomenia peregrina (Scytosiphonales, Phaeophyceae) from japan. Phycologia, 36, 337-344. 
Kolar, C. and D. Lodge, 2001: Progress in invasion biology: predicting invaders. Trends in Ecology E Evolution, 16, 199-205.

Korpinen, S., V. Jormalainen, and T. Honkanen, 2007: Effects of nutrients, herbivory and depth on the macroalgal community in the rocky sublittoral. Ecology, 88, 839-852.

Kremp, A. and D. M. Anderson, 2000: Factors regulating germination of resting cysts of the spring bloom dinoflagellate Scrippsiella hangoei from the northern Baltic Sea. Journal of Plankton Research, 22, 1311-1327.

Levin, S. A. and R. Paine, 1974: Disturbance, patch formation, and community structure. Proceedings of the National Academy of Sciences of the United States of America, 71, 2744-2747.

Lockwood, J., P. Cassey, and T. Blackburn, 2005: The role of propagule pressure in explaining species invasions. Trends in Ecology and Evolution, 20, 223-228.

Longpierre, S., A. Robert, F. Levi, and P. Francour, 2005: How an invasive alga species (Caulerpa taxifolia) induces changes in foraging strategies of the benthivorous fish Mullus surmuletus in coastal Mediterranean ecosystems. Biodiversity and Conservation, 14, 365-376.

Lubchenco, J., 1978: Plant species diversity in a marine intertidal community: importance of herbivore food preference and algal competitive abilities. The American Naturalist, 112, 23-39.

Lubchenco, J., 1980: Algal zonation in the New England rocky intertidal community: an experimental analysis. Ecology, 61, 333-344.

Lubchenco, J. and J. Cubit, 1980: Heteromorphic life histories of certain marine algae as adaptations to variations in herbivory. Ecology, 61, 676687. 
Lyons, K. G. and M. W. Schwartz, 2001: Rare species loss alters ecosystem function - invasion resistance. Ecology Letters, 4, 358-365.

Maclsaac, H., 1996: Potential abiotic and biotic impacts of zebra mussels on the inland waters of North America. American Zoologist, 36, 287-299.

Mack, R., D. Simberloff, W. Lonsdale, H. Evans, M. Clout, and F. Bazzaz, 2000: Biotic invasions: causes, epidemiology, global consequences, and control. Ecological Applications, 10, 689-710.

Martins, G., S. Hawkins, R. Thompson, and S. Jenkins, 2007: Community structure and functioning in intertidal rock pools: effects of pool size and shore height at different successional stages. Marine Ecology Progress Series, 329, 43-55.

Matsuda, S., 2004: Succession and growth rates of encrusting crustose coralline algae (Rhodophyta, Cryptonemiales) in the upper fore-reef environment off Ishigaki Island, Ryukyu Islands. Coral Reefs, 7, 185-195.

McQuoid, M. R., 2005: Influence of salinity on seasonal germination of resting stages and composition of microplankton on the Swedish west coast. Marine Ecology Progress Series, 289, 151-163.

McShane, P. E. and R. Naylor, 1996: Variation in spawning and recruitment of Haliotis iris (Mollusca: Gastropoda). New Zealand Journal of Marine and Freshwater Research, 30, 325-332.

Meese, R. and P. Tomich, 1992: Dots on rocks: a comparison of percentage cover estimation methods. Journal of Experimental Marine Biology and Ecology, 165, 59-73.

Meinesz, A., J. de Vaugelas, B. Hesse, and X. Mari, 1993: Spread of the introduced tropical green alga Caulerpa taxifolia in northern Mediterrean waters. Journal of Applied Phycology, 5, 141-147. 
Menge, B. A., 1976: Organization of the New England rocky intertidal community; role of predation, competition, and environmental heterogeneity. Ecological Monographs, 46, 355-393.

Menge, B. A., 1995: Indirect effects in marine rocky intertidal interaction webs - patterns and importance. Ecological Monographs, 65, 21-74.

Menge, B. A. and J. P. Sutherland, 1987: Community regulation: variation in disturbance, competition, and predation in relation to environmental stress and recruitment. The American Naturalist, 130, 730-757.

Moberg, F., N. Nyström, N. Kautsky, M. Tedengren, and P. Jarayabhand, 1997: Effects of reduced salinity on the rates of photosynthesis and respiration in the hermatypic corals Porites lutea and Pocillopora damicornis. Marine Ecology Progress Series, 157, 53-59.

Mooney, H. and E. Cleland, 2001: The evolutionary impact of invasive species. Proceeding of the National Academy of Sciences, 98, 5446-5451.

Moss, G., 1999: Factors affecting settlement and early post-settlement survival of the New Zealand abalone Haliotis australis. New Zealand Journal of Marine and Freshwater Research, 33, 271-278.

Murphy, L. R., S. T. Kinsey, and M. J. Durako, 2003: Physiological effects of short-term salinity changes on Ruppia maritima. Aquatic Botany, 75, 292-309.

Nelson, W., 1994: Marine invaders of New Zealand coasts. Journal of the Auckland Botantical Society, 49, 4-14.

Nelson, W., 1999: A revised checklist of marine algae naturalised in New Zealand. New Zealand Journal of Botany, 37, 355-359.

Nelson, W. A. and N. M. Adams, 1987: Marine algae of the Bay of Islands area: a list of species. National Museum of New Zealand. 
Nielsen, K. J., C. A. Blanchette, B. A. Menge, and J. Lubchenco, 2006: Physiological snapshots reflect ecological performance of the sea palm, Postelsia palmaeformis (Phaeophyceae) across intertidal elevation and exposure gradients. Journal of Phycology, 42, 548-559.

Nybakken, J., 2001: Marine biology: an ecological approach (5th edition). Benjamin Cummings.

Nyberg, C. and I. Wallentinus, 2005: Can species traits be used to predict marine macroalgal introductions? Biological Invasions, 7, 265-279.

Oates, B., 1985: Photosynthesis and amelioration of desiccation in the intertidal saccate alga Colopmenia peregrina. Marine Biology, 89, 109-119.

Oates, B., 1986: Components of photosynthesis in the intertidal saccate alga Halosaccion americanum (Rhodophyta, Palmariales). Joumal of Phycology, 22, 217-223.

Oates, B., 1988: Water relations of the intertidal saccate alga Colpomenia peregrina (Phaeophyta, Scytosiphonales). Botanica Marina, 31, 57-63.

Olden, J. D., N. L. Poff, M. R. Douglas, and K. D. Fausch, 2004: Ecological and evolutionary consequences of biotic homogenization. Trends in Ecology and Evolution, 19, 18-24.

Paine, R., 1980: Food webs: linkage, interaction strength and community infrastructure. Journal of Animal Ecology, 49, 667-685.

Paine, R. and S. A. Levin, 1981: Intertidal landscapes: disturbance and the dynamics of pattern. Ecological Monographs, 51, 145-178.

Paine, R. and A. Trimble, 2004: Abrupt community change on a rocky shore - biological mechanisms contributing to the potential formation of an alternative state. Ecology Letters, 7, 441-445. 
Paine, R. T., 1966: Food web complexity and species diversity. The American Naturalist, 100, 65-75.

Paine, R. T., 1969: The pisaster-tegula interaction: prey patches, predator food preference, and intertidal community structure. Ecology, 50, 950961.

Paine, R. T., 1974: Intertidal community structure: experimental studies on the relationship between a dominant competitor and its principle predator. Oecologia, 15, 93-120.

Parsons, M., 1982: Colpomenia (Endlicher) Derbś et Solier (Phaeophyta) in New Zealand. New Zealand Journal of Botany, 20, 289-301. April 1982.

Pinder III, J. E., J. G. Wiener, and M. H. Smith, 1978: The weibull distribution: a new method of summarizing survivorship data. Ecology, 59, 175-179.

Plante, C. and S. Wilde, 2004: Biotic disturbance, recolonization, and early succession of bacterial assemblages in intertidal sediments. Microbial Ecology, 48, 154-166.

Polis, G. A. and D. R. Strong, 1996: Food web complexity and community dynamics. American Naturalist, 147, 813-846.

Qian, H. and R. E. Ricklefs, 2006: The role of exotic species in homogenizing the North American flora. Ecology Letters, 9, 1293-1298.

Ramirez, M. and V. Rojas, 1991: El genero Colpomenia (F.C. Mertens ex Roth) Derbès et Solier (Phaeophyceae) en Chile. Boletin del Museo Nacional de Historia Natural, Chile, 42, 11-24.

Rodrigo, M. and R. Robaina, 1997: Stress tolerance of photosynthesis in sporelings of the red algae Grateloupia doryphora compared to that of Stage III thalli. Marine Biology, 128, 689-694. 
Ross, S. T., 1991: Mechanisms structuring stream fish assemblages: are there lessons from introduced species? Environmental Biology of Fishes, 30 , 359-368.

Ruiz, G. M., J. T. Carlton, E. D. Grosholz, and A. H. Hines, 1997: Global invasions of marine and estuarine habitats by non-indigenous species: Mechanisms, extent, and consequences. American Zoology, 37, 621-632.

Sánchez, I. and C. Fernández, 2005: Impact of the invasive seaweed Sargassum muticum (Phaeophyta) on an intertidal macroalgal assemblage. Journal of Phycology, 41, 923-930.

Sánchez, I., C. Fernández, and J. Arrontes, 2005: Long-term changes in the structure of intertidal assemblages after invasion by Sargassum muticum (Phaeophyta). Journal of Phycology, 41, 942-949.

Saroussi, S. and S. Beer, 2007: Alpha and quantum yield of aquatic plants derived from pam fluorometry: uses and misues. Aquatic Botany, 86, 8992.

Schaffelke, B., J. E. Smith, and C. L. Hewitt, 2006: Introduced macroalgaea growing concern. Journal of Applied Phycology, 18, 529-541.

Schiel, D., S. Wood, R. Dunmore, and D. Taylor, 2006: Sediment on rocky intertidal reefs: effects on early post-settlement stages of habitat-forming seaweeds. Journal of Experimental Marine Biology and Ecology, 331, 158-172.

Schiel, D. R. and S. A. Lilley, 2007: Gradients of disturbance to an algal canopy and the modification of an intertidal community. Marine Ecology Progress Series, 339, 1-11.

Schoener, T., 1983: Field experiments on interspecific competition. Amercian Naturalist, 122, 240-285. 
Schreiber, U., R. Gademann, P. Ralph, and A. Larkum, 1997: Assessment of photosynthetic performance of Prochloron in Lissoclinum patella in hospite by chlorophyll fluorescence measurements. Plant and Cell Physiology, 38, 945-951.

Seapy, R. and M. Littler, 1982: Population and species diversity fluctuations in a rocky intertidal community relative to severe aerial exposure and sediment burial. Marine Biology, 71, 87-96.

Shepherd, S. and J. Turner, 1985: Studies on southern Australian abalone (genus Haliotis): habitat preference, abundance, and predators of juveniles. Journal of Experimental Marine Biology and Ecology, 93, 285-298.

Simberloff, D. and B. Von Holle, 1999: Positive interactions of nonindigenous species: invasional meltdown? Biological Invasions, 1, 21-32.

Somero, G. N., 2002: Thermal physiology and vertical zonation of intertidal animals: optima, limits, and costs of living. Integrative and Comparative Biology, 42, 780-789.

Sousa, W., 1984: The role of disturbance in natural communities. Annual Review of Ecology and Systematics, 15, 353-391.

Sousa, W. P., 1979a: Disturbance in marine intertidal boulder fields: the nonequilibrium maintenance of species diversity. Ecology, 60(6), 12251239. December.

Sousa, W. P., 1979b: Experimental investigations of disturbance and ecological succession in a rocky intertidal algal community. Ecological Monographs, 49, 227-254.

South, G. R. and N. Adams, 1976: Marine algae of the Kaikoura Coast: a list of species. National Museum of New Zealand.

Steneck, R., 1982: A limpet-coralline alga association: adaptations and defenses between a selective herbivore and its prey. Ecology, 63, 507-522. 
Steneck, R., 1986: The ecology of coralline algal crusts: convergent patterns and adaptative strategies. Annual Review of Ecology and Systematics, 17, 273-303.

Steneck, R. S., S. D. Hacker, and M. N. Dethier, 1991: Mechanisms of competitive dominance between crustose coralline algae: an herbivoremediated competitive reversal. Ecology, 72, 938.

Stillman, J. H. and G. N. Somero, 1996: Adaptation to temperature stress and aerial exposure in congeneric species of intertidal porcelain crabs (genus Petrolisthes): correlation of physiology, biochemistry and morphology with vertical distribution. The Journal of Experimental Biology, 199, 1845-1855.

Strauss, S. Y., J. A. Lau, and S. P. Carroll, 2006: Evolutionary responses of natives to introduced species: what do introductions tell us about natural communities? Ecology Letters, 9, 357-374.

Strayer, D. L. and H. M. Malcom, 2006: Long-term demography of a zebra mussel (Dreissena polymorpha) population. Freshwater Biology, 51, $117-130$.

Stuart, M. D., 2004: Review of research on Undaria pinnatifida in New Zealand and its potential impacts on the eastern coast of the South Island. Technical report, Department of Conservation- Science Internal Series 166 .

Taylor, P. R. and M. E. Hay, 1984: Functional morphology of intertidal seaweeds: adaptive significance of aggregate vs. solitary forms. Marine Ecology Progress Series, 18, 295-302.

Taylor, P. R. and M. M. Littler, 1982: The roles of compensatory mortality, physical disturbance, and substrate retention in the development and organisation of a sand influenced, rocky intertidal community. Ecology, 63, 135-146. 
Thoms, C., R. Ebel, and P. Proksch, 2006: Activated chemical defense in Aplysina sponges revisited. Journal of Chemical Ecology, 32, 97-123.

Thornber, C. S., B. P. Kinlan, M. H. Graham, and J. J. Stachowicz, 2004: Population ecology of the invasive kelp Undaria pinnatifida in California: environmental and biological controls on demography. Marine EcologyProgress Series, 268, 69-80.

Torquemada, Y. F., M. J. Durako, and J. L. S. Lizaso, 2005: Effects of salinity and possible interactions with temperature and $\mathrm{pH}$ on growth and photosynthesis of Halophila johnsonii Eiseman. Marine Biology, 148, 251-260.

Toste, M. F., M. I. Parente, and A. I. Neto, 2003: Life history of Colpomenia sinuosa (Scytosiphonaceae, Phaeophyceae) in the Azores. Journal of Phycology, 39, 1268-1274.

Townsend, C. R., M. Begon, and J. L. Harper, 2002: Essentials of Ecology. Blackwell Publishing.

Turner, M. G., W. L. Baker, C. J. Peterson, and R. K. Peet, 1998: Factors influencing succession: lessons from large, infrequent natural disturbances. Ecosystems, 1, 511-523.

Turner, T., 1983: Facilitation as a successional mechanism in a rocky intertidal community. American Naturalist, 121, 729-738.

Underwood, A., 2000: Experimental ecology of rocky intertidal habitats: what are we learning? Journal of Experimental Marine Biology and Ecology, 250, 51-76.

Underwood, A., 2006: Why overgrowth of intertidal encrusting algae does not always cause competitive exclusion. Journal of Experimental Marine Biology and Ecology, 330, 448-454. 
Underwood, A. and M. Chapman, 1996: Scales of spatial patterns of distribution of intertidal invertebrates. Oecologia, 107, 212-224.

Valentine, J. P. and C. R. Johnson, 2003: Establishment of the introduced kelp Undaria pinnatifida in Tasmania depends on disturbance to native algal assemblages. Journal of Experimental Marine Biology and Ecology, 295, 63-90.

Vandermeulen, H., R. DeWreede, and K. Cole, 1984: Nomenclatural recommendations for three species of Colpomenia (Scytosiphonales, Phaeophyta). Taxon, 33, 324-329.

Walz, H., 2003: Imaging PAM chlorophyll fluorometer instrument handbook. Heinz Walz GmbH.

Wegmann, K., 1986: Osmoregulation in eukaryotic algae. FEMS Microbiology Letters, 39, 37-43.

Winters, G., Y. Loya, R. Röttgers, and S. Beer, 2003: Photoinhibition in shallow water colonies of coral Stylophora pistillata as measured in situ. Limnology and Oceanography, 48, 1388-1393.

Witman, J. D., 1992: Physical disturbance and community structure of exposed and protected reefs: a case study from St. John, U.S. Virgin Islands. American Zoologist, 32, 641-654.

Wolcott, T. G., 1973: Physiological ecology and intertidal zonation in limpets (Acmaea): a critical look at "limiting factors". The Biological Bulletin, 145, 389-422.

Wootton, J. T., 1992: Indirect effects, prey susceptibility, and habitat selection: impacts of birds on limpets and algae. Ecology, 73, 981-991.

Wootton, J. T., 1994: The nature and consequences of indirect effects in ecological communities. Annual Review of Ecology and Systematics, 25, 443466. 
Wotton, D. M. and C. L. Hewitt, 2004: Marine biosecurity post-border management: developing incursion response systems for New Zealand. New Zealand Journal of Marine and Freshwater Research, 38, 553-559.

York, P., D. Booth, T. Glasby, and B. Pease, 2006: Fish assemblages in habitats dominated by Caulerpa taxifolia and native seagrasses in southeastern Australia. Marine Ecology Progress Series, 312, 223-234.

Zabin, C. J. and A. Altieri, 2007: A Hawaiian limpet facilitates recruitment of a competitively dominant invasive barnacle. Marine Ecology Progress Series, 337, 175-185. 